\title{
Users Manual for an Expert System (HSPEXP) for Calibration of the Hydrological Simulation Program-Fortran
}

By Alan M. Lumb, Richard B. McCammon, and John L. Kittle, Jr.

U.S. GEOLOGICAL SURVEY

Water-Resources Investigations Report 94-4168

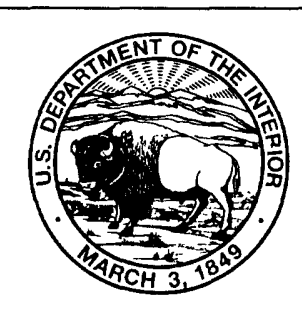




\title{
U.S. DEPARTMENT OF THE INTERIOR BRUCE BABBITT, Secretary
}

\author{
U.S. GEOLOGICAL SURVEY \\ Gordon P. Eaton, Director
}

The use of trade, product, industry, or firm names is for descriptive purposes only and does not imply endorsement by the U.S. Government.

For additional information write to:

Copies of this report can be purchased from:

Chief, Hydrologic Analysis Support Section

U.S. Geological Survey

U.S. Geological Survey, WRD

Earth Science Information Center

415 National Center

Open-File Reports Section

Reston, VA 22092

Box 25286, MS 517

Denver Federal Center

Denver, CO 80225 


\section{CONTENTS}

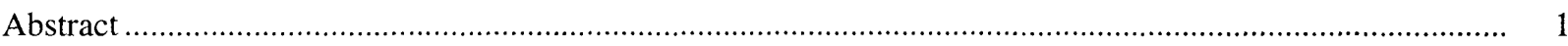

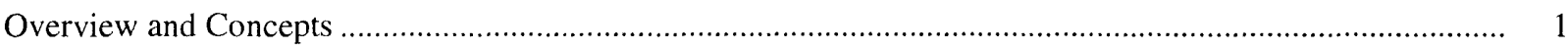

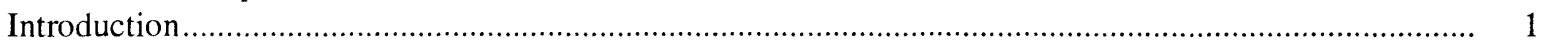

Procedures for Manual Calibration of Hydrological Simulation Program—Fortran (HSPF) ...................... 2

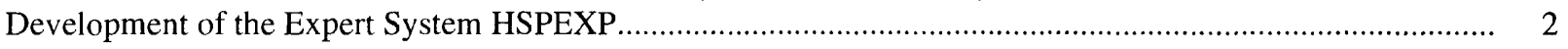

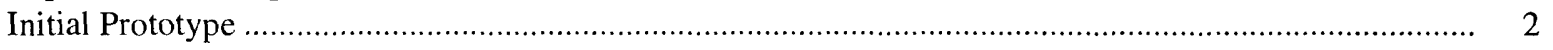

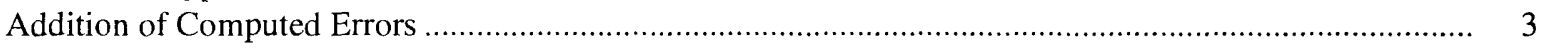

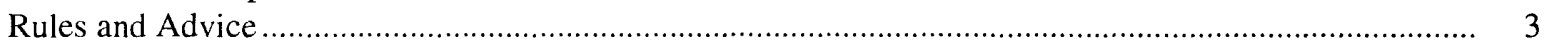

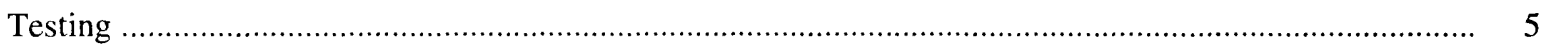

Overview of Procedures to Calibrate HSPF with HSPEXP ………............................................................ 7

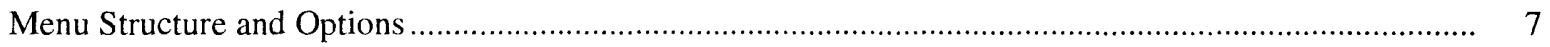

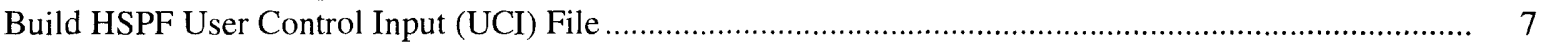

Build Watershed Data Management (WDM) File ............................................................................... 7

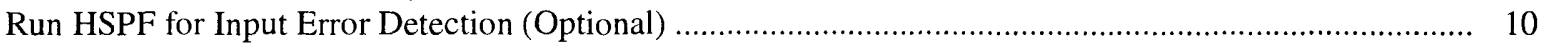

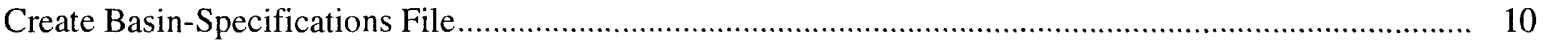

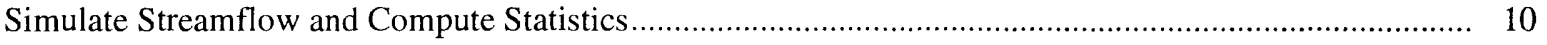

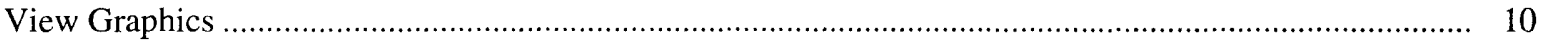

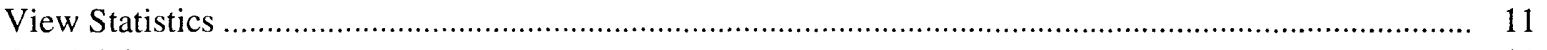

Get Advice …

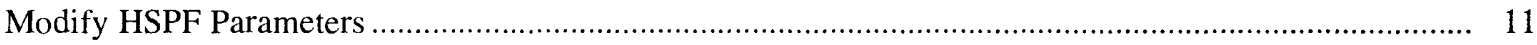

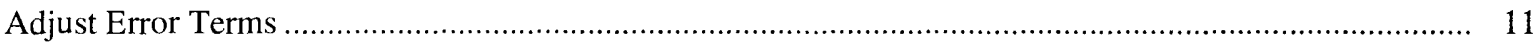

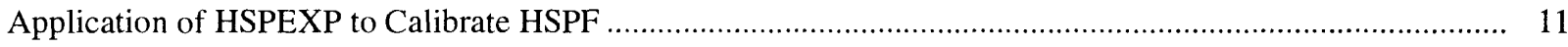

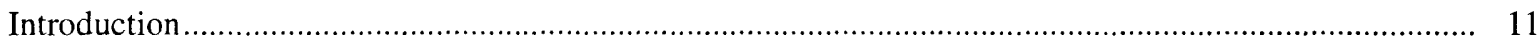

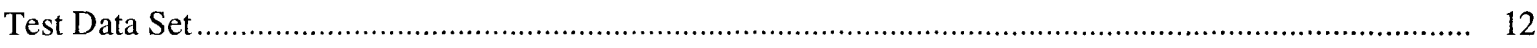

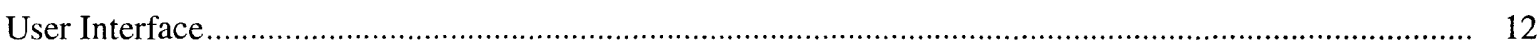

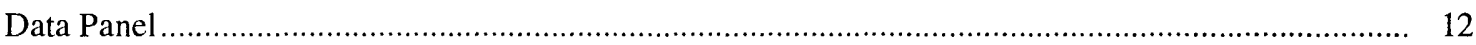

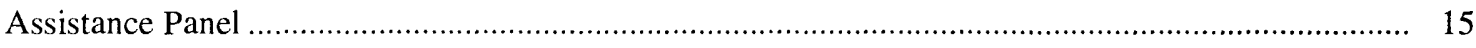

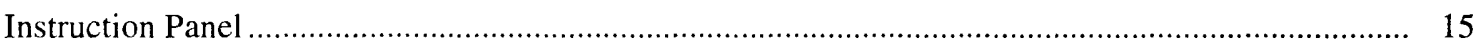

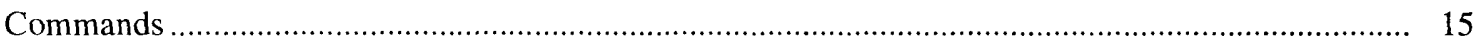

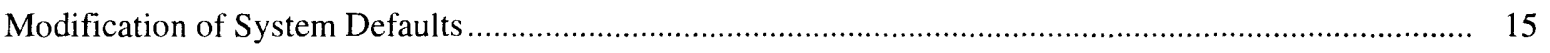

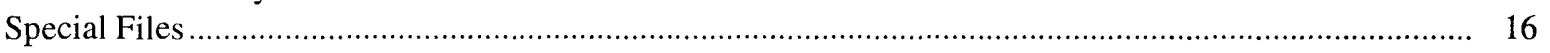

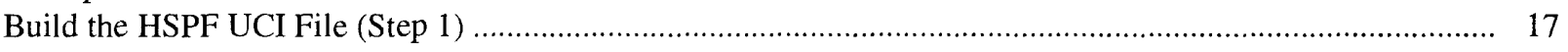

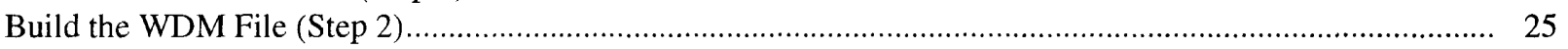

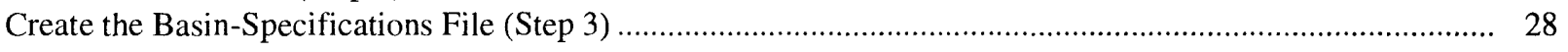

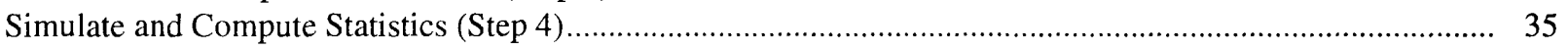

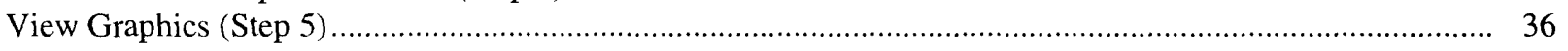

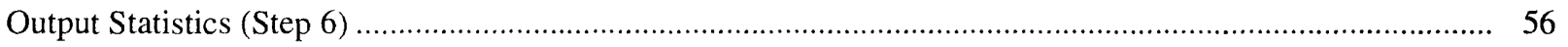

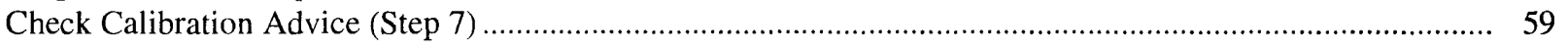

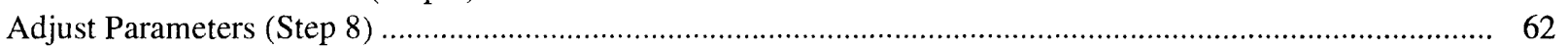

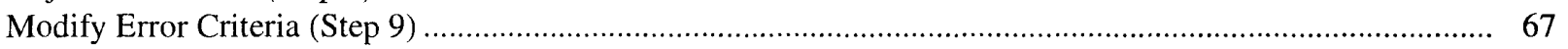

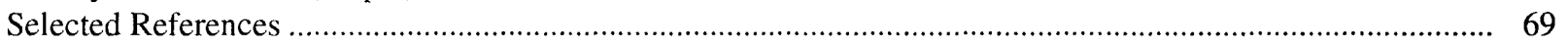

Appendix A. Rules and Advice for Calibration of HSPF .......................................................... 71

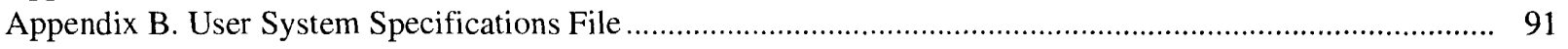

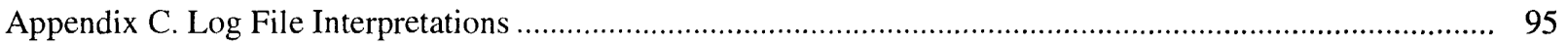

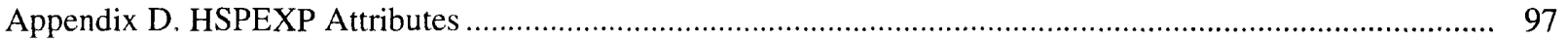




\section{FIGURES}

1. General Steps for Calibrating HSPF with HSPEXP

2. Options and Menu Structure in HSPEXP, the Expert System for Calibration of HSPF ............................. 8

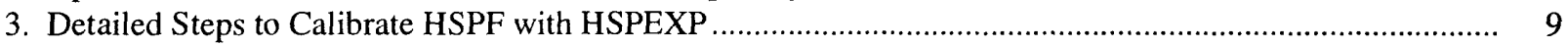

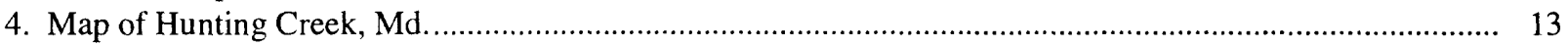

5. Basic Screen Layout and Available Commands for HSPEXP ............................................................. 14

6. Listing of the UCI File for the Test Data, hunting.uci ..................................................................... 19

7. Listing of Basin-Specifications File for Test Data, hunting.exs...............................................................

8. Time-Series Plot of Daily Precipitation and Logarithms of Daily Observed and Simulated Flow with

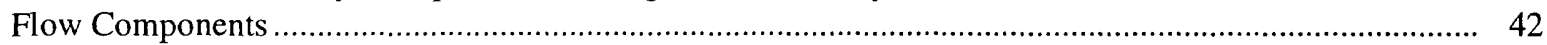

9. Time-Series Plot of Daily Precipitation and Logarithms of Daily Observed and Simulated Flow ................ 43

10. Time-Series Plot of Daily Precipitation and Daily Observed and Simulated Flow ...................................... 44

11. Time-Series Plot of Monthly Precipitation and Monthly Observed and Simulated Flow ............................ 45

12. Plot of the Error in Daily Flows and the Simulated Daily Upper Zone Storage Values ............................... 46

13. Plot of the Error in Daily Flows and the Simulated Daily Lower Zone Storage Values ................................ 47

14. Plot of the Error in Monthly Flows and the Month of the Year.............................................................. 48

15. Plot of the Error in Daily Flows and the Observed Data Flows ............................................................. 49

16. Time-Series Plot of Potential and Simulated Evapotranspiration.............................................................. 50

17. Flow Duration Curves for Observed and Simulated Daily Flows ........................................................ 51

18. Storm Hydrographs of Observed Flow and Simulated Flow with Flow Components ............................... 52

19. Frequency Curves of Daily Computed Flow Recession Rates for Observed and Simulated Flows .............. 53

20. Time-Series Plot of Cumulative Differences Between Simulated and Observed Daily Flow....................... 54

21. Listing of Graphics-specifications File for Test Data, hunting.plt ............................................................ 55

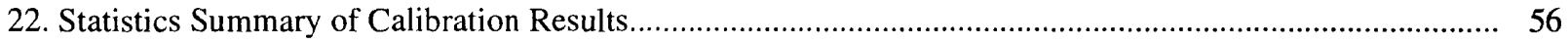

\section{TABLES}

1. Recommended Values for TGROUP for Time Series of a Given Time Step and Record Length.................. 26

2. Required Data Sets for HSPEXP Applications ..................................................................................... 27

3. Basin-Specifications File (.exs) Content and Format ........................................................................... 34

4. Graphics-Specifications File (.plt) Content and Format ....................................................................... 55

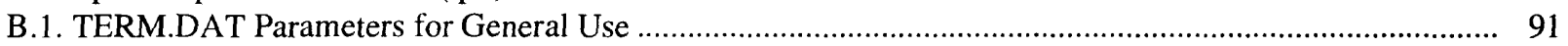

B.2. TERM.DAT Parameters for Color Display (MS-DOS PC) …........................................................ 91

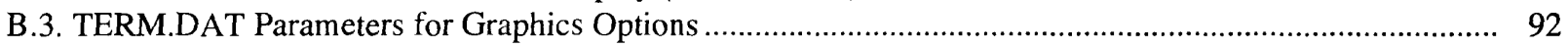

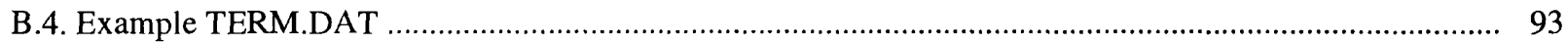

C.1. Codes Used for Nonprinting Characters in a Log File ...................................................................... 95

\section{CONVERSION FACTORS}

\begin{tabular}{rcl}
\hline Multiply & By & To obtain \\
\hline & & \\
inch (in.) & 25.4 & millimeter $(\mathrm{mm})$ \\
foot $(\mathrm{ft})$ & 0.3048 & meter $(\mathrm{m})$ \\
mile $(\mathrm{mi})$ & 1.609 & kilometer $(\mathrm{km})$ \\
acre & 0.4047 & square hectometer $\left(\mathrm{hm}^{2}\right)$ \\
acre-foot (acre-ft) & 1,233 & meter $\left(\mathrm{m}^{3}\right)$ \\
cubic foot per second $\left(\mathrm{ft}^{3} / \mathrm{s}\right)$ & 0.02832 & cubic meter per second $\left(\mathrm{m}^{3} / \mathrm{s}\right)$
\end{tabular}




\title{
Users Manual for an Expert System (HSPEXP) for Calibration of the Hydrological Simulation Program- Fortran
}

\author{
By Alan M. Lumb ${ }^{1}$ Richard B. McCammon ${ }^{1}$, and John L. Kittle, Jr. ${ }^{2}$
}

\section{ABSTRACT}

Expert system software was developed to assist less experienced modelers with calibration of a watershed model and to facilitate the interaction between the modeler and the modeling process not provided by mathematical optimization. A prototype was developed with artificial intelligence software tools, a knowledge engineer, and two domain experts. The manual procedures used by the domain experts were identified and the prototype was then coded by the knowledge engineer. The expert system consists of a set of hierarchical rules designed to guide the calibration of the model through a systematic evaluation of model parameters.

When the prototype was completed and tested, it was rewritten for portability and operational use and was named HSPEXP. The watershed model Hydrological Simulation Program-Fortran (HSPF) is used in the expert system. This report is the users manual for HSPEXP and contains a discussion of the concepts and detailed steps and examples for using the software. The system has been tested on watersheds in the States of Washington and Maryland, and the system correctly identified the model parameters to be adjusted and the adjustments led to improved calibration.

\section{OVERVIEW AND CONCEPTS}

\section{Introduction}

Watershed models have been used for more than two decades for the continuous simulation of river basin response to meteorologic variables of precipitation and potential evapotranspiration for flood forecasting, stormwater management, environmental impact assessments, and the design and operation of water-control facilities. Various parameters in the watershed models are modified to adapt the models to specific river basins. Some of the parameters can be estimated from measured properties of the river basins but others must be estimated by mathematical optimization or manual calibration. Optimization techniques used over the past two decades have not been totally satisfactory. Such techniques reduce the interaction between the model user and the modeling process and thus do not improve user understanding of the processes as simulated by the model and the actual processes in the watershed. Even though objective functions can be minimized by optimization, the physical meaning of such optimized model parameters is left, for the most part, unexplained. Manual calibration also has not

\footnotetext{
${ }^{1}$ U.S. Geological Survey

${ }^{2}$ Consultant
} 
been totally satisfactory because it requires experienced watershed modelers and there are more potential users of watershed models than there are experienced modelers. With that in mind, the expertise of the experienced watershed modeler was placed within the context of an expert system so that the less-experienced modelers can "manually" calibrate the model and improve their understanding of the link between the simulated processes and the actual processes. This report describes the expert system.

The watershed model Hydrological Simulation Program-Fortran (HSPF) (Bicknell and others, 1993) was selected as the basis for testing the feasibility of developing an expert system for parameter calibration. In earlier attempts, an expert system was developed to estimate initial parameters for HSPF (Gaschnig and others, 1981). That system weighted measured data on watershed characteristics with judgments on the importance of the characteristic in defining the value of the parameter. Unfortunately, the software for that system is not available.

\section{Procedures for Manual Calibration of HSPF}

In the present effort, two experienced watershed modelers, Alan M. Lumb and Norman H. Crawford (Hydrocomp, Inc.), documented procedures used to manually calibrate the rainfall-runoff module of HSPF. Richard B. McCammon was the knowledge engineer on the project. These calibration procedures are divided into four major phases: (1) water balance, (2) low flow, (3) stormflow, and (4) seasonal adjustments. A fifth phase, to identify any bias within the model, was also documented. During each of the four major phases, a different set of calibration parameters was evaluated by comparing simulated streamflow with observed streamflow. In more than two decades of experience with HSPF and similar models over a wide range of climates and topographies, experienced modelers have learned which parameters can be meaningfully adjusted to reduce the error of estimation. Although the adjustments in parameter values during manual calibration produce an error of estimation not significantly different from mathematical optimization routines, the parameters developed from manual calibration can be more meaningful and useful for regional applications of the model to ungaged watersheds. Mathematical optimization tends to treat the model as a "black box" and usually considers minimization of only one criterion, which is typically the sum of the square of the difference between simulated and observed flows.

\section{DEVELOPMENT OF THE EXPERT SYSTEM HSPEXP}

\section{Initial Prototype}

For the initial prototype of the expert system, a set of conditions was developed for each of the major calibration phases in which the user supplies or is prompted for the general observations of the differences between simulated and measured flows. For example, the user would be asked if simulated stormflows are too high in the summer, if total volumes of simulated flow are too low, and so forth. Given the user's responses, the initial prototype expert system identified the name of the parameter to be changed, direction of the change, and the reason for the change. 


\section{Addition of Computed Errors}

Although the advice on parameter adjustments from the initial prototype of the expert system was useful, there was a major burden on the user as to how to identify the errors and problems and to communicate them to the system. To ease that burden, seven error terms are computed by the new system from the simulated and observed streamflow time series:

1. error in total runoff volume for the calibration period,

2. error in the mean of the low-flow-recession rates based on the computed ratios of daily mean flow today divided by the daily mean flow yesterday for each day for the highest 30 percent (default) of the ratios less than 1.0 ,

3. error in the mean of the lowest 50 percent of the daily mean flows,

4. error in the mean of the highest 10 percent of the daily mean flows,

5. error in flow volumes for selected storms,

6. seasonal volume error, June-August runoff volume error minus

December-February runoff volume error, and

7. error in runoff volume for selected summer storms.

In addition, other computations are made:

1. ratio of simulated surface runoff and interflow volumes, and

2. the difference between the simulated actual evapotranspiration and the potential evapotranspiration.

With these computed values, the expert system can provide advice without the subjective input from the user. Several of the rules, however, contain optional subjective judgments that the user may supply. Examples are the type of vegetation, the water-holding capacity of the soil, the soil depth, or whether there is substantial recharge to a deep aquifer.

\section{Rules and Advice}

The expert system advice is based on a set of rules that use statistical measures and subjective judgments provided by the user that reflect the sensitivity of the parameters in the rainfall-runoff module of HSPF to those measures and judgments. The statistical measures are calculated after each HSPF simulation run. The user is asked to make subjective judgments by the prototype expert system when such judgments, in combination with the rules, affect the advice offered by the program. In the final version, the subjective judgments are optional input.

In its simplest form, a rule can be expressed by the following:

IF condition 1 condition $_{2}$ condition $_{3}$

THEN action , 
where the conditions are tested from left to right. The action will be taken if any of the previously specified conditions are true. The action is advice given to the user about whether to increase or decrease the value of a particular parameter. To take one rule as an example:

IF (the simulated total runoff is E1 percent higher than observed

AND the ET difference is less than the flow difference)

(the simulated total runoff is E1 percent higher than observed

AND there could be recharge to deeper aquifers)

THEN the advice is to increase DEEPFR,

where the error level E1 is set by the user, the ET difference is the potential ET minus the simulated ET, the ET and runoff differences are calculated from the output for the run, and the judgment about whether there could be recharge to deeper aquifers is elicited from the user if necessary. In this case, if the simulated total runoff does not exceed the observed runoff by E1 percent, there is no need to pursue this rule further, and no need to ask the user whether there could be recharge to deeper aquifers. Furthermore, if the first condition is true, the advice is to increase DEEPFR. There is no need to check the second condition or to ask the user about possible deeper recharge. Only if the simulated total runoff exceeds the observed runoff by E1 percent, and the ET difference is greater or equal to the flow difference, is there a need to ask the user whether there could be recharge to deeper aquifers.

In addition to the advice offered by the system, an explanation is given. In the case of the above rule, the explanation is:

Water losses from watersheds include surface-water flow at the outlet, actual evapotranspiration, and subsurface losses. Because observed precipitation and surface flow are fixed, and the potential evapotranspiration provides a ceiling for evapotranspiration, the only way to reduce surface flow is to increase subsurface losses. DEEPFR is the only parameter used to roughly estimate those losses and should be based on a ground-water study of the area.

The above rule and explanation is only one example for the case when the simulated runoff exceeds the observed runoff by a large percent. Some of the advice from other rules suggests a reevaluation of the input potential evapotranspiration. The explanations associated with advice have the greatest value to inexperienced hydrologists and to hydrologists unfamiliar with the HSPF program. Such explanations provide an excellent training mechanism. As the knowledge of the user increases over time, however, explanations become less important.

Within the expert system, there are 79 rules that apply to the 14 major, process-related HSPF parameters. For many of these parameters, there is more than one rule that contains advice about whether or not the value of the parameter should be increased or decreased. To avoid potential conflict in the advice offered by the system, the rules are divided into the four phases previously defined, each phase determining the order in which the rules will be applied. Within each phase, there is only one rule that will advise whether a particular parameter should be increased or decreased. All rules within a 
phase are tested before moving on to the rules in the next phase. If any action is indicated in testing the rules within a phase, the corresponding advice is given and no further testing of the rules is done. This strategy eliminates the possibility of conflicting advice being offered by the system.

The initial prototype is written in Envos Lisp Object-Oriented Programming System (LOOPS), formerly called Xerox LOOPS (Stefik and others, 1983). LOOPS adds access, object, and rule-oriented programming to the procedure-oriented programming of Common Lisp and Interlisp-D. The result made it possible to create an extended environment for the development of the prototype. Data objects in the prototype system include the main menu, the hydrologic response units, the rainfall-runoff parameters used in HSPF, the acceptable levels of error, and a number of graphical objects. On the computer screen, the major storm periods selected by the user are shown. The current values of the acceptable level of errors can be changed at any time. Such changes may change the states of the present rules. The icons along the bottom of the screen store ancillary information that is available to the user. Such information is the current advice, the rule descriptions, an ET map, and the storm periods currently selected. At the bottom right is the icon that, when activated, invokes execution of the HSPF program. In this way, HSPF and the prototype are linked.

To enable distribution and provide additional testing of the expert system, the program has been converted to American National Standards Institute (ANSI) standard languages using public-domain software tools for the user interface, data management, and graphics. The production version, HSPEXP, is written in Fortran with a subroutine for each rule. The graphics utilities use the ANSI and Federal Information Processing Standard (FIPS) Graphical Kernel System (GKS) library, which is available for most computers. The user interface uses the ANNIE Interactive Development Environment (AIDE) tool developed by the U.S. Environmental Protection Agency and the U.S. Geological Survey (Kittle and others, 1989), and a Watershed Data Management (WDM) file is used for time-series data management (Lumb and others, 1990).

The basic steps to be followed when using HSPEXP for calibration of HSPF are shown in figure 1. HSPF may be run within HSPEXP to begin the process. HSPEXP must be used to compute the required statistics, modify acceptable levels of error, and input ancillary data. Following the advice provided by the program, HSPF parameters could be changed and HSPF run again or the error levels could be reset and advice requested again. The iterations can continue until no more advice is provided for the current error levels.

\section{Testing}

HSPEXP has been used in the analyses of three watersheds: two rural watersheds in Maryland and an urban watershed in the Seattle, Wash., area. In each case the advice was verified by the experienced modeler, and in each case the advice resulted in a reduction of the error. Quantitative evaluations of the effectiveness of the system have not yet been conducted; however, the response of users in training classes has been very positive. 


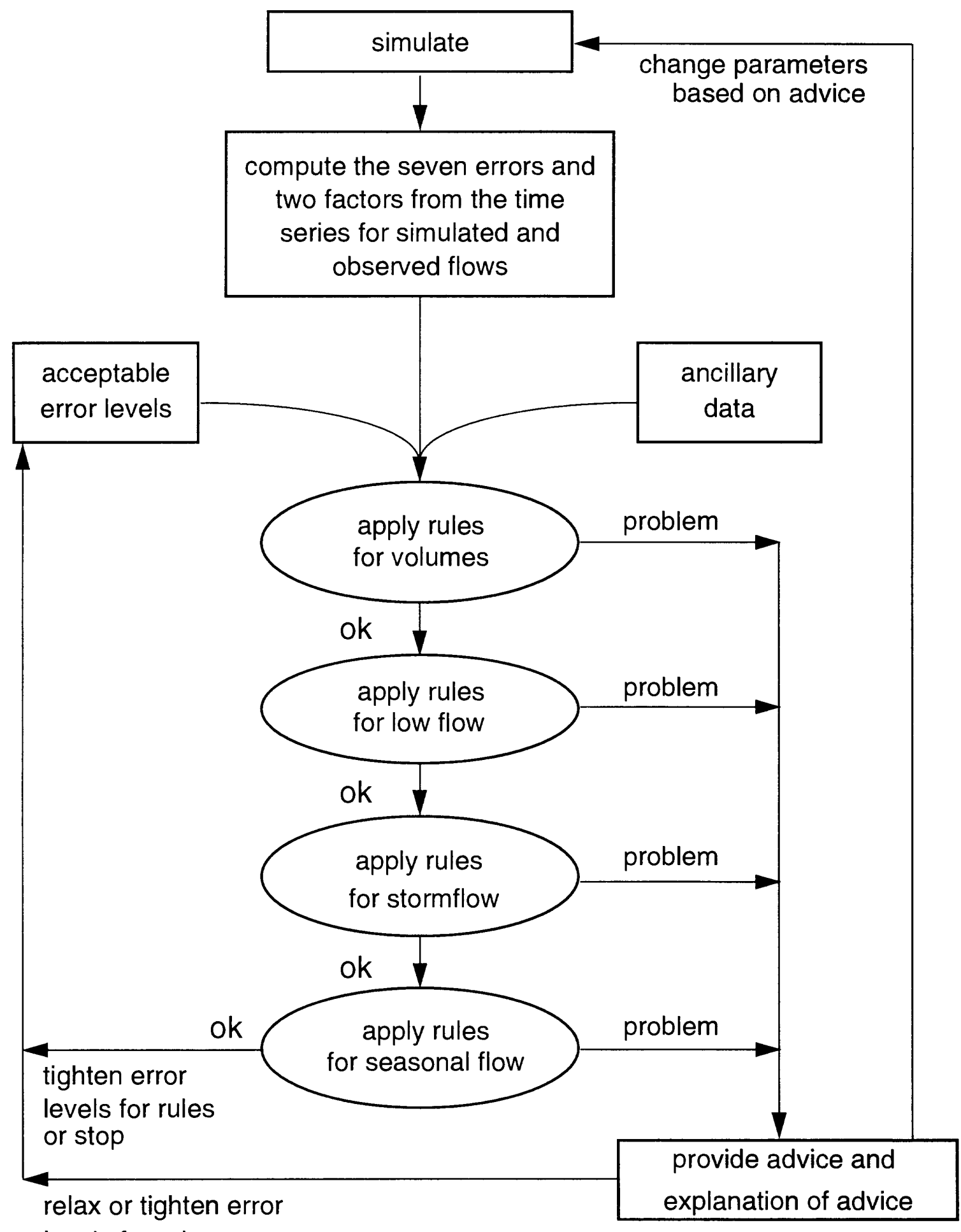

levels for rules

Figure 1. General steps for calibrating HSPF with HSPEXP. 


\section{OVERVIEW OF PROCEDURES TO CALIBRATE HSPF WITH HSPEXP}

\section{Menu Structure and Options}

The options and menu structure for HSPEXP are shown on figure 2. The words such as BASIN and ADVISE are menu options from which the user makes a selection. Examples of the menus and input forms are shown in the section "Application of HSPEXP to Calibrate HSPF." Following any of the lowest options in the menu structure on figure 2, input forms appear or an action is taken. Commands such as Help, Limits, Accept, and Previous are available in the system. Details on the use of the menus and forms are found in the section "User Interface."

The steps and procedures to calibrate HSPF with HSPEXP are shown in figure 3, which expands on figure 1. An overview of these steps is described in the following sections.

\section{Build HSPF User Control Input (UCI) File}

Step 1 is to build a UCI file within a text editor for input to HSPF, as described in the HSPF users manual (Bicknell and others, 1993) and the HSPF application guide (Donigian and others, 1984). The UCI file must have the lower case suffix .uci. The expert system will require some specific records on the UCI file under the EXT TARGETS block of the input. The purpose of those records is to store on the WDM file computed time series for eight variables used in HSPEXP in combination with observed time series of streamflow to compute statistics needed to generate the expert advice. The eight computed time series are:

1. simulated total runoff (inches),

2. simulated surface runoff (inches),

3. simulated interflow (inches),

4. simulated base flow (inches),

5. potential evapotranspiration (inches),

6. actual evapotranspiration (inches),

7. upper zone storage (inches), and

8. lower zone storage (inches).

If there is more than one PERLND operation or IMPLND operation, these time series must be prorated by drainage area and combined before placed on the WDM file.

\section{Build WDM File}

A WDM file for the time-series input and output for HSPF must be built with the program ANNIE or a companion program IOWDM (Lumb and others, 1990). The WDM file name must have the lower case suffix .wdm. The observed streamflow must be put in the WDM file, as well as all meteorologic time series and diversions that are 


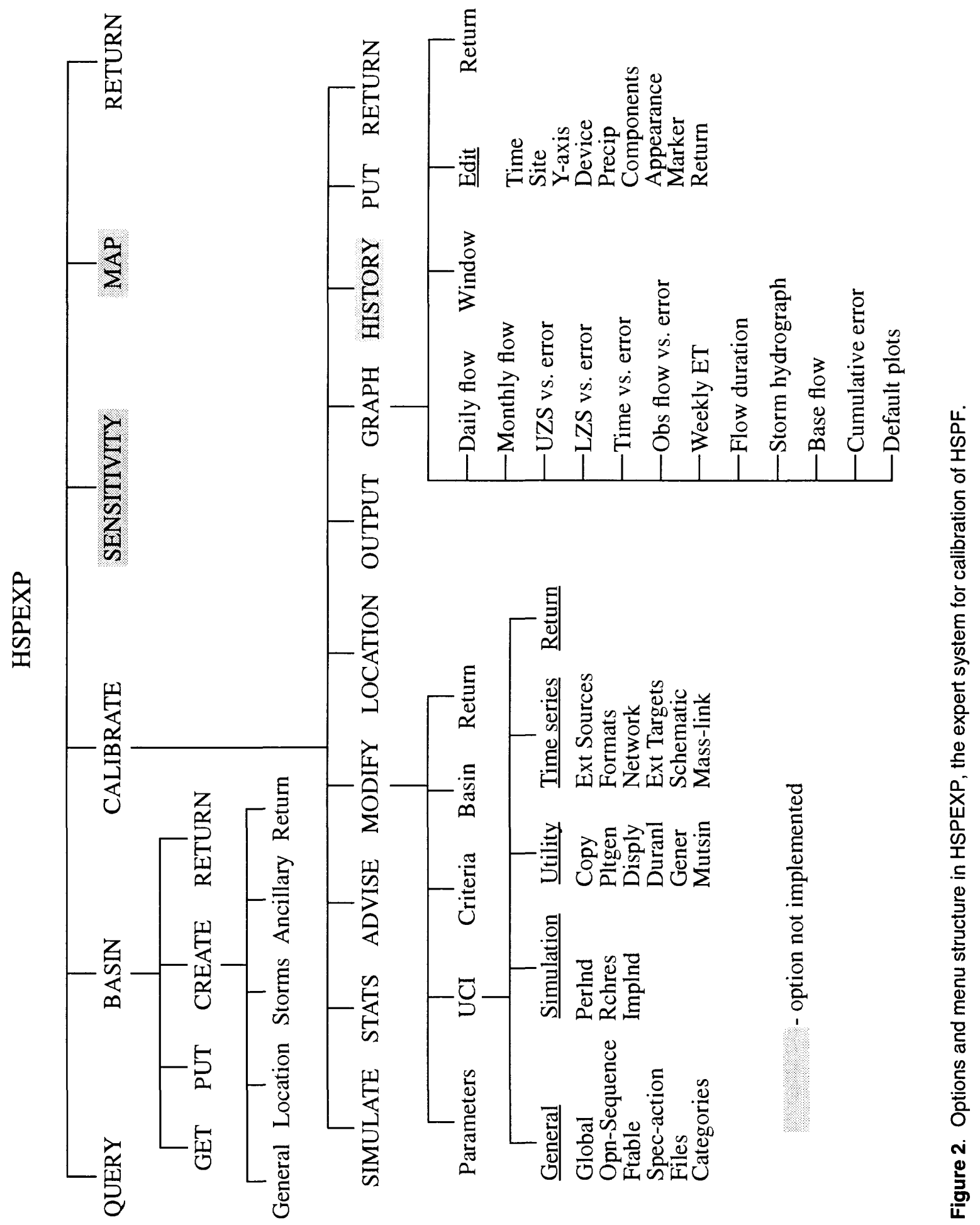




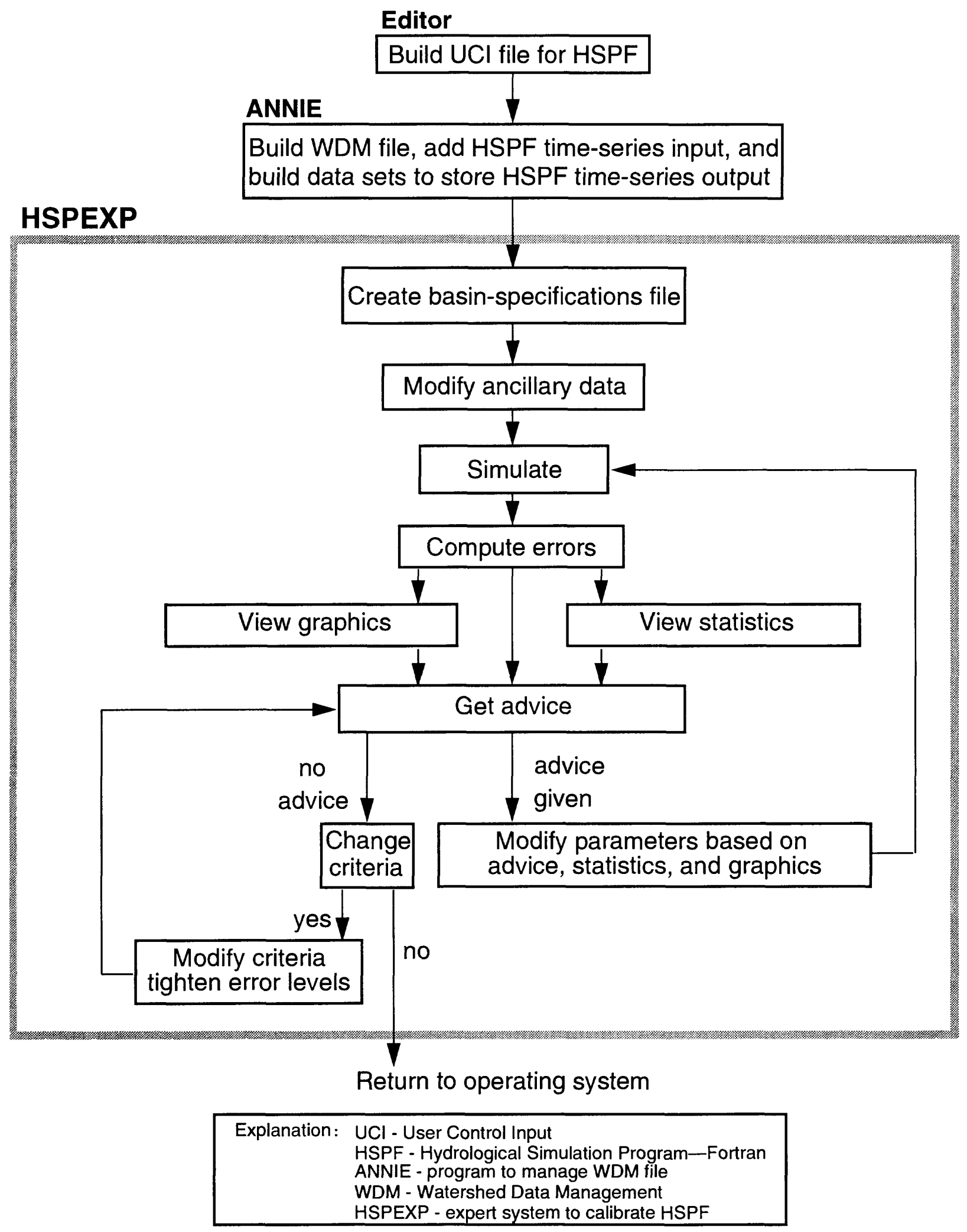

Figure 3. Detailed steps to calibrate HSPF with HSPEXP. 
identified in the EXT SOURCES block of the UCI file. Data sets for storage of the nine HSPF computed time series must also be built.

\section{Run HSPF for Input Error Detection (Optional)}

When the WDM and UCI files have been built, the batch version of HSPF can be run to check for any errors in the UCI and WDM files. HSPEXP does not provide as many checks as the batch version of HSPF. All subsequent steps should involve running HSPEXP.

\section{Create Basin-Specifications File}

The acceptable limits for errors, data-set numbers for 10 of the time series, ancillary data, storm periods, and location names are stored in a basin-specifications file. The file name must have the lower case suffix .exs. The HSPEXP CREATE option should be used to build the basin-specifications file so that the validity of the values entered is checked.

There are 23 pieces of ancillary information that can be provided to the expert system with the HSPEXP CREATE menu option ANCILLARY. The defaults to each are "unknown" and will be used unless modified with HSPEXP. Rules with ancillary data will not be used when the ancillary data values are tagged "unknown." It is useful to answer as many of these questions as possible. To permanently store all inputs in the basin-specifications file, the PUT option must be selected before ending an HSPEXP session.

\section{Simulate Streamflow and Compute Statistics}

Simulate streamflow for the basin using the CALIBRATE and SIMULATE options. The expert system uses seven computed error terms along with any ancillary data to offer advice. The error terms are computed automatically with the STATS option each time streamflow is simulated by using the SIMULATE option. The STATS option is included in the menu for the case when the HSPF simulation is done outside the expert system.

\section{View Graphics}

At any time, plots can be generated to visually assess the success of the calibrations. Eleven different plots can be generated and, for UNIX workstations under X-Windows, 1 to 4 of those plots can be shown on the monitor at one time. The most useful plots are the daily and monthly flow hydrographs and the flow duration plots. The plots of streamflow error with upper zone storage (UZS), lower zone storage (LZS), observed flow, or time are useful at later stages of the calibration to check for various types of biases. The duration plot of recession rates is useful for evaluating the effectiveness of the recession-rate error term that is calculated and provides information to reset the criterion that defines the percent of time that flows are in a low-flow (base flow) recession period. The evapotranspiration time-series plots have less utility than the other plots but can identify periods of moisture deficiency. The EDIT option under the GRAPH option can be selected to modify the plotting specifications. The XWINDOW option is used to set the number of plots and their location on the monitor. When leaving the GRAPH option, a file is written with the plotting specifications, which are applied 
in subsequent applications of HSPEXP. The plot file has the suffix .plt and the prefix must be the same as the exs file.

\section{View Statistics}

The OUTPUT option will provide the user with tables of the simulated and observed flow statistics, computed errors, and the acceptable level of errors that the expert system uses to select which rules and advice to offer to the user. Use of the OUTPUT option can be helpful for statistically tracking the calibration progress and for learning parameter sensitivity.

\section{Get Advice}

When the above steps have been completed, the ADVISE option in HSPEXP will provide the user with advice on which model parameter(s) to change, the direction of the change, and a brief explanation. All possible advice is listed in Appendix A. The advice can be sent to the screen (monitor), to a file, or both.

\section{Modify HSPF Parameters}

Following the expert system advice, an amount of change for each specified parameter is assumed. These changes are made with HSPEXP menu options CALIBRATE, MODIFY, and PARAMETERS. The UCI option can be used as a more generic alternate to the PARAMETERS option and is needed to change the multipliers in the EXTERNAL SOURCES block and to input monthly parameter values for LZETP and CEPSC. The modified parameter values will be applied for the next simulation. If a permanent change in the UCI file is desired, the BASIN and PUT options must be selected.

\section{Adjust Error Terms}

Initially, the default values of the acceptable levels of error should be appropriate. Upon several iterations of simulation, expert advice, and parameter changes, a point may be reached where no more advice is given. At that point (1) calibration can end, (2) the modeler can make further adjustments by trial-and-error, or (3) the error terms can be "tightened." To change (tighten or loosen) the error terms, use menu options CALIBRATE, MODIFY, and CRITERIA. As the error terms are tightened, a point may be reached when advice will oscillate among different types of advice because no parameter set can meet all acceptable levels of error. At this point, the calibration process should end.

\section{APPLICATION OF HSPEXP TO CALIBRATE HSPF}

\section{Introduction}

This section presents detailed examples illustrating the steps described in the overview section. Bold headings are placed at the top of each page with the title of the step for easy reference. For each step, the procedures are described, the user interaction is shown, input or output files are listed, and output graphics are shown. The examples use 
the test data set that is distributed with the software. In addition to HSPEXP, the software packages HSPF, ANNIE, and IOWDM are needed.

\section{Test Data Set}

The test data set used for the examples is for Hunting Creek in Prince Georges County, Md. It is a small watershed of about 6,000 acres outside of Washington, D.C. The entire watershed is located on the Geological Survey 7.5-minute series map titled Prince Frederick Quadrangle, Maryland - Calvert County. The Geological Survey streamgage (station number 01594670 ) is located at the bridge on Highway 263 approximately 200 feet from Highway 2. The rainfall data are from a weather station located 10 miles west in Mechanicsville, Md., and in several cases do not adequately represent the amount of rain that fell in the watershed. The watershed is mostly forested with crop and pasture lands along the ridges. A map of the watershed is provided in figure 4.

The test data sets do not represent a final calibration. Further adjustments could be made for a few of the parameters, additional reaches could be added, and the FTABLES refined. Test data sets provide examples as well as data to verify that HSPEXP is installed correctly and reproduces the test results.

\section{User Interface}

Each screen consists of at least two boxed-in regions or "panels," the data panel at the top and the instruction panel at the bottom. A third region, the assistance panel, may appear in the middle. Beneath the panels the available commands appear with their associated function keys. Commands are used to provide additional information and movement between screens. Figure 5 shows the basic layout of the screens. See the README file distributed with the program if panel borders are not properly drawn on your terminal.

All three panels and the line of available commands can be viewed on an 80 by 24 character screen. Each panel has a distinct purpose. User interaction with the program takes place in the data panel where menus, input forms, and informational text are displayed. In the assistance panel, help information, valid ranges for input values, and details on program status can be displayed. The instruction panel contains information on the keystrokes necessary to interact with the program.

Each screen has a name, which is located where the words "screen name" appear in figure 5. The first screen is called the opening screen. All subsequent screens are given a name based on the menu option selected. Screen names are followed by a "path," which is a list of characters representing the first letters of menu options chosen to arrive at the current screen. This list of menu initials can aid in keeping track of the position of the current screen in the menu hierarchy.

\section{Data Panel}

Menu options in the data panel are chosen by highlighting the desired option by using the arrow keys and then invoking the Accept (F2 function key) command. Alternatively, the first letter of the desired menu option can be typed. If more than one menu option begins with the same letter, enough characters must be typed to uniquely identify the desired option. 


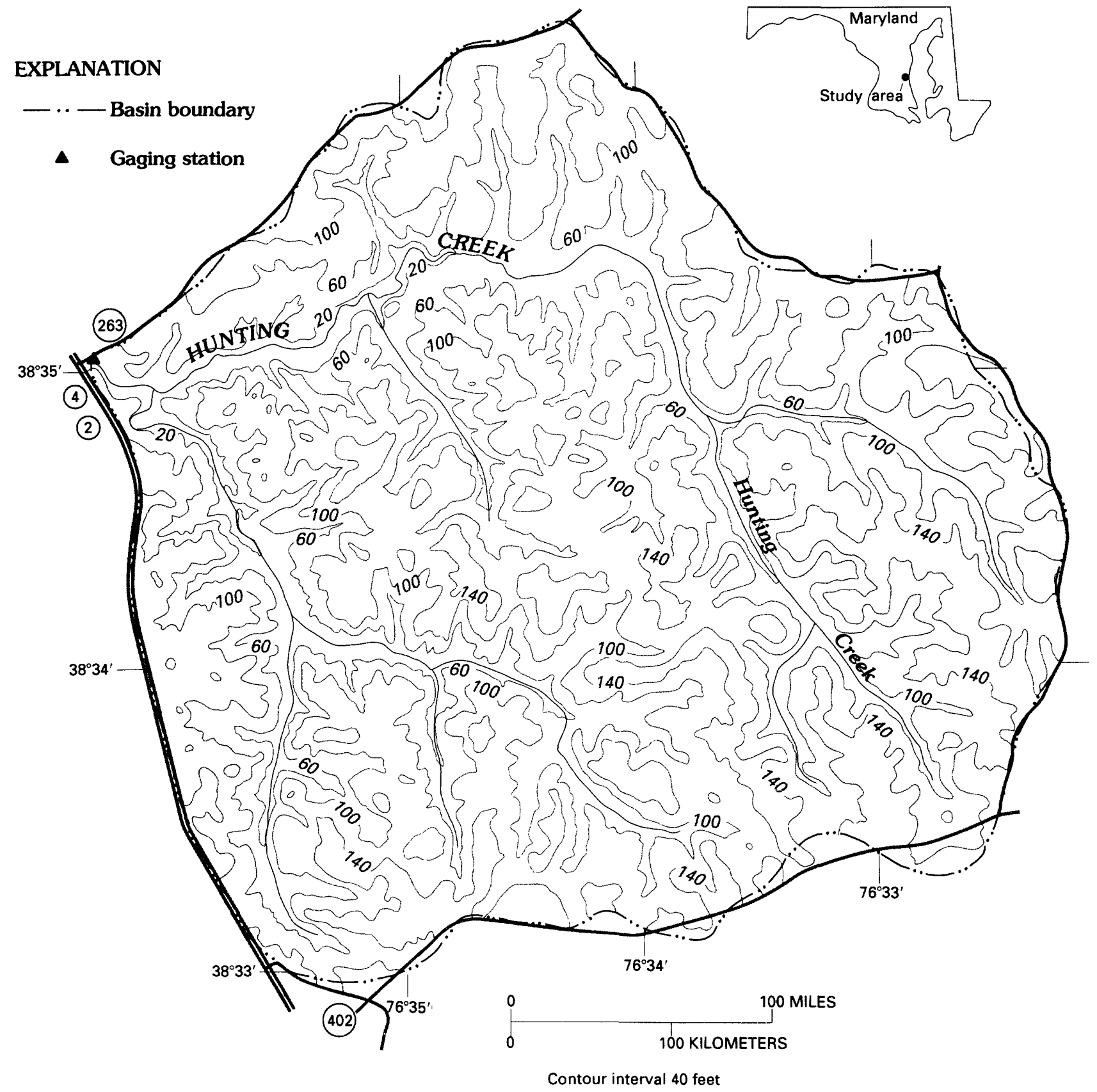

Figure 4. Map of Hunting Creek, Md. 


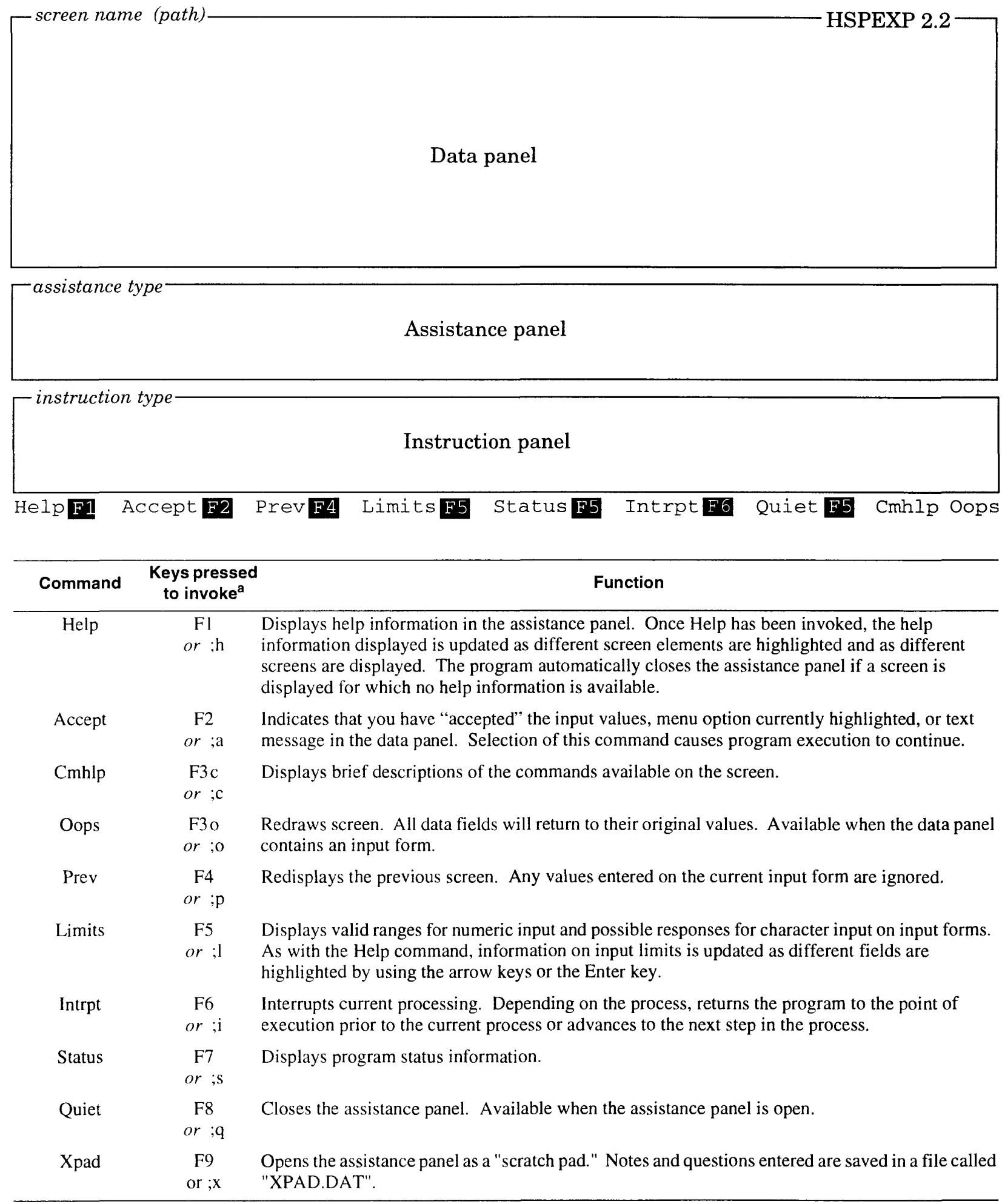

a. The function keys will invoke the commands on most computer systems. For those systems where this is not the case, the semicolon key (";") followed by the first letter of the command can be pressed instead.

Figure 5. Basic screen layout and available commands for HSPEXP. 
Input forms may require character input, such as a "yes" or "no" response, numeric input, or pressing the space bar to activate or deactivate an option. The cursor is moved around these screens by using the arrow keys or the Enter (Return) key.

An input form may consist of a single field into which a file name is typed. These file names are checked for validity and warnings are issued for invalid file names.

Informational text is displayed to give information on tasks in progress or already completed, as well as to give explanatory information or error messages. When these messages are displayed, the Accept (F2) command is invoked to continue.

\section{Assistance Panel}

The assistance panel appears when the commands Help (F1), Limits (F5), Status (F7), or Cmhlp (F3c) are invoked. The name of the command invoked appears in the upper left corner of the assistance panel, where the words "assistance type" appear in figure 5. The assistance panel is closed by invoking the Quiet (F8) command.

In some instances, there may be more assistance information than will fit in the four available lines. In these cases, the Page Up and Page Down keys can be used to scroll through the information, and then F3 or ";" is used to reactivate the data panel.

\section{Instruction Panel}

The instruction panel explains how to interact with the current data panel-how to enter responses and advance to another screen. Error messages related to invalid keystrokes are also displayed in the instruction panel. When error messages are displayed, the instruction type in the upper left corner of the panel changes from the usual "INSTRUCT" to "ERROR."

\section{Commands}

Figure 5 describes the available commands. Most commands are invoked by pressing a single function key. The Accept (F2) command is the most frequently used command. Commands not invoked by a single function key are invoked by pressing the F3 function key or the semicolon key (";") followed by the first letter of the command. Pressing either the F3 function key or the semicolon key causes the cursor to move to the bottom of the screen; any command can then be invoked by typing its first letter. Pressing either of these keys (F3 or ";") a second time without invoking a command will reactivate the data panel. The F3 function key or the semicolon key is also used to reactivate the data panel when the assistance panel becomes the active panel on the screen as described under "Assistance Panel."

\section{Modification of System Defaults}

When the program is started, the following message usually appears, "Optional TERM.DAT file not opened, defaults will be used." System defaults have been predefined to suit most users' needs, but various aspects of program operation may be modified by creating a "TERM.DAT" file. This file resides in the directory where the program is being used. The format and contents of the TERM.DAT file are described in Appendix B. 


\section{Special Files}

Each time the program is run, two files are produced that aid in troubleshooting and in future program execution-ERROR.FIL and HSPEXP.LOG.

The ERROR.FIL file contains any error messages produced while running the program. Diagnostic messages may be written to this file to aid in debugging. This file should be consulted if an unexpected program response is encountered.

The HSPEXP.LOG file contains a log of all keystrokes made while running the program. This record of keystrokes is helpful when the program is repeatedly used to perform the same functions. The file can be used as input to the program; the keystrokes are read from the file as if they were typed in. To use the file in this way, first change its name to something other than HSPEXP.LOG to prevent the file from being overwritten the next time the program is started. On any screen within the program, type "@" to be prompted for the log file name. The contents of the file will be read and executed as appropriate. A message will be displayed when the end of the log file is reached.

The first line in the log file should be an appropriate response to the screen where the name of the log file is provided. Occasionally, the log file contents will get out of sync with the input expected by the program. When this happens, the program should be terminated and the log file should be edited to correctly order the responses.

Log files are most easily created by using the program for the processes to be repeated and then modifying the log file for future program execution. Alphabetic keys pressed will be recorded in the log file in the manner in which they were typed. Special keys that are pressed, such as the function keys, the semicolon, the arrow keys, or the Page Up and Page Down keys, will be represented in the log file by a unique code number preceded by a pound sign ("\#"). These code numbers are listed in Appendix C. When planning to use a log file, you will discover it is easier to interpret the file when a menu option is chosen by entering a character instead of pressing the Enter or F2 key. 


\section{BUILD THE HSPF UCI FILE (Step 1)}

\section{FILES}

\section{DELINEATION}

\section{GLOBAL}

\section{FILES}

OPN SEQUENCE

\section{PERLND}

\section{IMPLND}

To create a UCI file for your watershed or river basin, it is recommended that the UCI file listed in figure 6 for the test case be copied to your working directory. This file includes simulation of runoff and routing and does not include snow accumulation, snowmelt, or water quality. HSPEXP can simulate snowmelt, sediment, and water quality, but the graphics and expert advice only apply to the runoff and routing processes. The file must be given a name followed by the suffix .uci (for example, hunting.uci). The five files used by HSPEXP must all have the same prefix usually taken from the name of the watershed. Suffixes for the other four files are .wdm, .plt, .exs, and .ech; and these are described in a later section. The HSPF users manual describing the input on the UCI file should be used along with the time-series catalog portion of the manual.

Before editing the UCI file, drainage boundaries, extent of river reaches, drainage areas, number, location and area of PERLND and IMPLND areas, and area of each PERLND and IMPLND by reach must be delineated and (or) determined. Automation of this process within a geographic information system (GIS) is currently in a planning and design phase. The GIS would generate a file of the above data and the expert system would use that file to generate a UCI file.

When each of the PERLND, IMPLND, and RCHRES segments has been delineated, an integer number assigned, and areas tabulated, the UCI file can be edited. The editing tasks are listed below under the block headings used in the UCI file.

Modify the title line and simulation period. Column location is critical so dates and time must remain in the same columns as found in the test case UCI file.

Change the word 'hunting' to an identifier name for your watershed.

The time step (INDELT) is set for 1 hour in the test case UCI file. This is usually set at the time step of the input precipitation data, but might be increased for very large watersheds or decreased for very small watersheds. Change the current list of operations to include all the delineated PERLND's, IMPLND's, and RCHRES's with your assigned integer number. The line with COPY must remain so that the simulated data needed for analysis is available to the expert system.

For each of the PERLND's identified in the OPN SEQUENCE block, provide the various tables of input options and parameters. Note the FORTRAN unit number ( 90 in the test case) in the GEN-INFO table must be included in the FILES block. Values in the model-parameter tables are not the best values for the test basin and are not typical or average values. If you have some experience with HSPF or HSPF has been calibrated for a watershed in the area, use this information to help you set initial values for the parameters. If not, read the HSPF users guide (Donigian and others, 1984) to estimate parameters or use the values in the test data set and let the expert system provide advice on parameter-value changes.

The discussion on PERLND above also applies to the IMPLND block. 


\section{BUILD THE HSPF UCI FILE (Step 1)}

\section{RCHRES}

COPY

EXT SOURCES

EXT TARGETS

SCHEMATIC

MASS-LINK

FTABLES
Three RCHRES's are used in the test case. Models of typical watersheds usually have more RCHRES segments. As a rough rule of thumb, the average traveltime through a reach should very roughly approximate the time step used. Also, more than about eight reaches above a point of interest usually does not noticeably improve the simulations.

The COPY block should remain and not be changed. If more output is desired, the number of time series could be increased but must not be decreased.

The input time series used by the expert system are identified in the EXT SOURCES block. The member names following the WDM data-set number must match exactly the TSTYPE name used in ANNIE or IOWDM when building the WDM data sets. You will also need to enter some of these data-set numbers when using HSPEXP to build the EXS file in step 3. A table listing all WDM data sets is provided under step 2 to assist in building the WDM data sets.

The output time series used by the expert system are identified in the EXT TARGETS block. The multiplication factor for the RCHRES item in EXT TARGETS is used to convert acre-feet/time step to watershed-inches and is equal to $12 \mathrm{in} / \mathrm{ft}$ divided by the watershed area in acres. For the PERLND items, the multiplication factor converts acre-inches to watershed-inches and is equal to 1.0 divided by the watershed area in acres. The member name is the same as the time-series types (TSTYPE) that was used when the data set was built.

The area factor (drainage area in acres) should be changed to the appropriate value for each PERLND and IMPLND identified in the OPN SEQUENCE block.

No changes should be made to this block.

An FTABLE must be prepared for each RCHRES specified in the RCHRES block. An FTABLE can be used for one or more reaches if the flow characteristics of the reaches are similar. FTABLES can be generated from rating tables where streamflow is observed, can be computed from reach cross-sectional data and Manning's equation, or can be computed from backwater analyses with different flows. 


\section{BUILD THE HSPF UCI FILE (Step 1)}

Figure 6. Listing of the $\mathrm{UCl}$ file for the test data, hunting.uci.

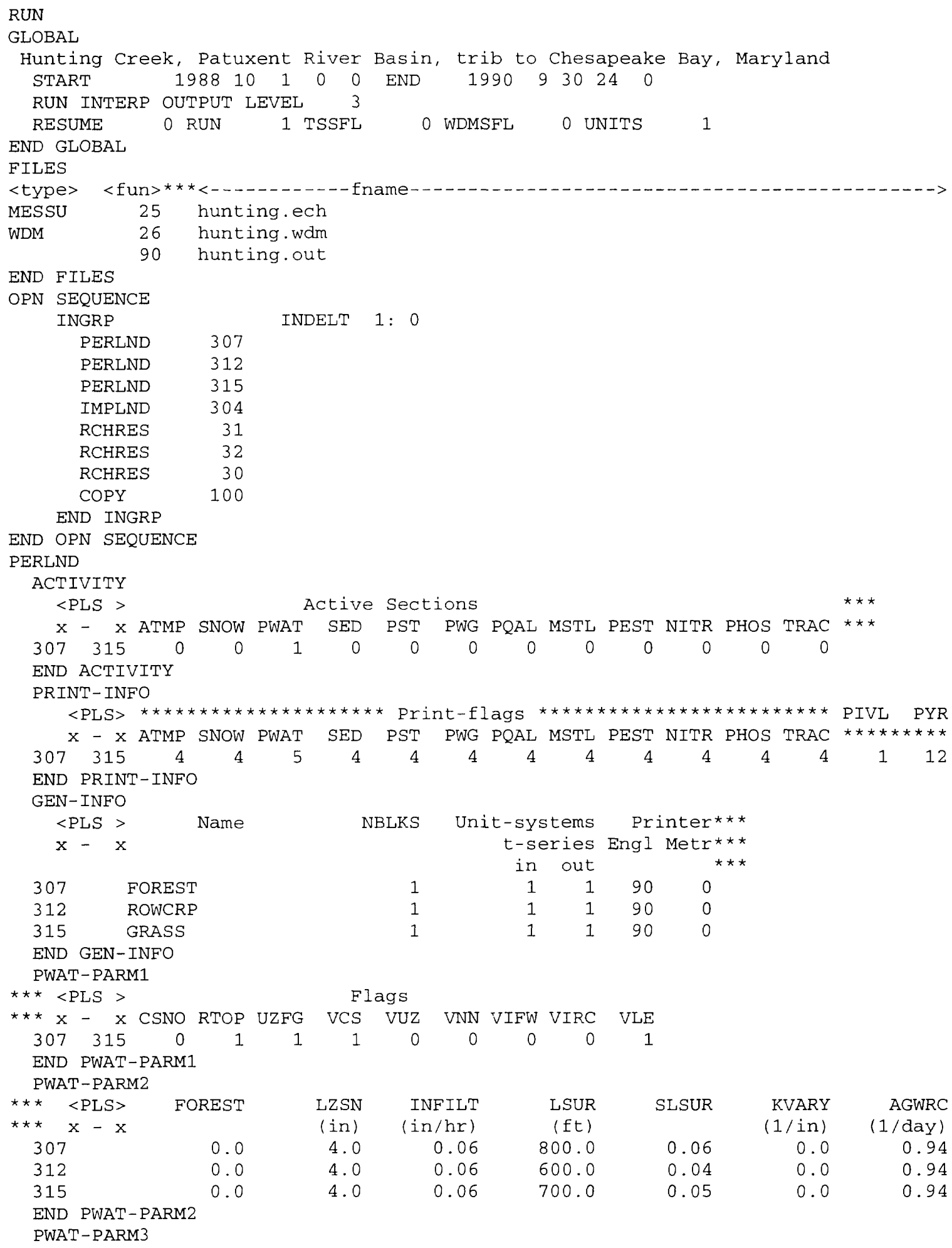




\section{BUILD THE HSPF UCI FILE (Step 1)}

Figure 6. Listing of the $\mathrm{UCl}$ file for the test data, hunting.uci---Continued

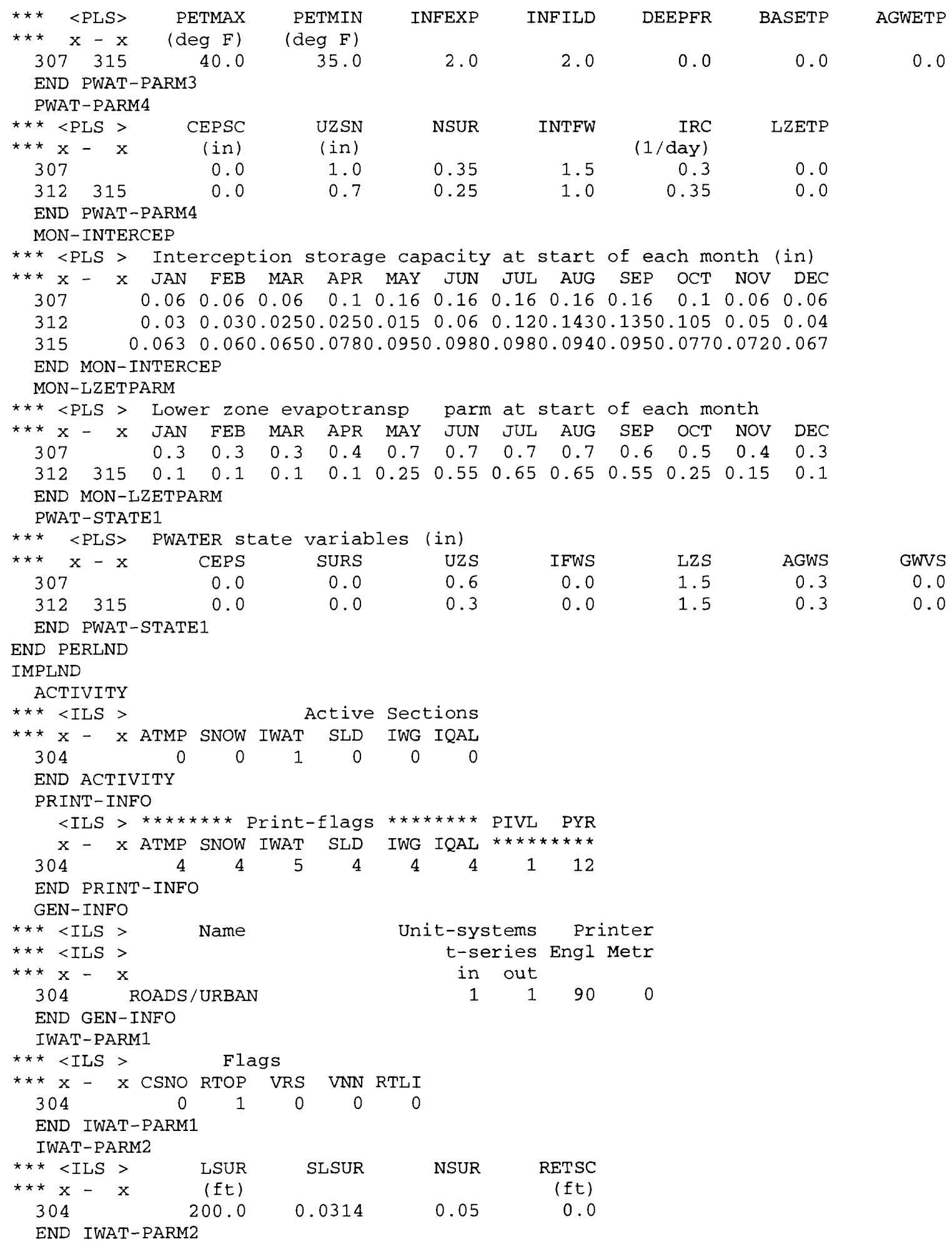




\section{BUILD THE HSPF UCI FILE (Step 1)}

Figure 6. Listing of the $\mathrm{UCl}$ file for the test data, hunting.uc.i--Continued

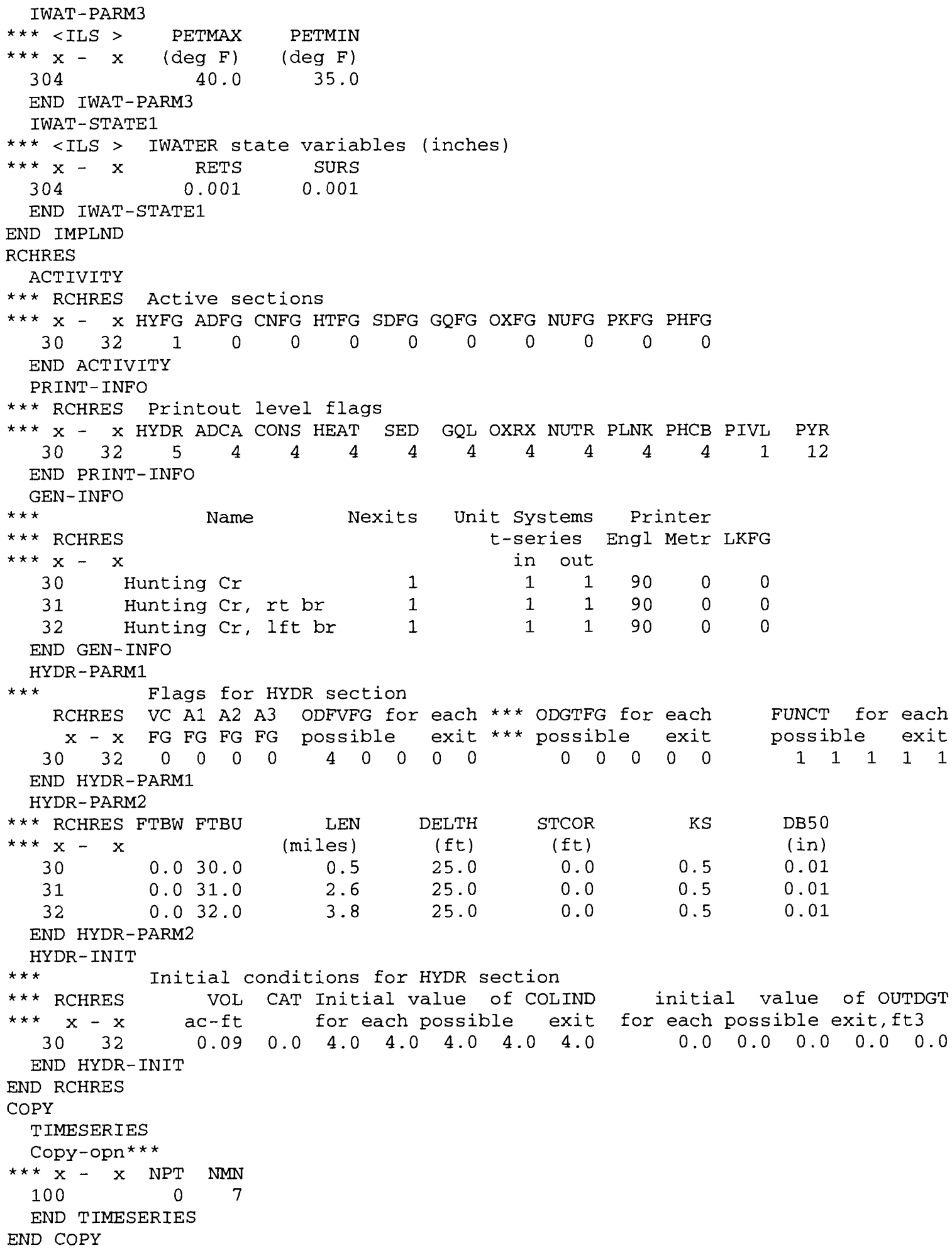




\section{BUILD THE HSPF UCI FILE (Step 1)}

Figure 6. Listing of the $\mathrm{UCl}$ file for the test data, hunting.uci.--Continued

\begin{tabular}{|c|c|c|c|c|c|c|c|c|c|c|c|}
\hline \\
\hline$<-$ Volume $->$ & & $<$ Name $>$ & $x$ tem & strs & $g<-$ factor->strg & $<$ Name $>$ & & $x \quad x$ & & $<$ Name $>\mathrm{x} \times$ & $\begin{array}{l}\star \star \star \\
\star \star \star\end{array}$ \\
\hline WDM & 106 & HPCP 1 & 10 ENGL & & & PERLND & $30^{\circ}$ & 7315 & EXTNL & $\begin{array}{lll}\text { PREC } & 1 & 1\end{array}$ & \\
\hline WDM & 111 & EVAP & 10 ENGL & & $0.75 \mathrm{DIV}$ & PERLND & $30^{\circ}$ & 315 & EXTNL & PETINP 1 & \\
\hline WDM & 106 & HPCP & 10 ENGL & & & IMPLND & 30 & & EXTNL & PREC 1 & \\
\hline WDM & 111 & EVAP & 10 ENGL & & $0.75 \mathrm{DIV}$ & IMPLND & 304 & & EXTNL & PETINP 11 & \\
\hline \multicolumn{12}{|c|}{ END EXT SOURCES } \\
\hline \multicolumn{12}{|c|}{ EXT TARGETS } \\
\hline \multirow{2}{*}{\multicolumn{3}{|c|}{ 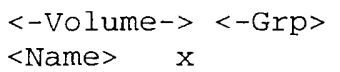 }} & \multicolumn{3}{|c|}{$<-$ Member $-><--$ Mult $-->$ Tran } & \multicolumn{2}{|c|}{$<-$ Volume- $>$} & \multirow{2}{*}{\multicolumn{2}{|c|}{$\begin{array}{l}<\text { Member }>\mathrm{T} \\
<\text { Name>qf }\end{array}$}} & Tsys Aggr Ama & $\star \star \star$ \\
\hline & & & $<$ Name $>$ & $x:$ & $x<-$ factor->strg & <Name> & & & & tem strg strg & *** \\
\hline RCHRES & 30 & ROFLOW & ROVOL & 1 & 10.0020107 & WDM & 42 & SIMQ & Q $1 \mathrm{EN}$ & NGL REPL & \\
\hline COPY & 100 & OUTPUT & MEAN & 1 & 10.0001678 & WDM & 421 & SURO & $1 E I$ & REPL & \\
\hline COPY & 100 & OUTPUT & MEAN & 2 & 10.0001678 & WDM & 42 & IFWO & $1 E N$ & REPL & \\
\hline OPY & 100 & OUTPUT & MEAN & 3 & 10.0001678 & WDM & 423 & AGWO & $1 \mathrm{EI}$ & REPL & \\
\hline COPY & 100 & OUTPUT & MEAN & 4 & 10.0001678 & WDM & 42 & PETX & $1 E I$ & NGL AGGR REPL & \\
\hline COPY & 100 & OUTPUT & MEAN & 5 & 10.0001678 & WDM & 42 & SAET & $1 \mathrm{EN}$ & NGL AGGR REPL & \\
\hline COPY & 100 & OUTPUT & MEAN & 6 & $10.0001678 \mathrm{AVER}$ & WDM & $42^{\circ}$ & UZSX & $1 E N$ & NGL AGGR REPL & \\
\hline COPY & 100 & OUTPUT & MEAN & 7 & 10.0001678 AVER & WDM & 428 & LZSX & $1 \mathrm{EI}$ & NGL AGGR REPL & \\
\hline END EXT & I TAF & RGETS & & & & & & & & & \\
\hline SCHEMAT & TIC & & & & & & & & & & \\
\hline$<-$ Volum & ne-> & & & & $<-$ Area--> & $<-$ Volum & he- & $<\mathrm{ML}$ & L\#> $>\star \star \star$ & & \\
\hline$<$ Name $>$ & & & & & $<-$ factor $->$ & $<$ Name $>$ & & & $\star \star \star$ & & \\
\hline PERLND & 307 & & & & 32.0 & RCHRES & 3 & & 1 & & \\
\hline PERLND & 312 & & & & 0.0 & RCHRES & 3 & & 1 & & \\
\hline PERLND & 315 & & & & 6.0 & RCHRES & 3 & & 1 & & \\
\hline IMPLND & 304 & & & & 0.0 & RCHRES & 3 & & 2 & & \\
\hline PERLND & 307 & & & & 1318.0 & RCHRES & 3 & & 1 & & \\
\hline PERLND & 312 & & & & 193.0 & RCHRES & 3 & & 1 & & \\
\hline PERLND & 315 & & & & 231.0 & RCHRES & 3 & & 1 & & \\
\hline IMPLND & 304 & & & & 84.0 & RCHRES & 3 & & 2 & & \\
\hline PERLND & 307 & & & & 3078.0 & RCHRES & 3 & & 1 & & \\
\hline PERLND & 312 & & & & 449.0 & RCHRES & 3 & & 1 & & \\
\hline PERLND & 315 & & & & 540.0 & RCHRES & 3 & & 1 & & \\
\hline IMPLND & 304 & & & & 35.0 & RCHRES & 3 & & 2 & & \\
\hline RCHRES & 31 & & & & & RCHRES & 3 & & 3 & & \\
\hline RCHRES & 32 & & & & & RCHRES & 3 & & 3 & & \\
\hline PERLND & 307 & & & & 4429.0 & COPY & 10 & & 90 & & \\
\hline PERLND & 312 & & & & 642.0 & COPY & 10 & & 90 & & \\
\hline PERLND & 315 & & & & 777.0 & COPY & 10 & & 90 & & \\
\hline IMPLND & 304 & & & & 120.0 & COPY & 10 & & 91 & & \\
\hline END SCF & AEMAT & IIC & & & & & & & & & \\
\hline ASS-LI & INK & & & & & & & & & & \\
\hline MASS - & -IINI & & 1 & & & & & & & & \\
\hline$<-$ Volun & ne $\rightarrow>$ & $<-G r p>$ & $<-$ Memb & er- & $><--$ Mult $-->$ Tran & $<-$ Targe & & vols> & $<-$ Grp $>$ & $<-$ Member $->$ & $\star \star \star \star ~$ \\
\hline$<$ Name $>$ & & & $<$ Name $>$ & $\mathrm{x}$ & $x<-$ factor $->$ strg & $<$ Name $>$ & & & & $<$ Name $>\mathrm{x} \mathrm{x}$ & $\star \star \star$ \\
\hline PERLND & & PWATER & PERO & & 0.0833333 & RCHRES & & & INFLOW & IVOL & \\
\hline END $\mathrm{N}$ & MASS- & -LINK & 1 & & & & & & & & \\
\hline MASS & - LINF & & 2 & & & & & & & & \\
\hline$<-$ Volun & ne-> & $<-$ Grp $>$ & $<-$ Memb & er- & $><--$ Mult $-->$ Tran & $<-$ Targe & & vols $>$ & $<-G r p>$ & $<-$ Member-> & $\star \star \star$ \\
\hline$<$ Name $>$ & & & $<$ Name $>$ & & $x<-$ factor->strg & $<$ Name $>$ & & & & $<$ Name $>\mathrm{x} \times$ & $\star \star *$ \\
\hline IMPLND & & IWATER & SURO & & 0.0833333 & RCHRES & & & INFLOW & IVOL & \\
\hline END 1 & MASS - & -LINK & 2 & & & & & & & & \\
\hline MASS - & - LINF & & 3 & & & & & & & & \\
\hline$<-$ Volun & ne-> & $<-G r p>$ & $<-$ Memb & & $><--$ Mult $-->$ Tran & $<-\operatorname{Targ} \theta$ & & vols> & $<-G r p>$ & $<-$ Member $->$ & $* * *$ \\
\hline$<$ Name $>$ & & & $<$ Name $>$ & & $\mathrm{x}<-$ factor $->$ strg & $<$ Name> & & & & $<$ Name $>\mathrm{x} \times$ & $\star \star * *$ \\
\hline RCHRES & & HYDR & ROVOL & & & RCHRES & & & INFLOW & IVOL & \\
\hline
\end{tabular}




\section{BUILD THE HSPF UCI FILE (Step 1)}

Figure 6. Listing of the $\mathrm{UCl}$ file for the test data, hunting.uci.--Continued

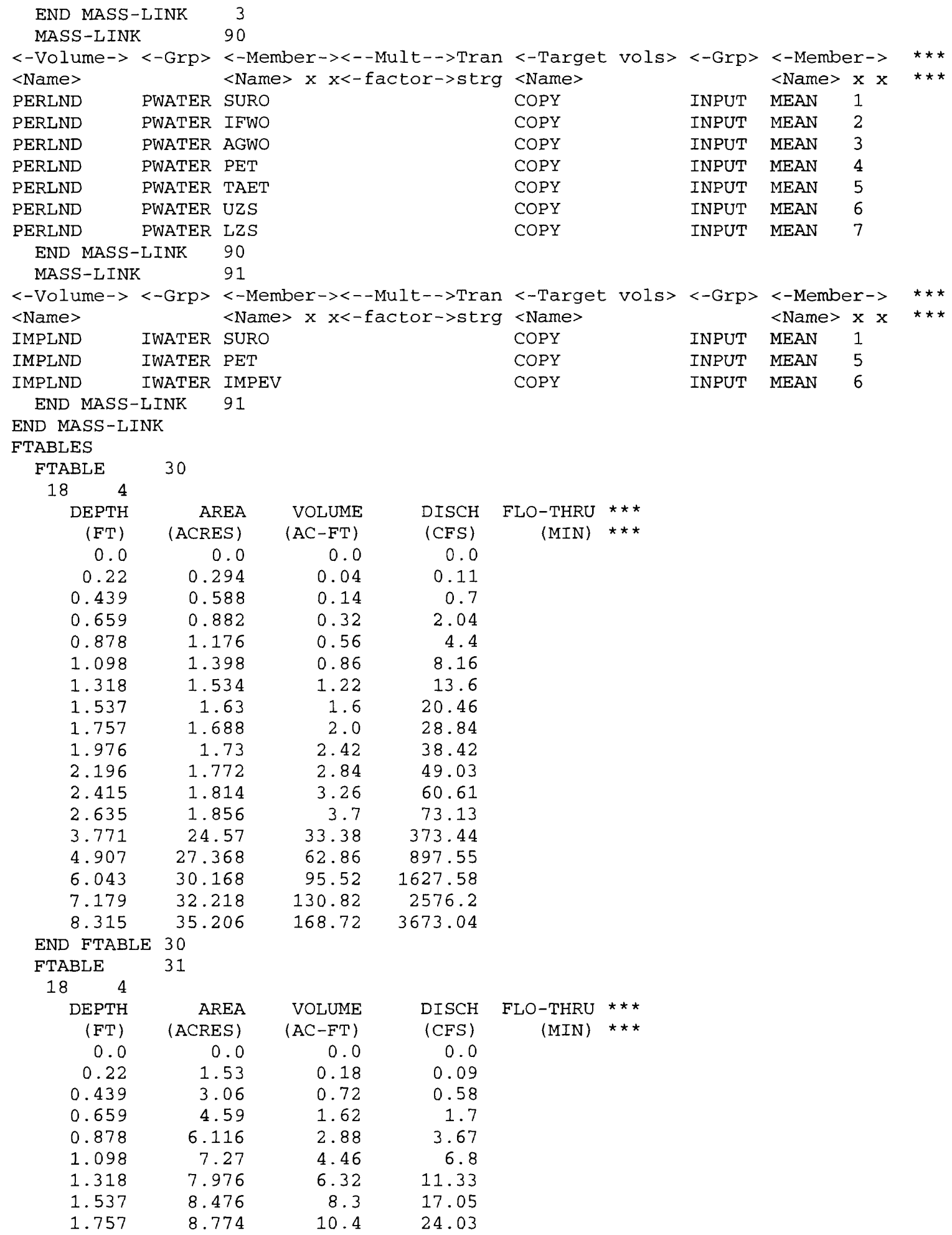




\section{BUILD THE HSPF UCI FILE (Step 1)}

Figure 6. Listing of the $\mathrm{UCl}$ file for the test data, hunting.uci.--Continued

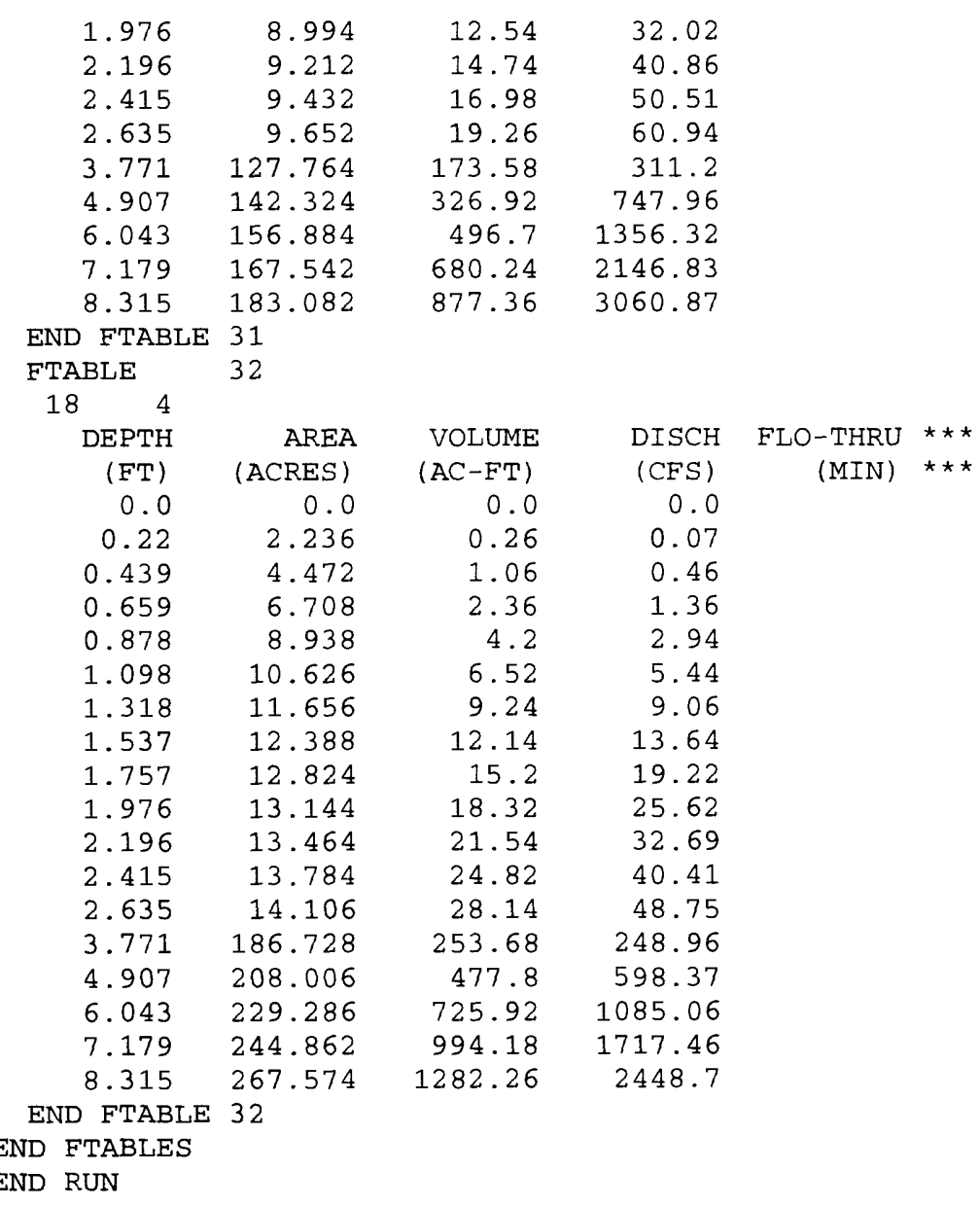




\section{BUILD THE WDM FILE (Step 2)}

\section{WDM FILE}

\section{STRUCTURE and MAINTENANCE}

\section{TIME-SERIES DATA COMPRESSION}

The program ANNIE is used for this step. After the WDM file has been built, all the WDM data sets identified in the UCI file from step 1 must be added. For the data sets in the EXT SOURCES block of the UCI file, the meteorologic time series must be added to the data set using the ANNIE IMPORT option or the program IOWDM. A general discussion of the WDM file follows and is very similar to the same discussion found in the ANNIE users manual (Lumb and others, 1990).

The WDM file is a binary, direct-access file used to store hydrologic, hydraulic, meteorologic, water-quality, and physiographic data. The WDM file is organized into data sets. Each data set contains a specific type of data, such as streamflow at a specific site or air temperature at a weather station. Each data set contains attributes that describe the data, such as station identification number, time step of data, latitude, and longitude. The WDM file can contain up to 32,000 data sets. Each data set may be described by either a few attributes or by hundreds of attributes. The WDM file may contain data for all data-collection stations for a basin, for a State, or for any other grouping selected by the user.

Disk space for the WDM file is allocated as needed in 40,960-byte increments (20 2,048-byte records). Data can be added, deleted, and modified without restructuring the data in the file. Space from deleted data sets within a WDM file is reused. Thus, the WDM file requires no special maintenance processing.

Time-series data can have time steps from 1 second to 1 year and can be grouped in periods of 1 hour to 1 century. Data are grouped for rapid access. Data may be tagged with a quality flag to indicate missing records, estimated data, historic floods, and so forth.

Time-series data are stored in a data set in one of two forms: compressed or uncompressed. The compressed form stores a value for every time step only when adjacent values are not the same or differ by more than a preset tolerance (see attribute TOLR). The uncompressed form stores a value for every time step. For adjacent values that are the same or less than the tolerance, the value and the number of time steps with that value are stored.

Before data are added to a WDM file, a unique data-set number (DSN) and values for required attributes that describe how the data are stored must be assigned. Once data have been added, the required attributes can no longer be modified. An extensive list of optional attributes is available for further characterization of data contained in a WDM data set. The current list of required and optional data-set attributes is provided in Appendix D. Optional attributes can be added to a data set at any time, but it is good practice to add them when the data set is prepared. 


\section{BUILD THE WDM FILE (Step 2)}

SPECIAL TIME-SERIES ATTRIBUTES COMPFG TOLR VBTIME TCODE TSSTEP TGROUP TSBYR TSBMO
FILE BUILD

DATA BUILD
Time-series data may be stored in several different patterns that affect the efficiency of data storage and retrieval. To minimize storage requirements, the attribute COMPFG should be set to 1 for data compression. If only strings of identical values are to be compressed, the attribute TOLR is not needed; otherwise, a small, nonzero value for TOLR should be stored.

If the data have a constant time step, the attribute VBTIME should be set to 1 and TSSTEP and TCODE set to the time step and units, respectively. This can reduce data retrieval time by a factor of 3 or more. However, if the time step changes one or more times for a data set, VBTIME must be set to 2 .

The attribute TGROUP can be used to minimize retrieval times. TGROUP establishes how the data are grouped in a data set. The software can readily locate the beginning of a group but must read sequentially within a group for the values to be retrieved. The maximum number of groups is set when the data set is built. Table 1 has been constructed as a guide to select a value for TGROUP.

Table 1. Recommended values for TGROUP for time series of a given time step and record length

\begin{tabular}{lll}
\hline \multicolumn{1}{c}{ Time step } & Length of record & $\begin{array}{c}\text { Recommended } \\
\text { TGROUP }\end{array}$ \\
\hline daily & $<=100$ years & 6 (years) \\
5 minute - daily & $<=8$ years & 5 (months) \\
5 minute - daily & $>8$ years & 6 (years) \\
monthly & $<=100$ years & 6 (years) \\
monthly & $>100$ years & 7 (centuries) \\
annual & $<=10,000$ years & 7 (centuries) \\
1 second-1 minute & $<=100$ days & 4 (days) \\
\hline
\end{tabular}

For data with daily or shorter time steps and a period of record in excess of 100 years but less than 200 years, it would be better to set the number of groups to 200 than to use centuries for groups. Attributes for the beginning year and month of the data, TSBYR and TSBMO, default to 1900 and 1, respectively. These attributes may need to be defined if the record will contain data before 1900 or months or days is used for the TGROUP attribute.

The BUILD option in ANNIE in the menu below the FILE option generates the WDM file. Once generated, the WDM file will automatically be enlarged as its original space allocation is filled. Hence, data storage requirements need not be specified. Although there are no restrictions on WDM file names, for HSPEXP the suffix .wdm must be used and the prefix must be the watershed name.

The BUILD option in ANNIE in the menu below the DATA option generates a new data set and specifies initial attributes. If the new data set has many of the same attribute values as an existing data set, the attributes of an existing data set can be used to make the new data set. If the new data set is not similar to an existing data set, values must be entered for the required attributes. Included in this category are the following attributes: TSTYPE, ISTAID or STAID, STANAM, TCODE, TSBYR, TSSTEP, TGROUP, TSFORM, VBTIME, and 
COMPFG. After these attributes have been entered, optional attributes may be entered (see ANNIE users manual for a complete list of required and optional attributes). Once data have been added to the data set, the required attributes that define data storage cannot be modified. Optional attributes can be modified at any time.

TSTYPE must be the same as the member name used on the UCI file. The TCODE and TSSTEP should match the time step of the simulation run for all data sets-except input EVAP, PETX, SAET, UZSX, and LZSX, which should be daily (TSSTEP=1, TCODE=4). TSBYR should be the same as the starting year for simulation. VBTIME should be 1 for a constant time step for greatest retrieval speeds. Except for precipitation, COMPFG can be 2 specifying no compression. TSFORM should be 1 for mean or total for all simulated data sets.

Table 2 includes all 11 required data sets for the test files and is provided to assist in organizing and building data sets in the WDM file. DSN and TSTYPE are the same as the test data files. The DSN and TSTYPE may be changed so long as corresponding changes are made in the UCI and EXS files. Values of TCODE, TSSTEP, and TGROUP for DSN 420, 421, 422, and 423 should be the same as DSN 106. Values of TCODE, TSSTEP, and TGROUP for DSN 425, 426, 427, and 428 should be the values shown in table 2 .

Table 2. Required data sets for HSPEXP applications

\begin{tabular}{lllllllll}
\hline \multicolumn{1}{c}{ Description } & DSN & TSTYPE & TCODE & TSSTEP TGROUP & TSBYR & TSFORM VBTIME \\
\hline $\begin{array}{c}\text { Observed rainfall } \\
\text { (inches) }\end{array}$ & 106 & HPCP & 3 & 1 & 5 & 1988 & 2 & 1 \\
$\begin{array}{c}\text { Pan evaporation } \\
\text { (inches) }\end{array}$ & 111 & EVAP & 4 & 1 & 6 & 1988 & 2 & 1 \\
$\begin{array}{c}\text { Observed stream- } \\
\text { flow (cfs) }\end{array}$ & 281 & FLOW & 3 & 1 & 5 & 1988 & 1 & 1 \\
$\begin{array}{c}\text { Simulated total } \\
\text { runoff (inches) }\end{array}$ & 420 & SIMQ & 3 & 1 & 5 & 1988 & 2 & 1 \\
$\begin{array}{c}\text { Simulated surface } \\
\text { runoff (inches) }\end{array}$ & 421 & SURO & 3 & 1 & 5 & 1988 & 2 & 1 \\
$\begin{array}{c}\text { Simulated interflow } \\
\text { (inches) }\end{array}$ & 422 & IFWO & 3 & 1 & 5 & 1988 & 2 & 1 \\
$\begin{array}{c}\text { Simulated base } \\
\text { flow (inches) }\end{array}$ & 423 & AGWO & 3 & 1 & 5 & 1988 & 2 & 1 \\
$\begin{array}{c}\text { Potential evapo- } \\
\text { transpiration } \\
\text { (inches) }\end{array}$ & 425 & PETX & 4 & 1 & 6 & 1988 & 2 & 1 \\
$\begin{array}{c}\text { Actual evapotran- } \\
\text { spiration (inches) }\end{array}$ & 426 & SAET & 4 & 1 & 6 & 1988 & 2 & 1 \\
$\begin{array}{c}\text { Upper zone storage } \\
\text { (inches) }\end{array}$ & 427 & UZSX & 4 & 1 & 6 & 1988 & 2 & 1 \\
$\begin{array}{l}\text { Lower zone storage } \\
\text { (inches) }\end{array}$ & 428 & LZSX & 4 & 1 & 6 & 1988 & 2 & 1 \\
\hline & & & & & & & & 1 \\
\hline
\end{tabular}

After creating the WDM file, the VIEW ATTRIBUTE option can be used to check and print the final attributes in a format similar to table 2 . 


\section{CREATE THE BASIN-SPECIFICATIONS FILE (Step 3)}

CREATE
The CREATE option under the BASIN option in HSPEXP is used to develop the EXS file. There are four options - GENERAL, STORM DATES, LOCATION, and ANCILLARY. The options GENERAL, STORM DATES, and LOCATION must be processed; the option ANCILLARY is optional and if not selected, defaults will be used. Items under the GENERAL option must be added. Storm dates must have been previously determined for entry under the STORM DATES option. To aid in storm date selection, ANNIE can be used to list or plot the precipitation and observed streamflow data sets. The ANNIE LIST option can list all precipitation or just the precipitation values above a threshold. The GRAPHICS option in ANNIE can be used to plot the observed streamflow and precipitation to visually select the storm periods. Up to 36 storm periods can be entered.

The LOCATION option in HSPEXP identifies the data-set numbers selected in the previous two steps creating the UCI and WDM files. The LOCATION form provides a field to enter a basin name to be used on tabular and graphical output and a field for the drainage area in acres. The ANCILLARY is used to provide additional information about the drainage basin. This information is used in the expert system when providing advice. Before leaving the BASIN option, the new EXS file can be saved by using the PUT command.

Below are the menus and forms that are provided in HSPEXP showing the values that were entered for the test data. Following the menus and forms is the resultant hunting.exs file that was produced (fig. 7). Although this file can be edited, it is better to modify the values using the expert system. A description of the format for the EXS file is presented after the EXS file as table 3. 


\section{CREATE THE BASIN-SPECIFICATIONS FILE (Step 3)}

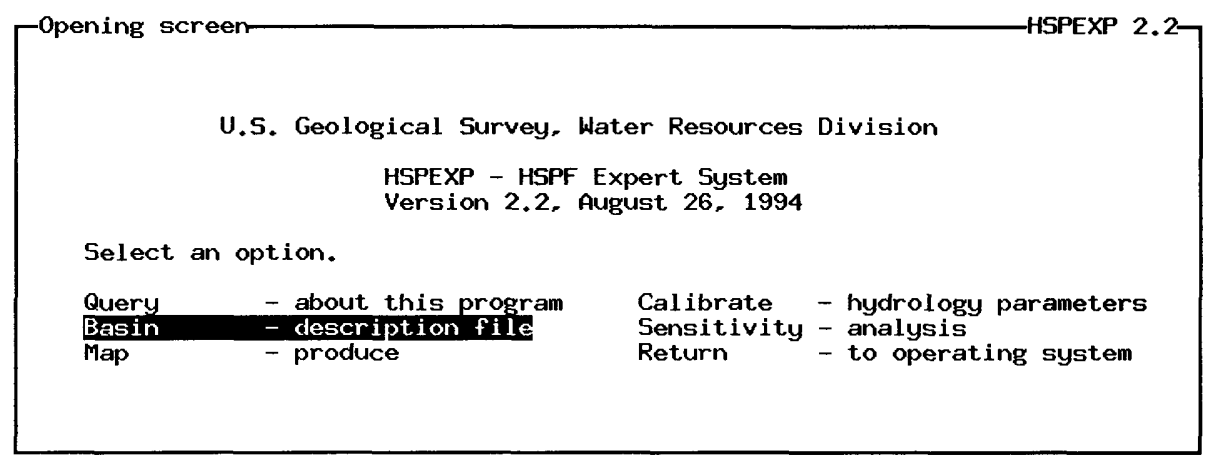

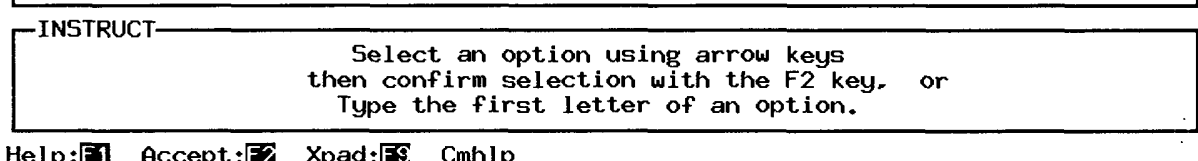

Help:F1 Accept:F2 Xpad:FG Cmhlp

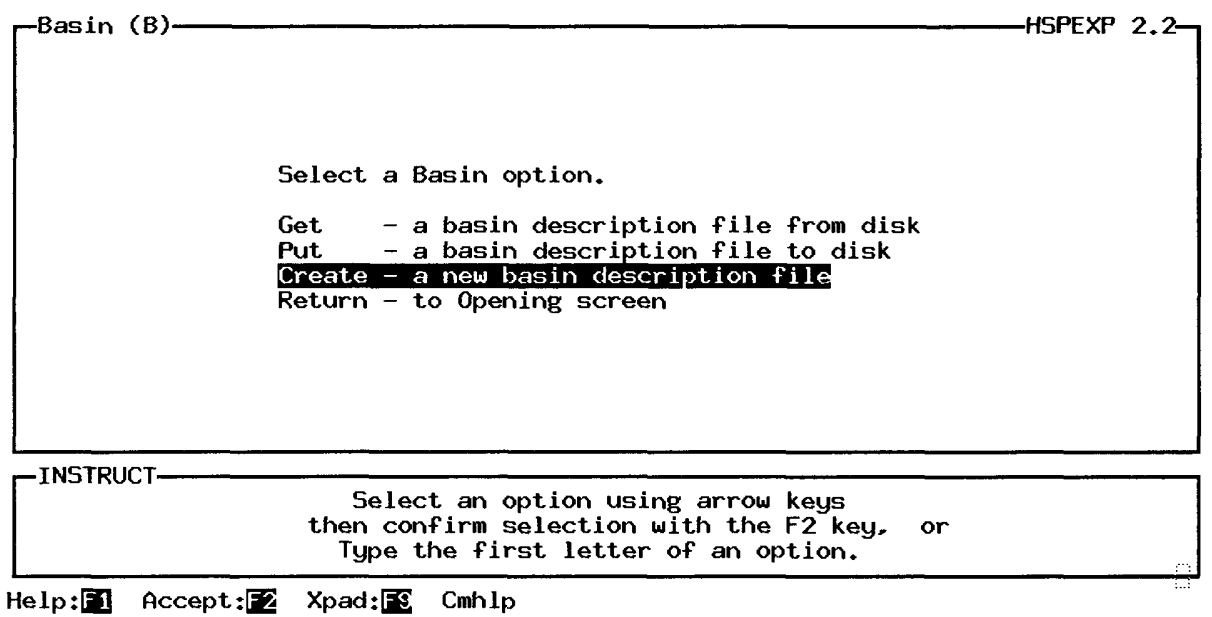

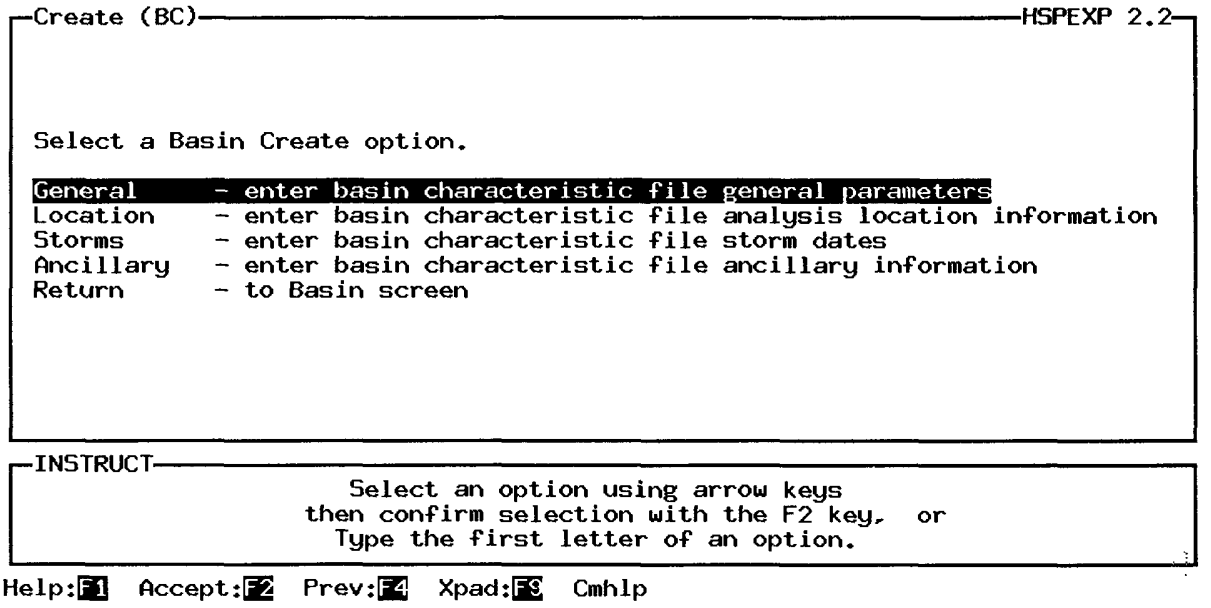




\section{CREATE THE BASIN-SPECIFICATIONS FILE (Step 3)}

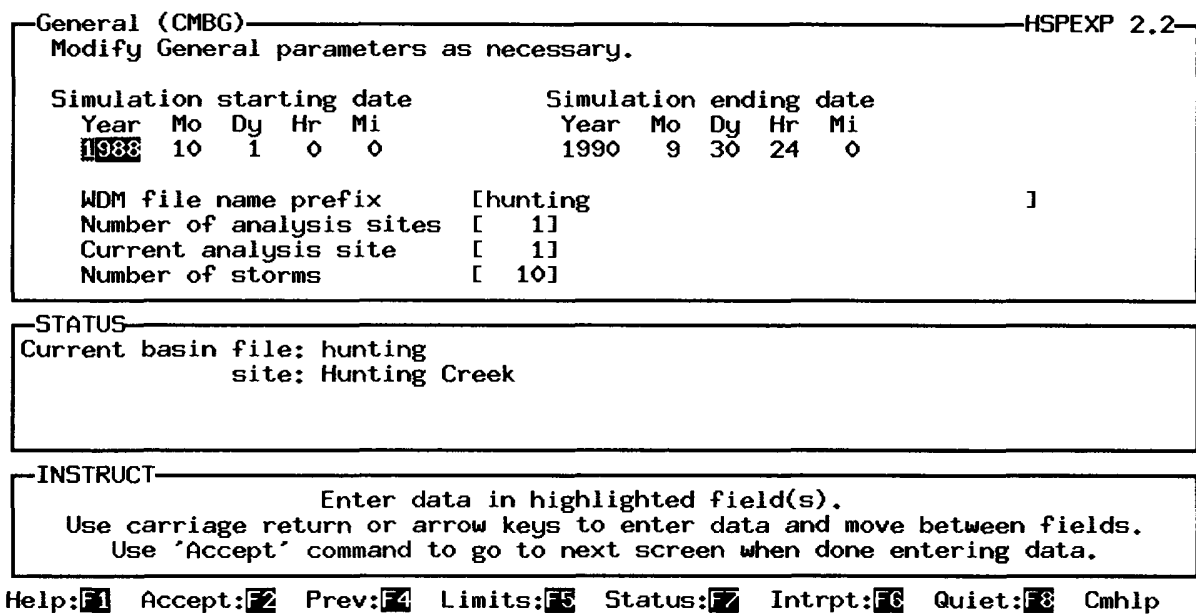

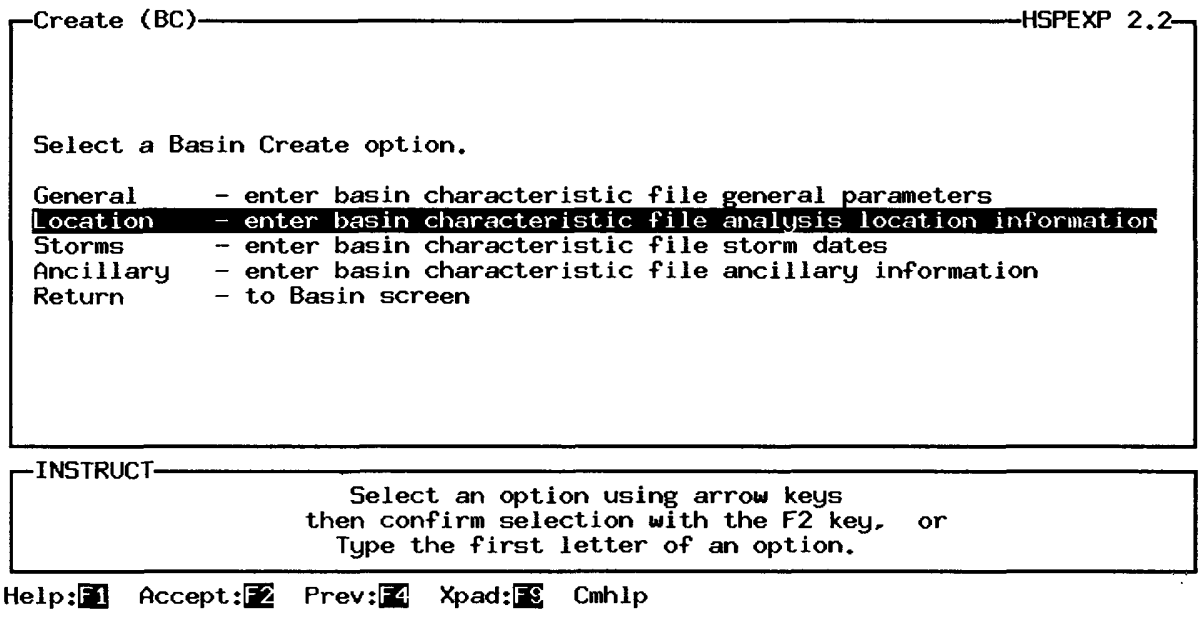

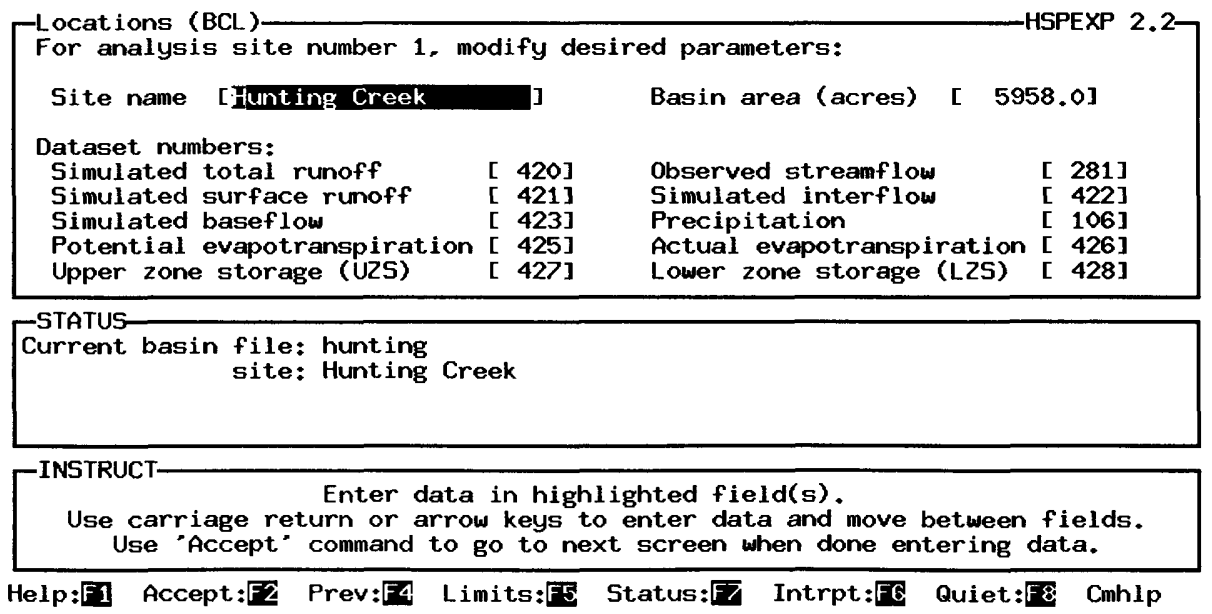




\section{CREATE THE BASIN-SPECIFICATIONS FILE (Step 3)}

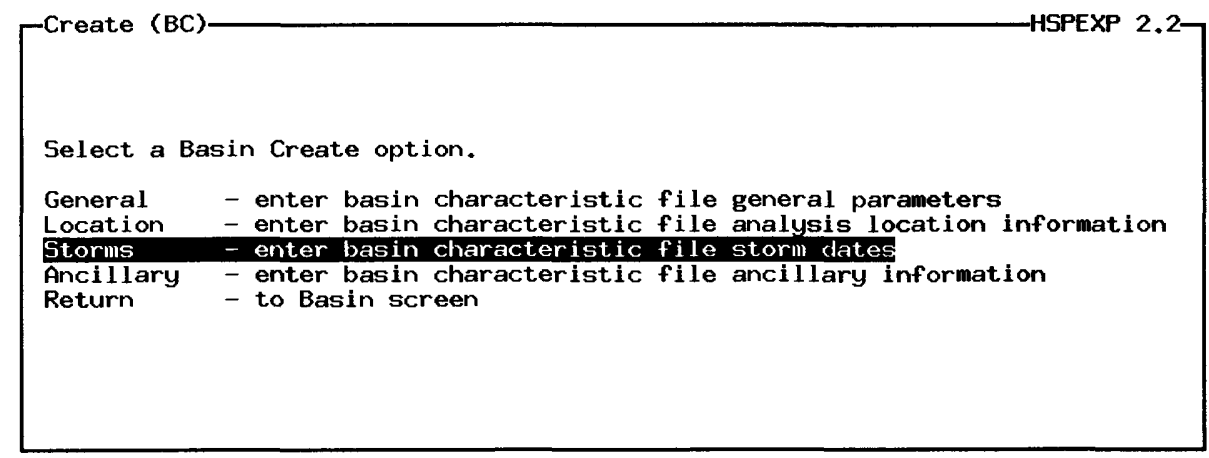

एINSTRUCT
$\begin{gathered}\text { Select an option using arrow keys } \\ \text { then confirm selection with the F2 key, or } \\ \text { Type the first letter of an option. }\end{gathered}$
Help:F1 Accept:F2 Prev:F4 Xpad:FG Cmhlp

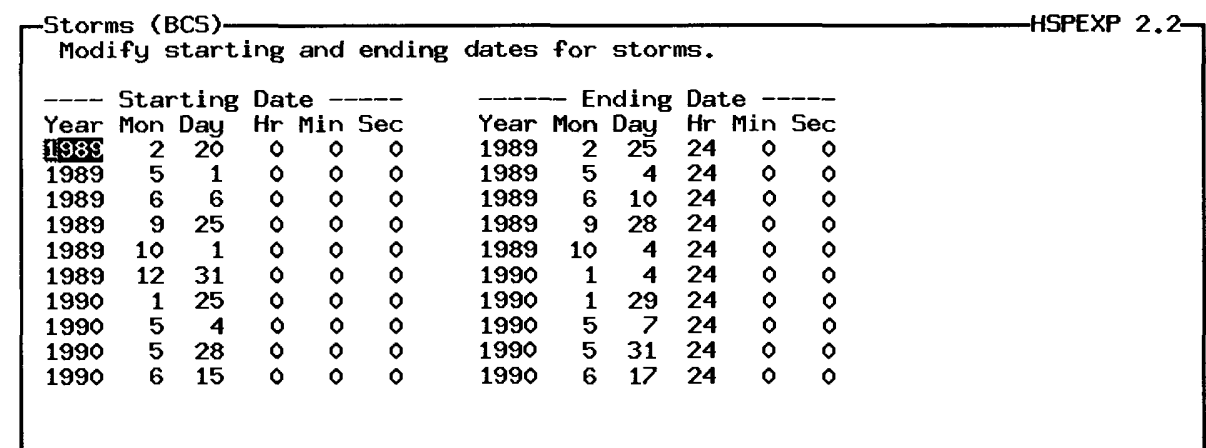

Enter data in highlighted field(s).
Use carriage return or arrow keys to enter data and move between fields.
Use "Accept" command to go to next screen when done entering data.

Help:F1 Accept:F2 Prev:F4 Limits:FS Status:FT Intrpt:FG Xpad:FG Cmhlp

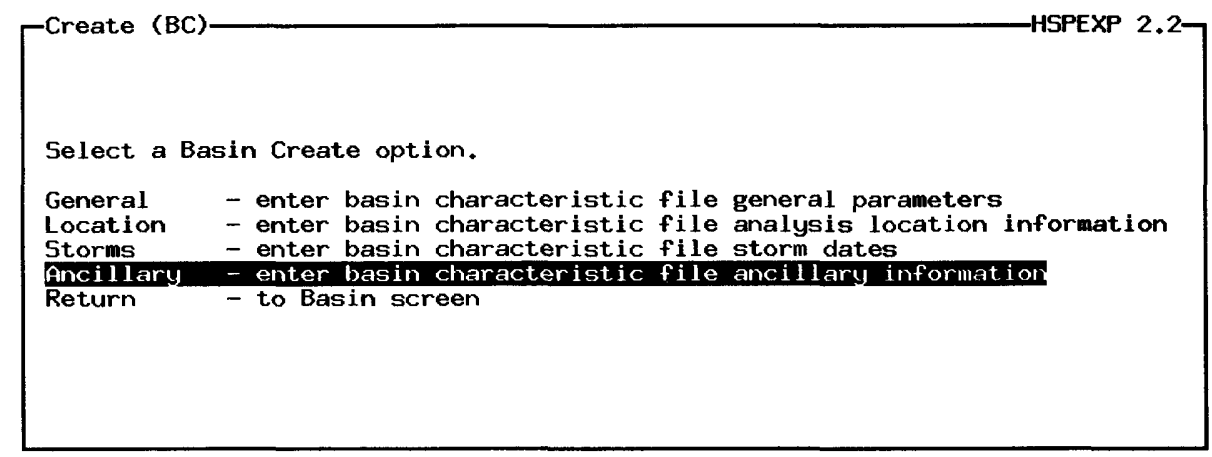

[INSTRUCT-
$\begin{gathered}\text { Select an option using arrow keys } \\ \text { then confirm selection with the F2 key. or } \\ \text { Type the first letter of an option. }\end{gathered}$
Help:F1 Accept:F2 Prev:F4 Xpad:FG Cmhlp




\section{CREATE THE BASIN-SPECIFICATIONS FILE (Step 3)}

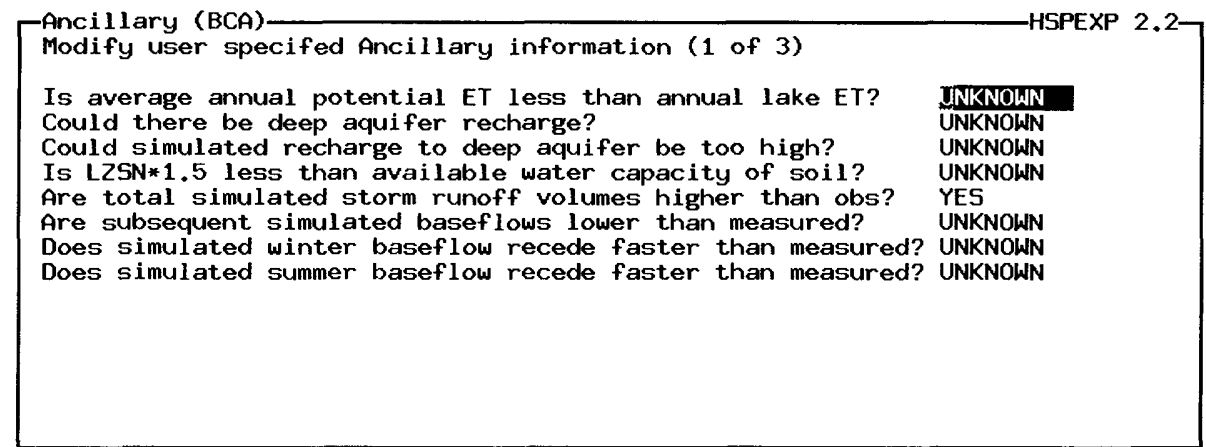

Enter data in highlighted field(s).
Use carriage return or arrow keys to enter data and move between fields.
Use "Accept' command to go to next screen when done entering data.

Help:F1 Accept:F2 Prev:F4 Limits:FS Status:FX Intrpt:FG Xpad:FG Cmhlp

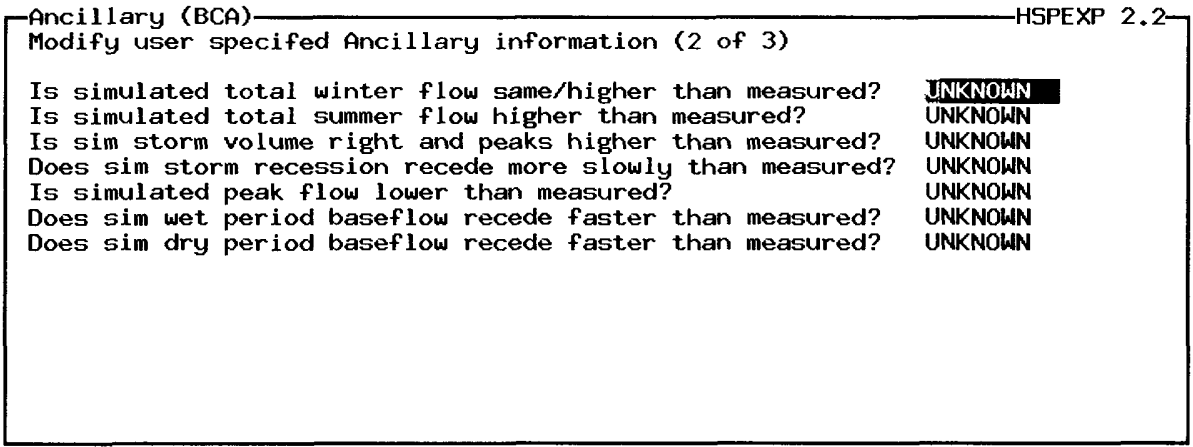

Enter data in highlighted field(s).
Use carriage return or arrow keys to enter data and move between fields.
Use 'Accept' command to go to next screen when done entering data.

Help:F1 Accept:F2 Prev:F4 Limits:FF Status:F7 Intrpt:FG Xpad:FG Cmhlp

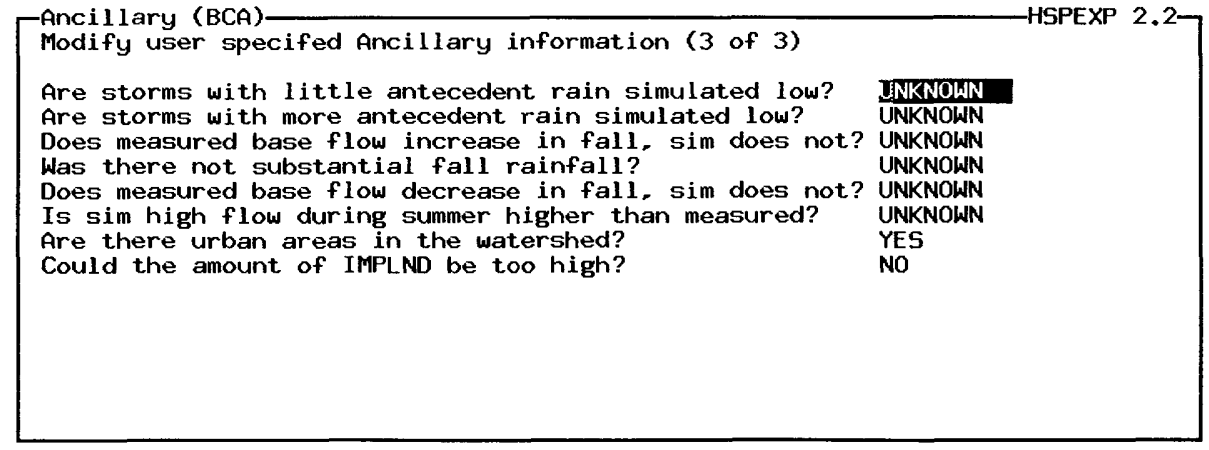

\footnotetext{
TINSTRUCT- Enter data in highlighted field(s).

Use carriage return or arrow keys to enter data and move between fields. Use "Accept' command to go to next screen when done entering data.

Help:F1 Accept:F2 Prev:F4 Limits:FG Status:FT Intrpt:FG Xpad:FG Cmhlp
} 


\section{CREATE THE BASIN-SPECIFICATIONS FILE (Step 3)}

Figure 7. Listing of basin-specifications file for test data, hunting.exs.

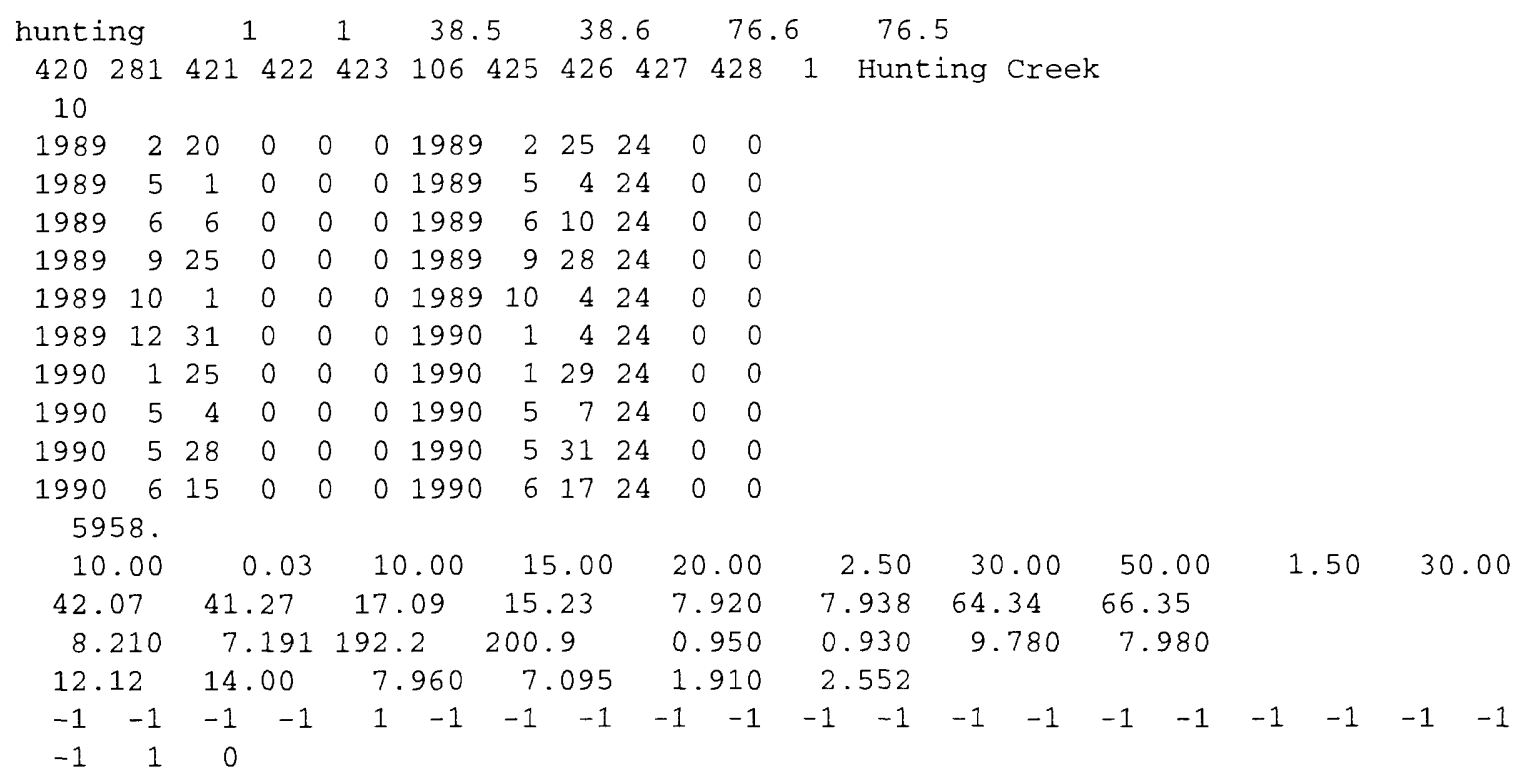




\section{CREATE THE BASIN-SPECIFICATIONS FILE (Step 3)}

Table 3. Basin-specifications file (.exs) content and format

\begin{tabular}{|c|c|c|}
\hline Number of records & Format & Description \\
\hline 1 & A8,2I5,4F8.1 & $\begin{array}{l}\text { Name of prefix for WDM file, number of sites, current site number, latitude and longitude } \\
\text { limits of basin }\end{array}$ \\
\hline \# sites & $\begin{array}{l}1014,1 X, 12 \\
2 X, 20 \mathrm{Al}\end{array}$ & $\begin{array}{l}\text { Data-set number for } \\
\text { simulated total runoff (inches) } \\
\text { observed streamflow (cubic feet per second) } \\
\text { simulated surface runoff (inches) } \\
\text { simulated interflow (inches) } \\
\text { simulated base flow (inches) } \\
\text { precipitation (inches) } \\
\text { potential evapotranspiration (inches) } \\
\text { actual evapotranspiration (inches) } \\
\text { upper zone storage (inches) } \\
\text { lower zone storage (inches) } \\
\text { Flag indicating whether statistics have been calculated for this site } \\
\text { Site name }\end{array}$ \\
\hline 1 & I4 & Number of storm periods (storm periods used to compute errors and statistics) \\
\hline \# storms & $\begin{array}{l}15,5 \mathrm{I} 3 \\
\mathrm{I} 5,5 \mathrm{I} 3\end{array}$ & Start and end date/time (yr,mo,dy,hr,min,sec) \\
\hline 1 & 10F8.0 & Drainage area (acres) for each site \\
\hline (the following three & records are re & $\begin{array}{l}\text { Values for error terms and criteria } \\
\text { acceptable error in total volume }(\%) \\
\text { acceptable error in low-flow recession (ratio } \mathrm{q}(\mathrm{t}-\mathrm{l}) / \mathrm{q}(\mathrm{t})) \\
\text { acceptable error in } 50 \text { percent lowest flows }(\%) \\
\text { acceptable error in } 10 \text { percent highest flows }(\%) \\
\text { acceptable error in storm volumes }(\%) \\
\text { ratio of interflow to surface runoff (in/in) } \\
\text { acceptable error in seasonal volume }(\%) \\
\text { acceptable error in summer storm volumes }(\%) \\
\text { multiplier on third and fourth error terms } \\
\text { percent of flows to use in low-flow recession error } \\
\text { ated for each site) }\end{array}$ \\
\hline 1 & $8 \mathrm{~F} 8.4$ & $\begin{array}{l}\text { Statistics computed in HSPEXP } \\
\text { SIMTRO - simulated total runoff (inches) } \\
\text { OBSTRO - observed total runoff (inches) } \\
\text { S010FD - simulated total of highest } 10 \text { percent daily mean of flows (inches) } \\
\text { O010FD - observed total of highest } 10 \text { percent daily mean of flows (inches) } \\
\text { S50100 - simulated totals of lowest } 50 \text { percent daily mean of flows (inches) } \\
\text { O50100 - observed total of lowest } 50 \text { percent daily mean of flows (inches) } \\
\text { TACTET - simulated total actual evapotranspiration (inches) } \\
\text { TPOTET - total potential evapotranspiration (inches) }\end{array}$ \\
\hline 1 & $8 \mathrm{~F} 8.4$ & $\begin{array}{l}\text { Statistics computed in HSPEXP } \\
\text { SISTVO - simulated total storm volume (inches) } \\
\text { OBSTVO - observed total storm volume (inches) } \\
\text { SPKSTR - simulated storm peaks volume (inches) } \\
\text { OPKSTR - observed storm peaks volume (inches) } \\
\text { QTRSIM - mean of simulated low-flow recession (dimensionless) } \\
\text { QTRMEA - mean of observed low-flow recession (dimensionless) } \\
\text { INFSUM - total simulated storm interflow (inches) } \\
\text { SROSUM - total simulated storm surface runoff (inches) }\end{array}$ \\
\hline 1 & $6 \mathrm{~F} 8.4$ & $\begin{array}{l}\text { Statistics computed in HSPEXP } \\
\text { SMRSIM - simulated summer flow volume (inches) } \\
\text { SMROBS - observed summer flow volume (inches) } \\
\text { WNRSIM - simulated winter flow volume (inches) } \\
\text { WNROBS - observed winter flow volume (inches) } \\
\text { SRHSIM - simulated summer storm volume (inches) } \\
\text { SRHOBS - observed summer storm volume (inches) }\end{array}$ \\
\hline 2 & $20 I 4 / 3 I 4$ & Flags for ancillary data ( $1=$ yes, $0=$ no, $-1=$ unknown, $-2=$ undefined $)$ \\
\hline
\end{tabular}




\section{SIMULATE and COMPUTE STATISTICS (Step 4)}

\section{SIMULATE}

The SIMULATE option under the CALIBRATE option simulates runoff from the watershed with HSPF. The UCI and WDM files are used as input for the simulation. Following the simulation the statistics are automatically computed. Two screens are provided to show the process of the simulation and computation of statistics. Simulations are done for blocks of time, each operation is simulated for the first block, then each operation for the next block. On the screen, dashes represent the operations and time blocks that have been completed, the X's show what operation and time block is currently being simulated, and the dots show what is left to be simulated. In the computation screen, the HSPF operations are shown. Examples of these two screens are shown below.
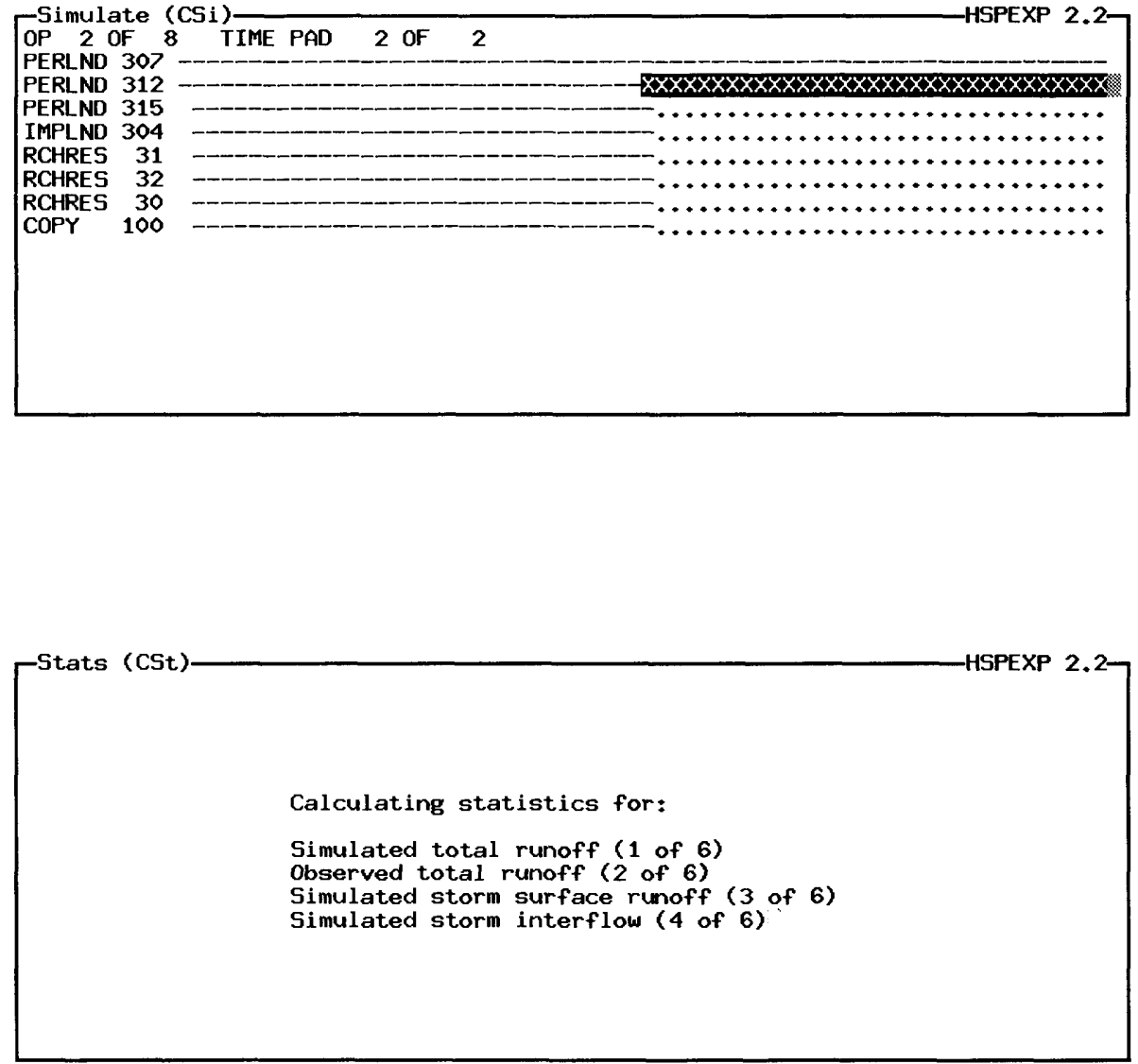


\section{VIEW GRAPHICS (Step 5)}

\section{WINDOW}

\section{EDIT \\ TIME \\ EDIT \\ SITE \\ EDIT \\ Y-AXIS}

\section{EDIT DEVICE}

\section{EDIT \\ PRECIPITATION}

\section{EDIT \\ COMPONENTS}

\section{EDIT APPEARANCE}

The first time the graphics option is chosen, the WINDOW option should be selected if you are using a UNIX workstation under X-Windows. This option lets you select the location of up to four graphs on the screen. The locations are specified by setting the top, bottom, right side, and left side for each graph as a fraction of the size of the monitor. You must leave space on the monitor for the window to use for the user interface. One graphics X-Window will always be active and is also specified on the form.

WARNING: When the graphics are displayed under X-Windows, you should not move, close, or resize the windows using X-Windows because the Graphical Kernel System implementation does not get the information on your changes. Also, if you reset the size and location of the graphic windows and there are currently graphic windows shown, the new sizes will not be used until the next use of HSPEXP.

Use the EDIT TIME option to change the time period and time step for the graphics. This is usually used to obtain more detailed results during a shorter period. The time step for storm hydrographs can also be changed on this screen.

When multiple sites of observed streamflow are used for calibration, the EDIT SITE option is used to change the site for graphics.

The EDIT Y-AXIS option can be used to select an arithmetic or logarithmic axis for the daily and storm hydrographs. For the arithmetic axis for daily hydrographs, the lower portion of the hydrograph can be plotted to better view the lowflow simulations. A value of 10 percent will enlarge the lowest 10 percent of the hydrograph. The default is 100 percent to show the full hydrographs. The logarithmic axis is useful to view low flows and compare recession rates.

The EDIT DEVICE option can be used to send the results to a printer (or postscript file), a metafile (Computer Graphics Metafile), or a pen plotter (or Hewlett Packard Graphics Language (HPGL) file).

Select the EDIT PRECIPITATION option to produce plots with precipitation on a separate axis above the monthly, daily, or storm hydrographs.

Select the EDIT COMPONENTS option to also display simulated base flow, and base flow plus interflow in addition to total simulated runoff. The base-flow and interflow components have not been routed through the channel reaches, but these plots usually do not provide a visualization problem unless a reservoir is simulated. When these components are added to the plots, the shading or color fill options are usually selected under the APPEARANCE option.

Select the EDIT APPEARANCE option to change line type, line color, fill color, or fill pattern for each time series. Fill colors are helpful for simulated flow and runoff components, but should not be used for observed flow, because that is plotted last and could cover the simulated values. Observed flow is usually plotted as a solid line. It is helpful for the precipitation to be plotted as a solid fill. Potential and actual evapotranspiration plots can also use fill colors because potential is usually larger and is plotted first. 


\section{VIEW GRAPHICS (Step 5)}

EDIT

MARKER

\section{DAILY}

PLOT

MONTHLY

PLOT

\section{BIAS}

PLOT

WEEKLY ET
PLOT

\section{FLOW- DURATION PLOT}

\section{STORM PLOT}

\section{BASE-FLOW RECESSION PLOT}

\section{CUMULATIVE ERROR PLOT}

EXAMPLES
For the bias plots, the type and color of the symbol can be selected.

The DAILY option plots hydrographs of simulated and observed flow (precipitation, base flow, and interflow are optional) on a daily time step.

The MONTHLY option plots hydrographs of simulated and observed flow (precipitation, base flow, and interflow are optional) on a monthly time step.

The BIAS option is used to view simulation errors. Three options plot the time series of error (simulated-observed) and (1) daily values for the upper zone storage (UZS), (2) daily values for the lower zone storage (LZS), and (3) observed daily flows. With these plots it can be determined if positive errors or negative errors result during wet or dry conditions or low flows or high flows. A fourth option plots the average monthly error for each month of the year for all years to determine if the error has a seasonal pattern.

The WEEKLY ET option plots the actual evapotranspiration (total from all storage components) and the potential evapotranspiration on a 7-day (weekly) time step. The 7-day time step is used because the impact of evapotranspiration on watershed response is cumulative over periods of several days. The plot helps assess periods where values of the potential evapotranspiration have most impact on the water balance.

The FLOW-DURATION plot is very useful to view the errors in simulation of high flows relative to simulation of low flows. It is also helpful when the stormby-storm simulations are poor because of poor rainfall representation. Although the storm-to-storm comparison may be poor, the model may represent the response of the watershed properly as shown by a flow-duration curve.

The STORM option lets you plot the simulated and observed flow (precipitation, base flow, and interflow are optional) for each storm period identified on the EXS file. A menu is provided with a letter for each storm period to select the storm for the plot. These plots are very useful for adjusting the FTABLE's for flow routing and fine tuning the parameters for interflow.

The BASE-FLOW RECESSION is a plot of the frequency of simulated and observed daily recession $\left(Q_{n} / Q_{n-1}\right)$ for each day. This plot is used to refine the error parameter (E10) that defines the percent of time streamflow is in a baseflow condition.

The CUMULATIVE ERROR plot provides information on trends in the simulation errors (simulated flow minus observed flows). Overall water-budget problems, seasonal problems, or problems in specific years can be identified on this plot.

The menus for graphics are shown below. Following those are samples of the plots that were produced (figs. 8-20). On the computer screen, color fill patterns were used. These were changed to dashed and dotted line types for the plots presented. Figure 21 lists the test PLT file and table 4 lists the description of the format for the PLT file. 


\section{VIEW GRAPHICS (Step 5)}
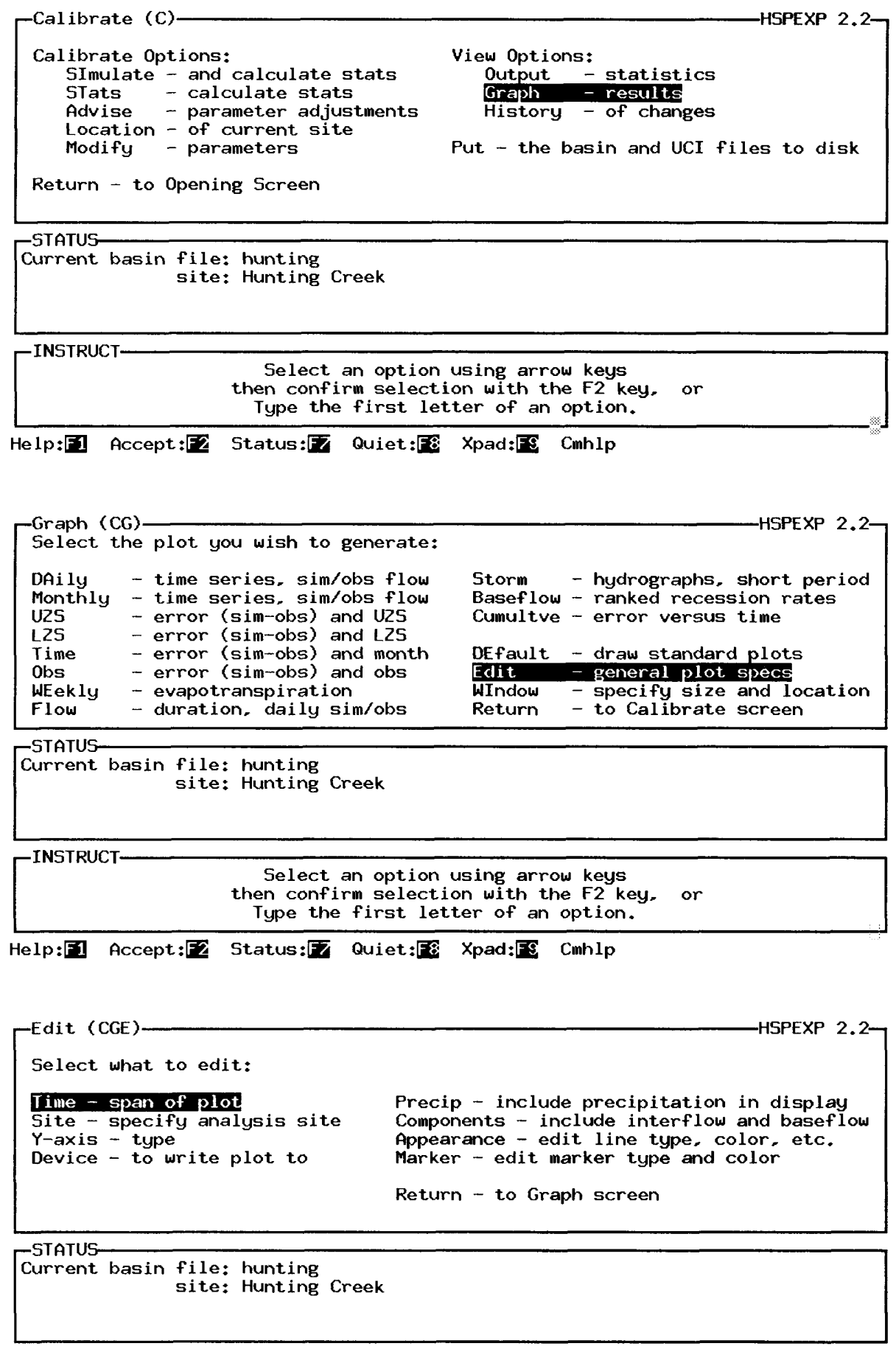

[INSTRUCT-
$\begin{gathered}\text { Select an option using arrow keys } \\ \text { then confirm selection with the F2 key. or } \\ \text { Type the first letter of an option. }\end{gathered}$
Help:F1 Accept:F2 Status:FT Quiet:Fg Xpad:FG Cmhlp




\section{VIEW GRAPHICS (Step 5)}

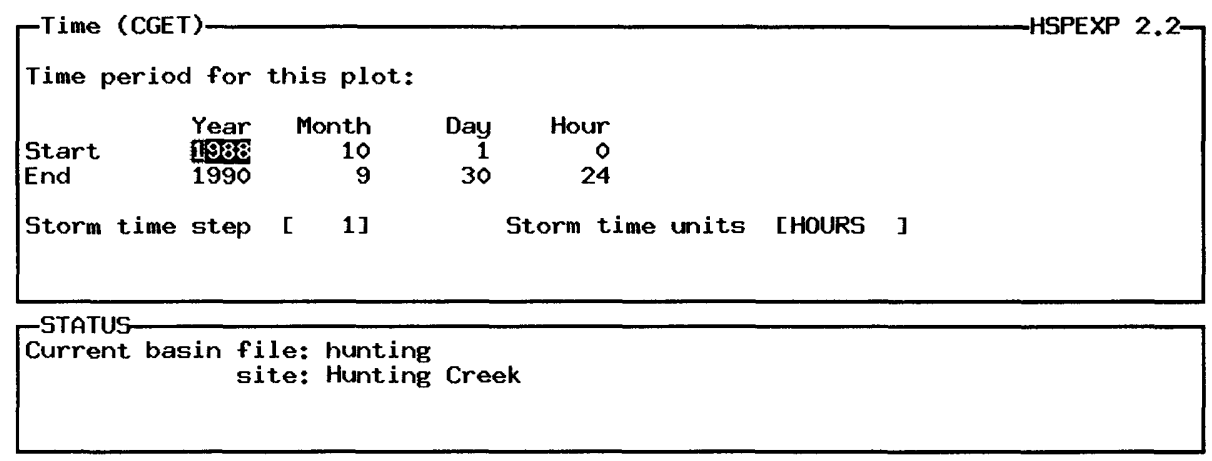

Enter data in highlighted field(s).
Use carriage return or arrow keys to enter data and move between fields.
Use "Accept" command to go to next screen when done entering data.

Help:F1 Accept:F2 Prev:F4 Limits:FF Status:F7 Quiet:F8 Xpad:FG Cmhlp

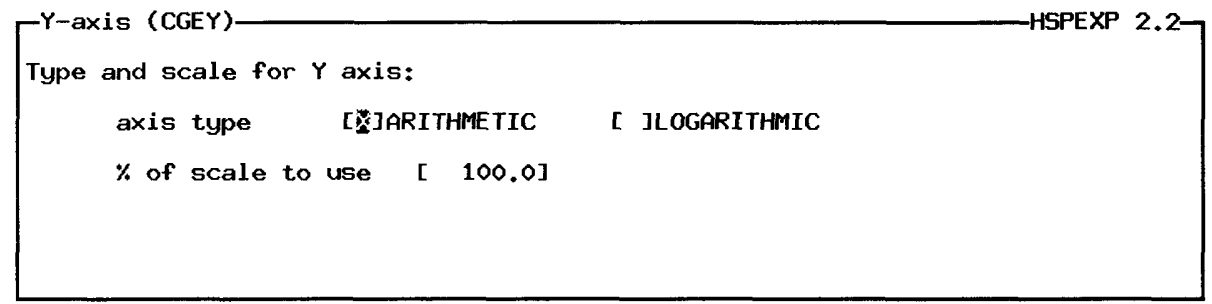

Current basin file: hunting
site: Hunting creek

INSTRUCT-
Option field: use space bar to toggle between oN ( $X$ ) and ofF ( ).
Use carriage return or arrow keys to move between fields.
Use 'Accept' command to go to next screen when done entering data.

Help:F1 Accept:F2 Limits:F5 Status:FC Quiet:F\& Xpad:FG Cmhlp Oops

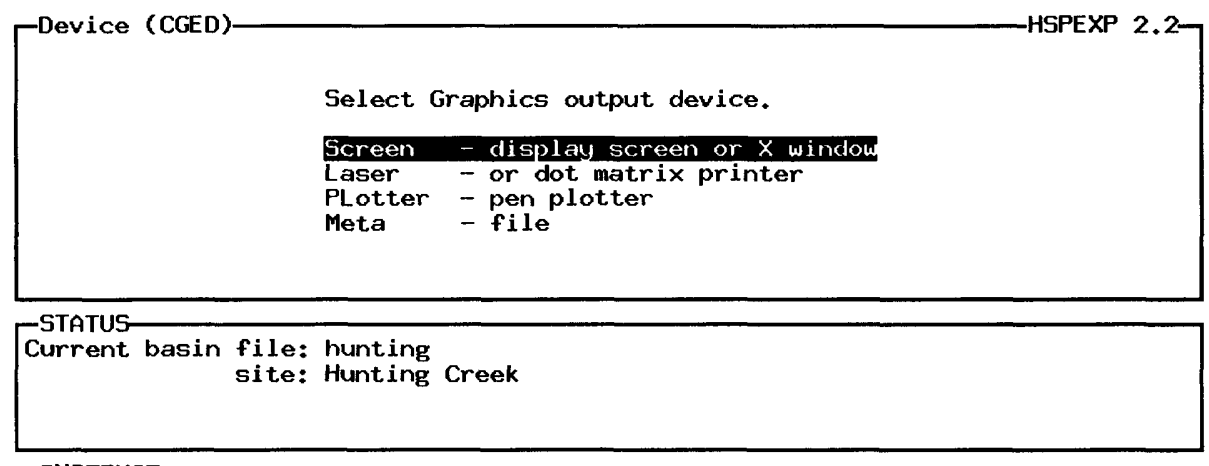

[INSTRUCT-
$\begin{gathered}\text { Select an option using arrow keys } \\ \text { then confirm selection with the F2 key. or } \\ \text { Type the first letter of an option. }\end{gathered}$
Help:F1 Accept:F2 Status:FT Quiet:FE Xpad:FG Cmhlp




\section{VIEW GRAPHICS (Step 5)}
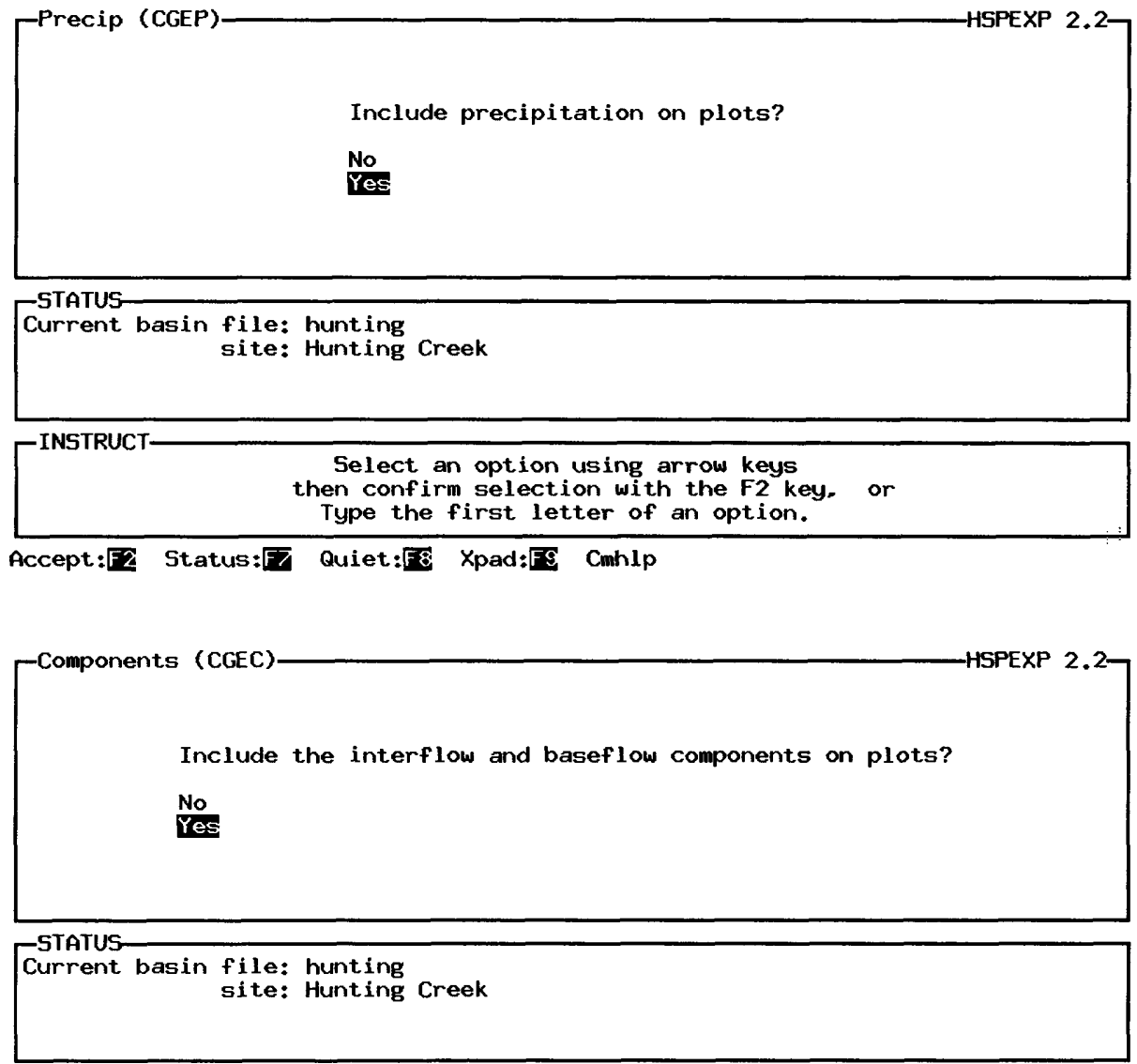

एINSTRUCT-
$\begin{gathered}\text { Select an option using arrow keys } \\ \text { then confirm selection with the F2 key, or } \\ \text { Type the first letter of an option. }\end{gathered}$
Accept:F2 Status:FT Quiet:F8 Xpad:FG Cmhlp

\begin{tabular}{|c|c|c|c|}
\hline $\begin{array}{l}\text { Modify appearance } \\
\text { specifications: }\end{array}$ & $\begin{array}{r}\text { line } \\
\text { type }\end{array}$ & color & $\begin{array}{c}\text { fill } \\
\text { pattern }\end{array}$ \\
\hline $\begin{array}{l}\text { SIMULATED } \\
\text { OBSERVED } \\
\text { PRECIPITATION } \\
\text { POTENTIAL ET } \\
\text { SIMULATED ET } \\
\text { SIM INTERFLOW + BASEFLOW } \\
\text { SIM BASEFLOW }\end{array}$ & $\begin{array}{l}\text { DOT } \\
\text { SOLID } \\
\text { SOL ID } \\
\text { SOL ID } \\
\text { SOL ID } \\
\text { DOT } \\
\text { DOT }\end{array}$ & $\begin{array}{l}\text { WHITE } \\
\text { WHITE } \\
\text { WHITE } \\
\text { WHITE } \\
\text { WHITE } \\
\text { WHITE } \\
\text { WHITE }\end{array}$ & $\begin{array}{l}\text { DIAGONAL } \\
\text { NONE } \\
\text { SOL ID } \\
\text { RDIAGON } \\
\text { DIAGONAL } \\
\text { RDIAGON } \\
\text { VERTICAL }\end{array}$ \\
\hline
\end{tabular}

Current basin file: hunting
site: Hunting creek

$\begin{gathered}\text { INSTRUCT- } \\ \text { Use carriage return or arrow keys to enter data and move between fields. } \\ \text { Use Accept command to go to next screen when done entering data. }\end{gathered}$
Help:F1 Accept:F2 Prev:F4 Limits:FF Status:FT Quiet:FF Xpad:FG Cmhlp




\section{VIEW GRAPHICS (Step 5)}

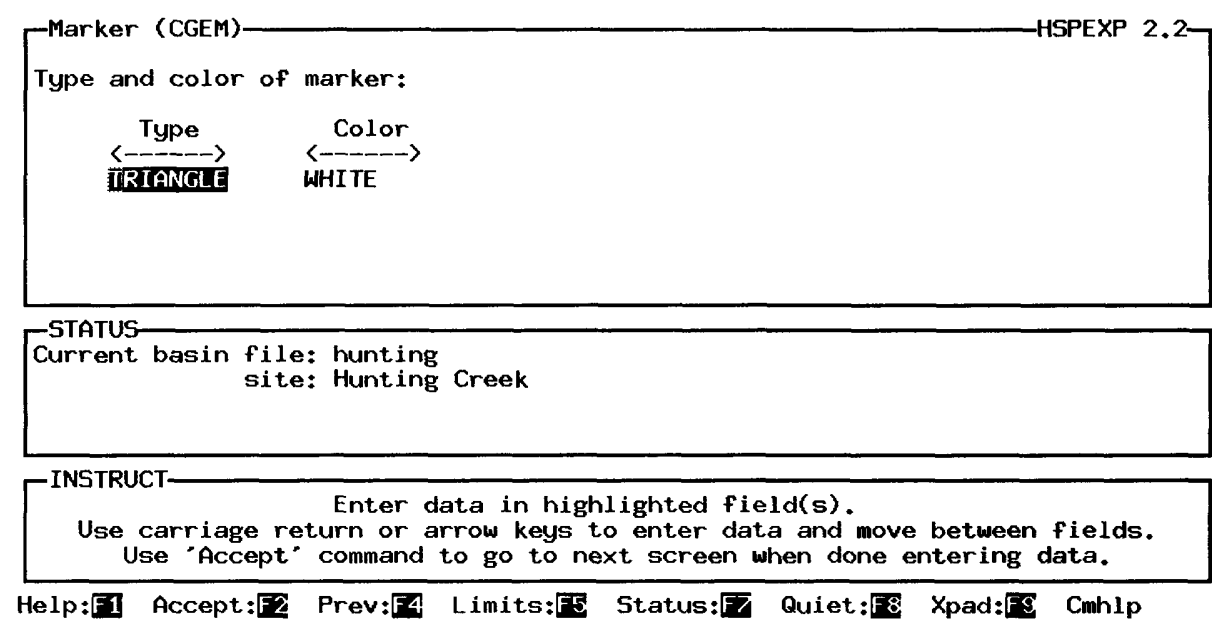

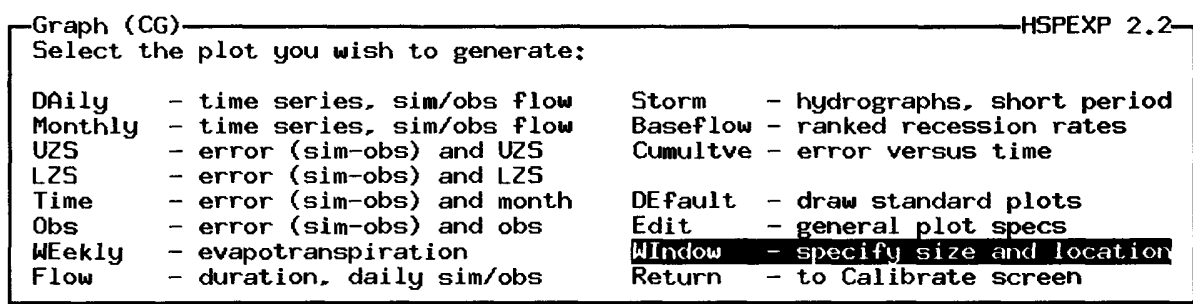

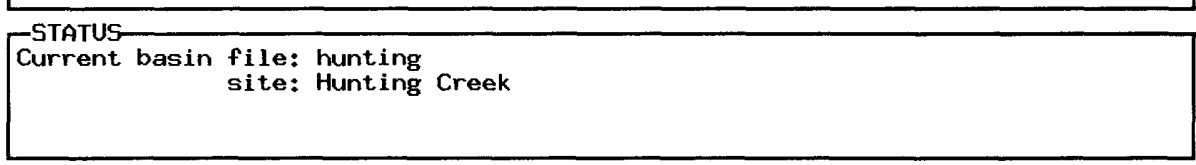

INSTRUCT- $\begin{gathered}\text { Select an option using arrow keys } \\ \text { then confirm selection with the F2 key. or } \\ \text { Type the first letter of an option. }\end{gathered}$
Help:F1 Accept:F2 Prev:F4 Status:F7 Quiet:F8 Xpad:FS Cmhlp

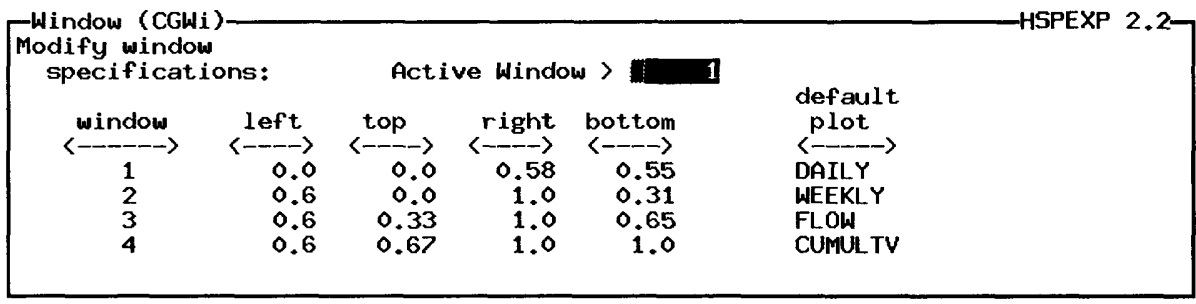

STATUS basin file: hunting
site: Hunting creek

\footnotetext{
Enter data in highlighted field(s).
Use carriage return or arrow keys to enter data and move between fields.
Use Accept command to go to next screen when done entering data.
} 


\section{VIEW GRAPHICS (Step 5)}
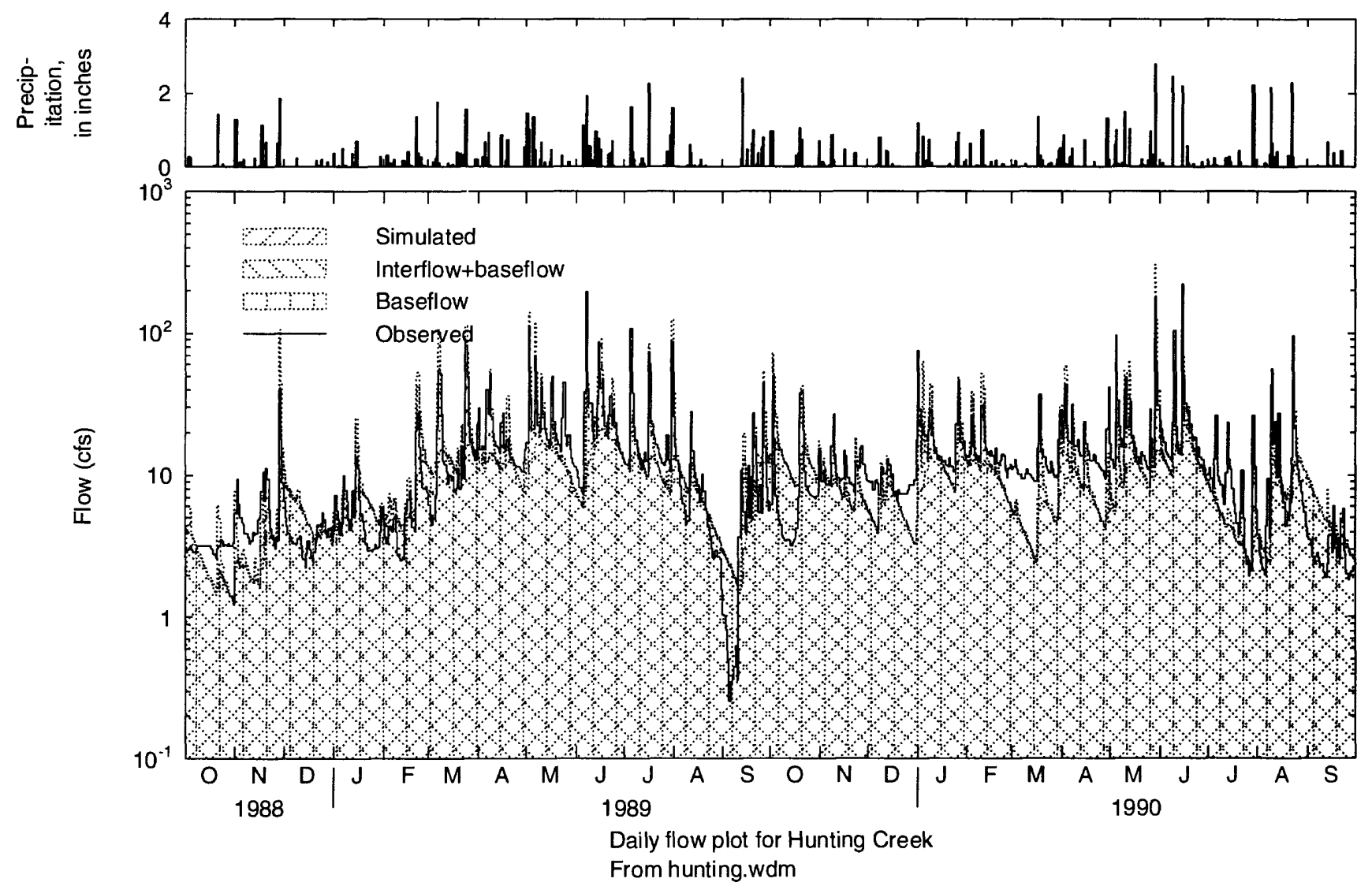

Figure 8. Time-series plot of daily precipitation and logarithms of daily observed and simulated flow with flow components. 


\section{VIEW GRAPHICS (Step 5)}
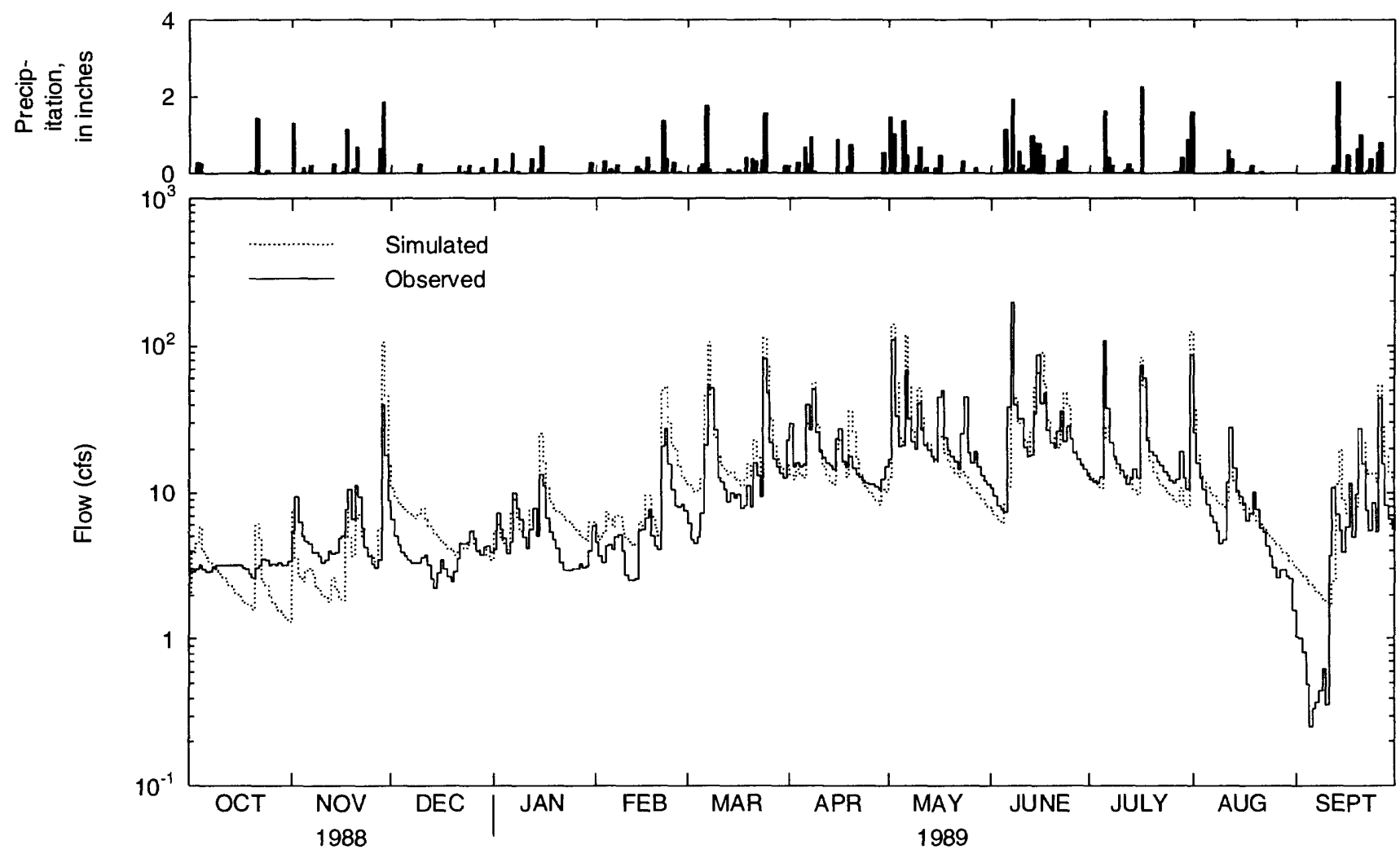

Daily flow plot for Hunting Creek

From hunting.wdm

Figure 9. Time-series plot of daily precipitation and logarithms of daily observed and simulated flow. 


\section{VIEW GRAPHICS (Step 5)}
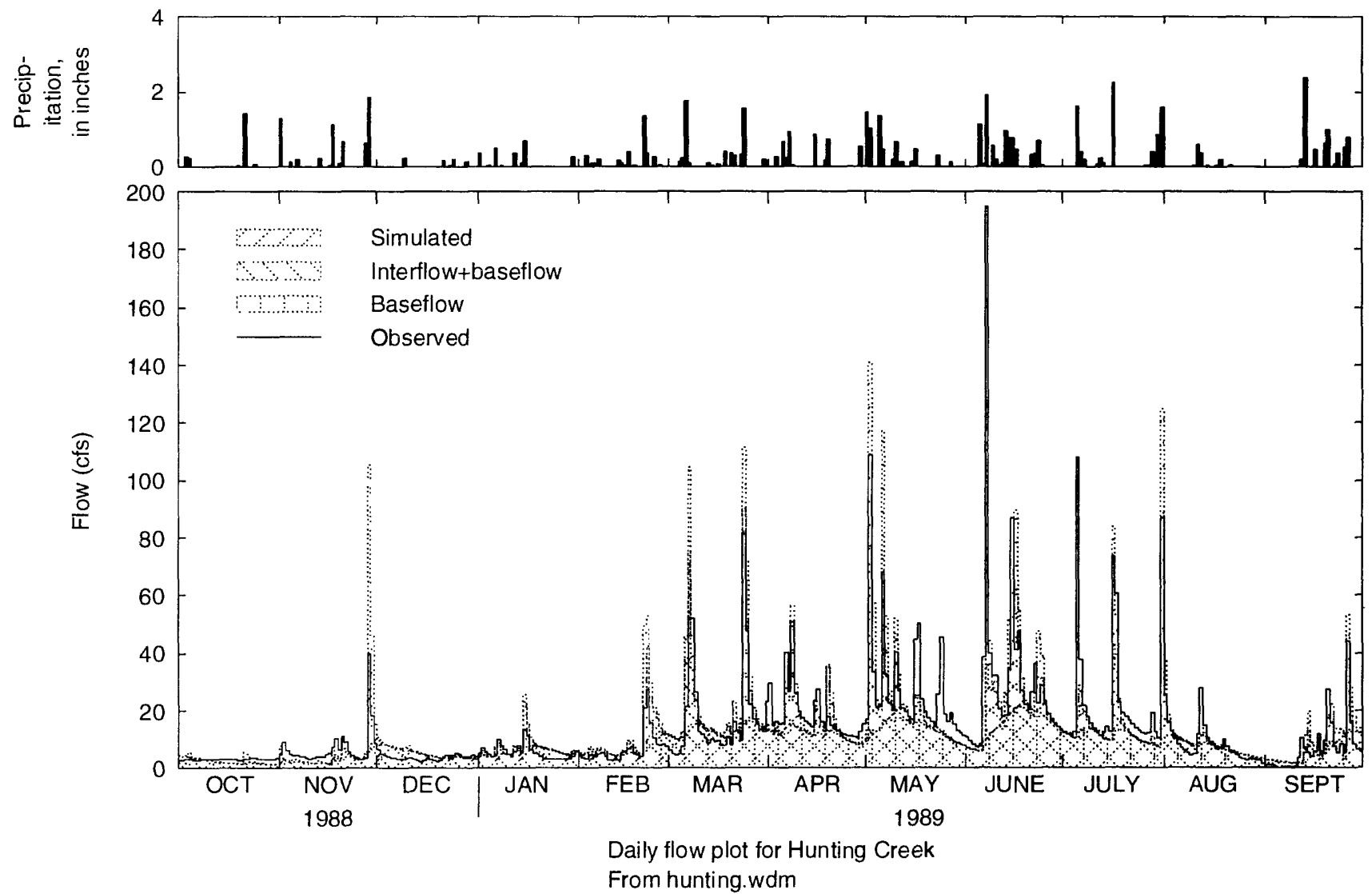

Figure 10. Time-series plot of daily precipitation and daily observed and simulated flow. 


\section{VIEW GRAPHICS (Step 5)}
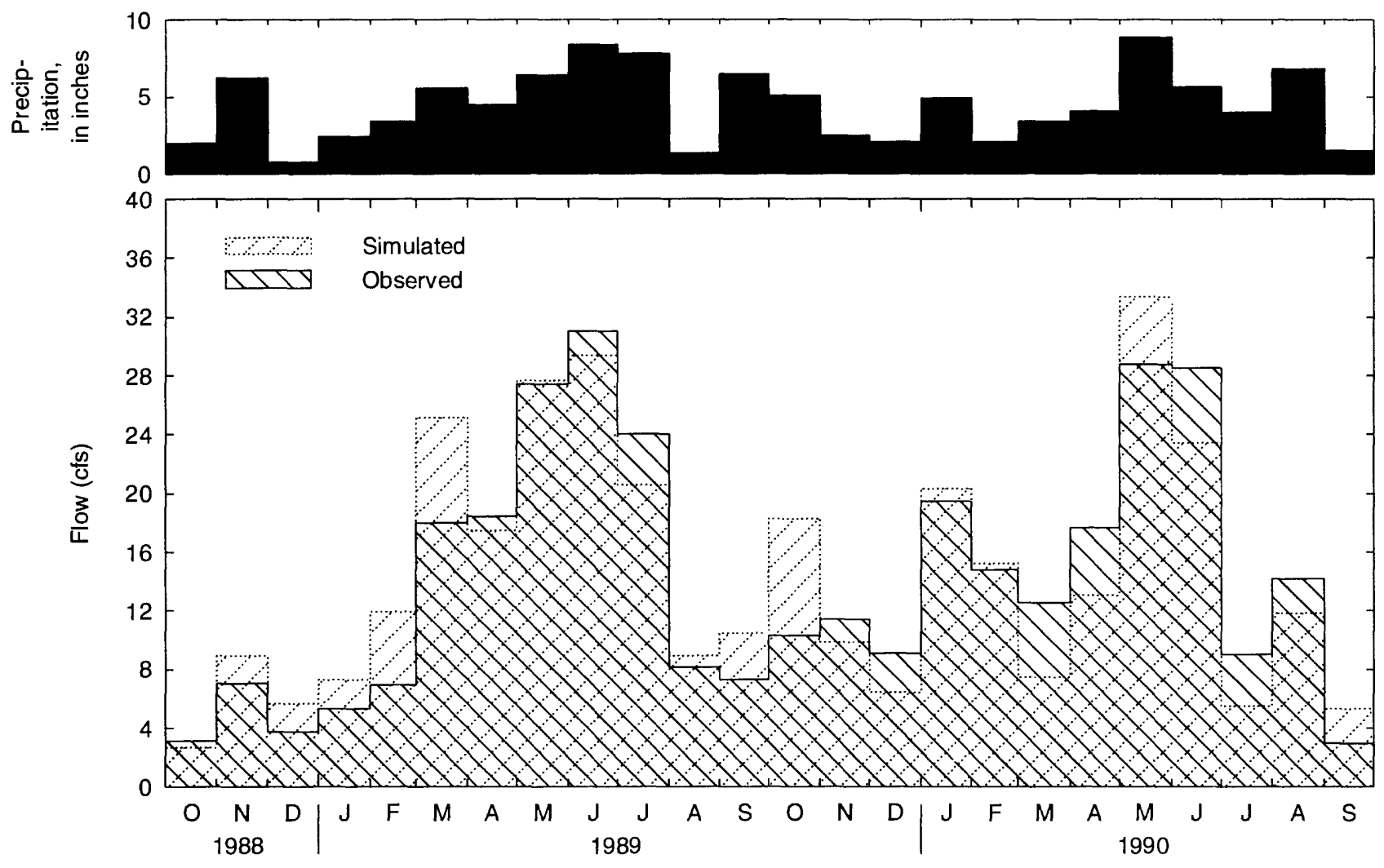

Monthly flow plot for Hunting Creek From hunting.wdm

Figure 11. Time-series plot of monthly precipitation and monthly observed and simulated flow. 


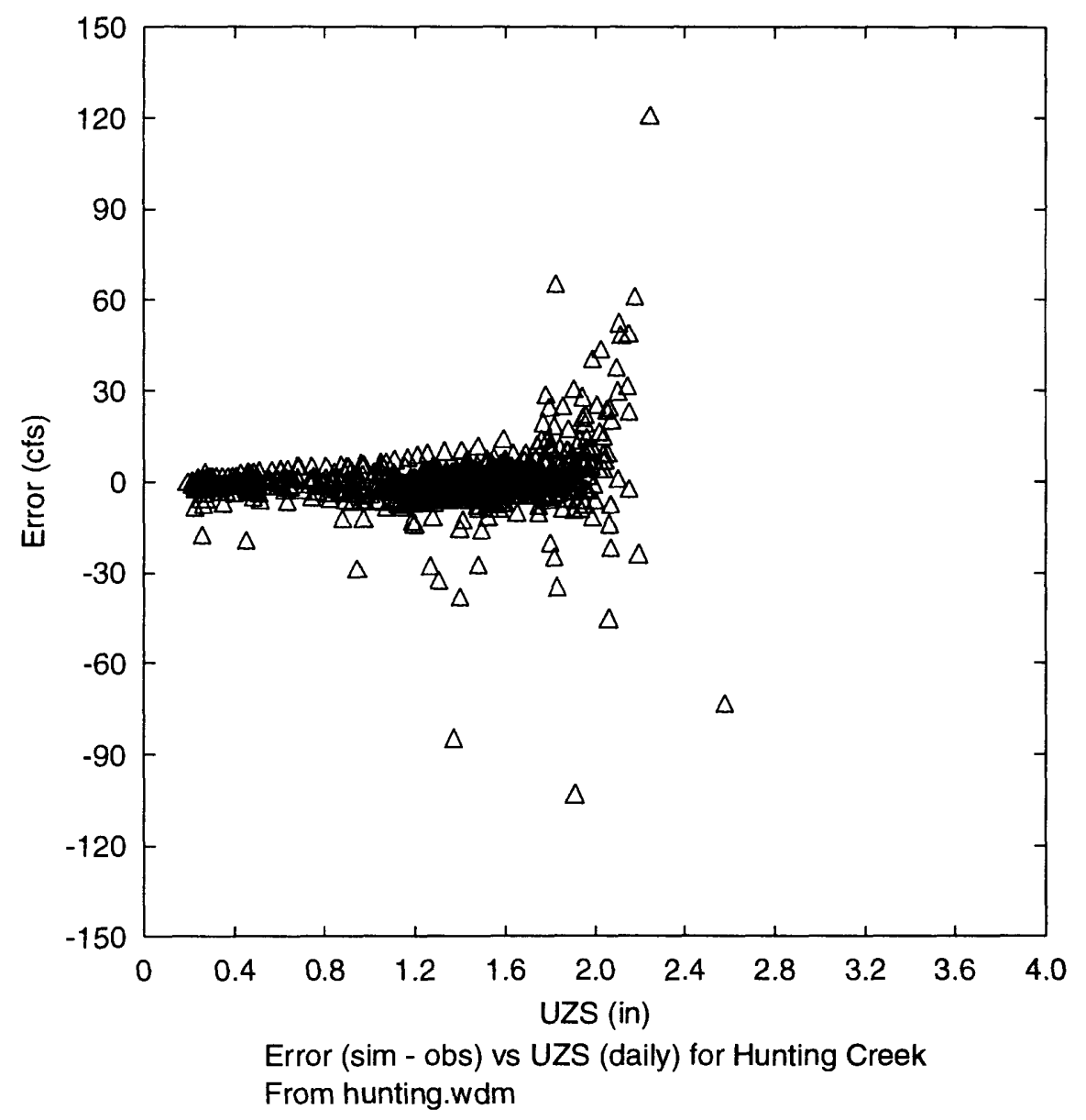

Figure 12. Plot of the error in daily flows and the simulated daily upper zone storage values. 


\section{VIEW GRAPHICS (Step 5)}

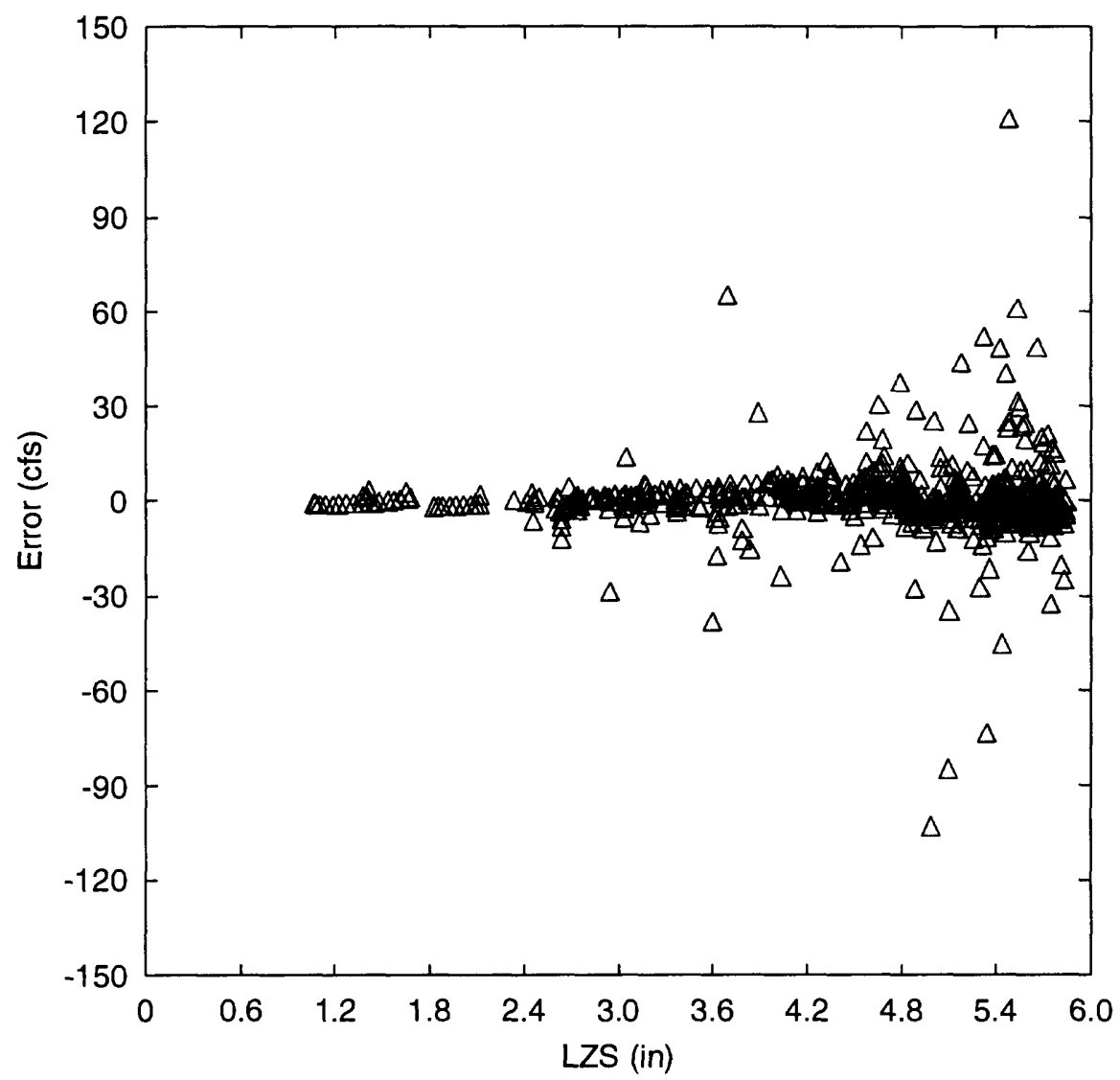

Error (sim - obs) vs LZS (daily) for Hunting Creek

From hunting.wdm

Figure 13. Plot of the error in daily flows and the simulated daily lower zone storage values. 
VIEW GRAPHICS (Step 5)

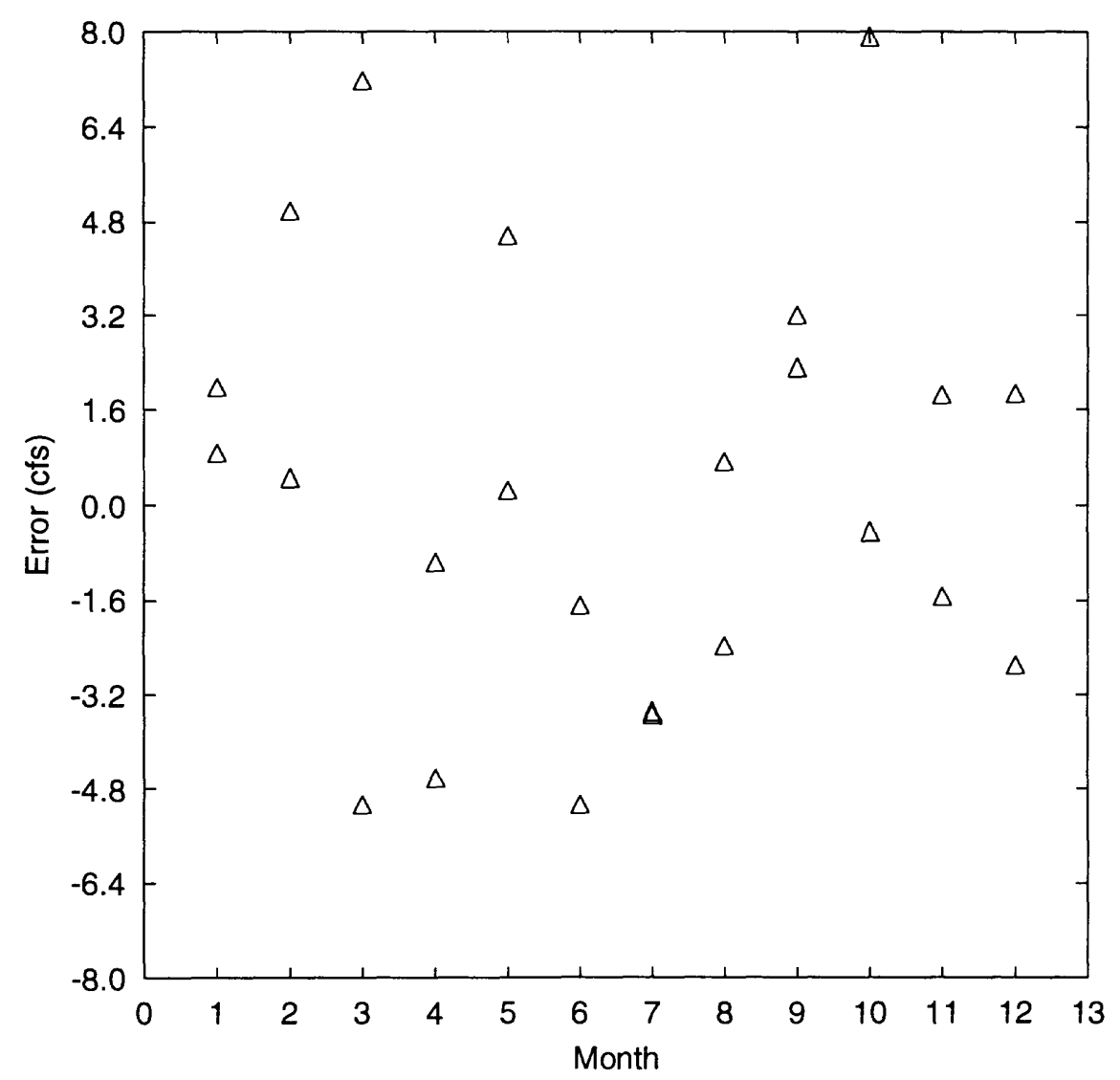

Error (sim - obs) vs Month for Hunting Creek

From hunting.wdm

Figure 14. Plot of the error in monthly flows and the month of the year. 


\section{VIEW GRAPHICS (Step 5)}

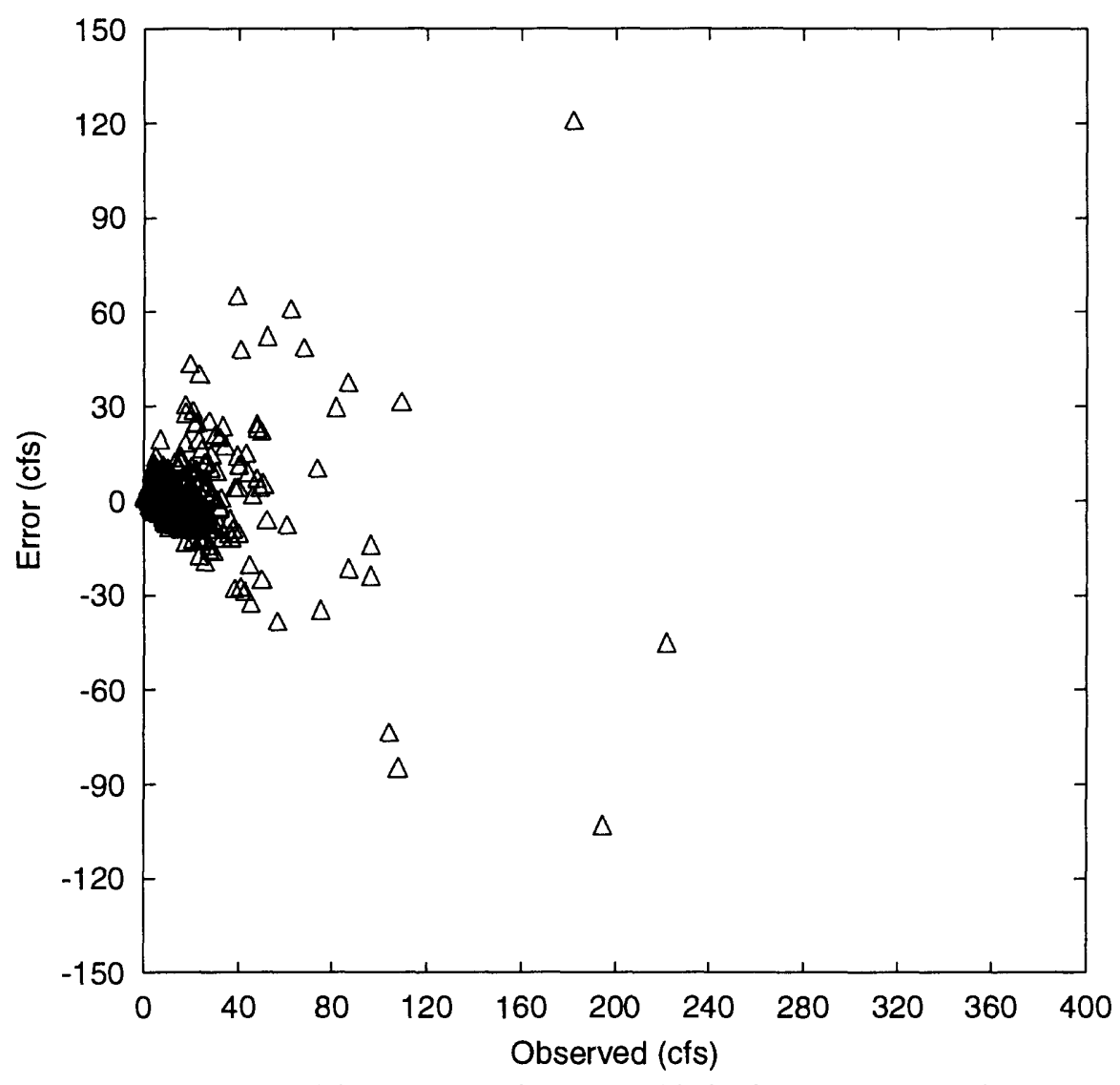

Error (sim - obs) vs Observed (daily) for Hunting Creek From hunting.wdm

Figure 15. Plot of the error in daily flows and the observed data flows. 


\section{VIEW GRAPHICS (Step 5)}

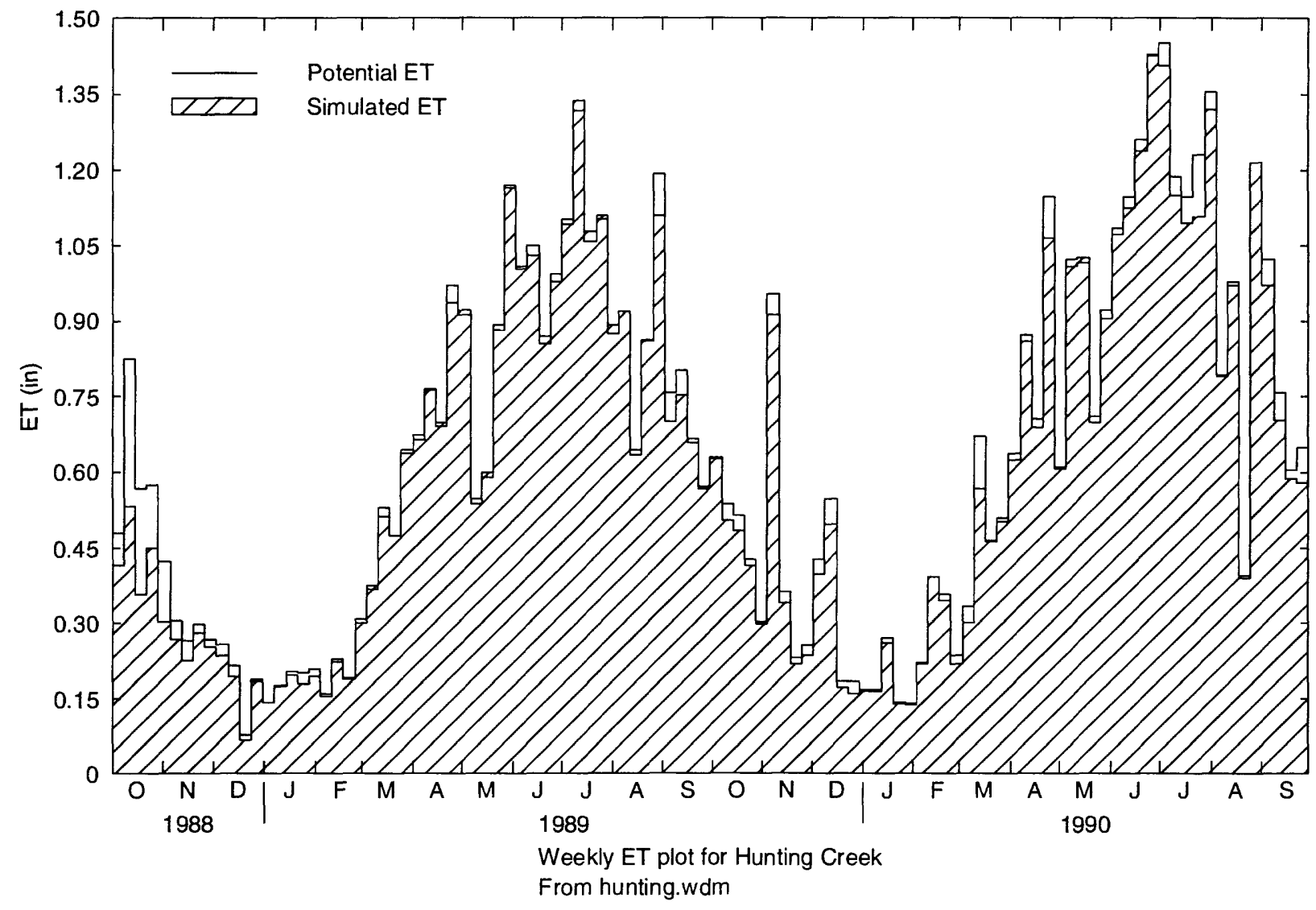

Figure 16. Time-series plot of potential and simulated evapotranspiration. 


\section{VIEW GRAPHICS (Step 5)}

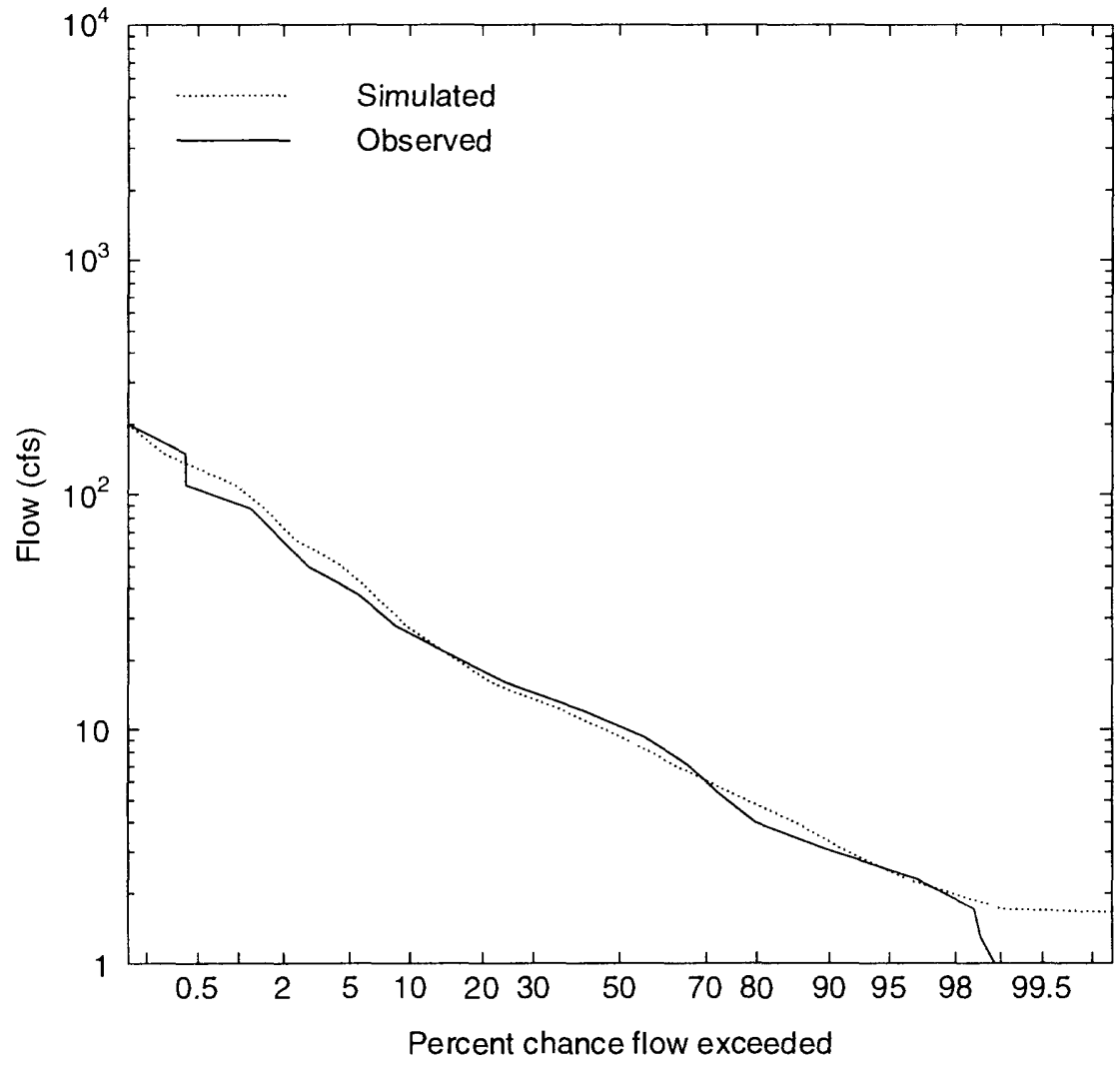

Flow-duration plot for Hunting Creek

From hunting.wdm

Figure 17. Flow duration curves for observed and simulated daily flows. 


\section{VIEW GRAPHICS (Step 5)}

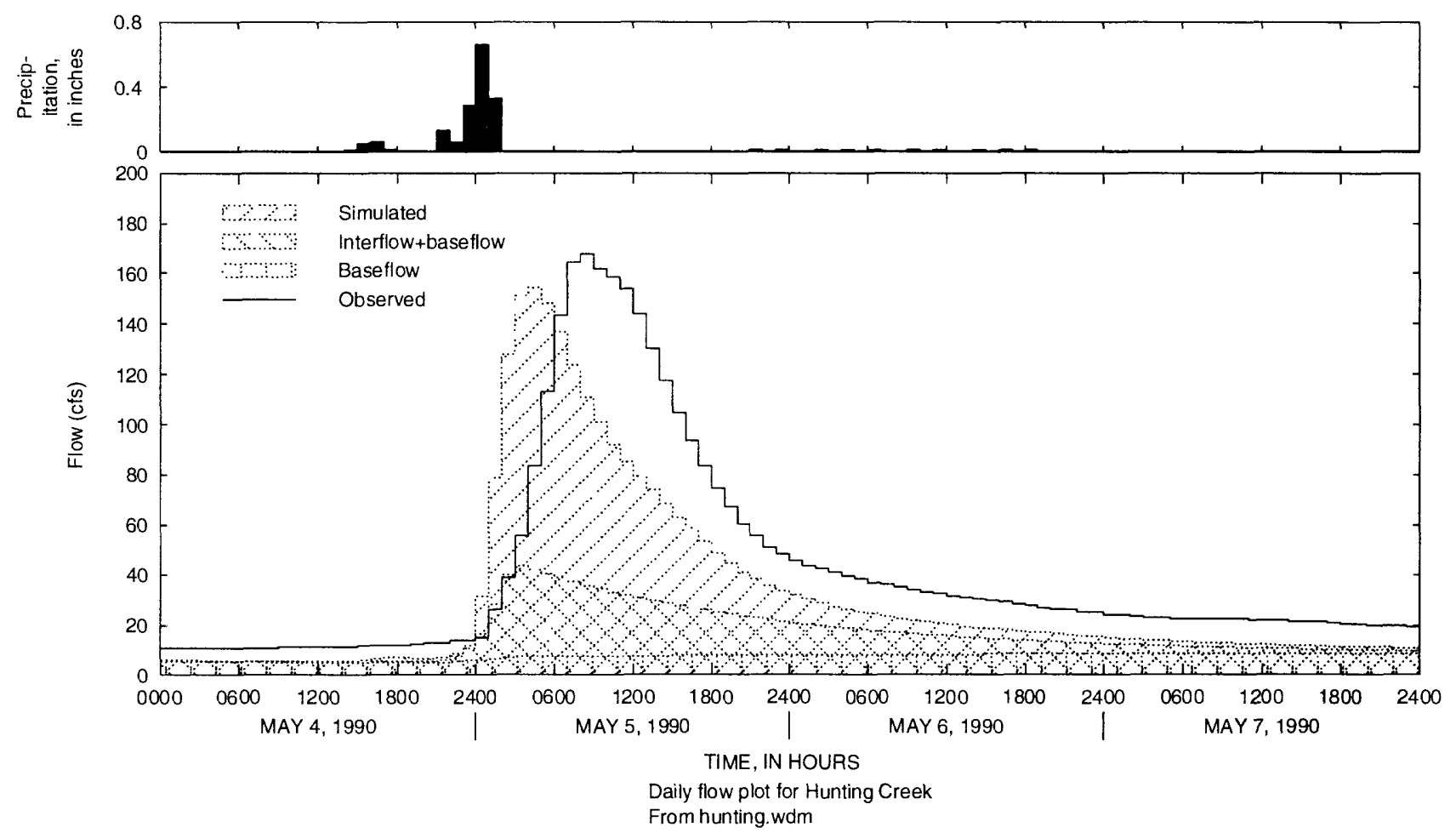

Figure 18. Storm hydrographs of observed flow and simulated flow with flow components. 


\section{VIEW GRAPHICS (Step 5)}

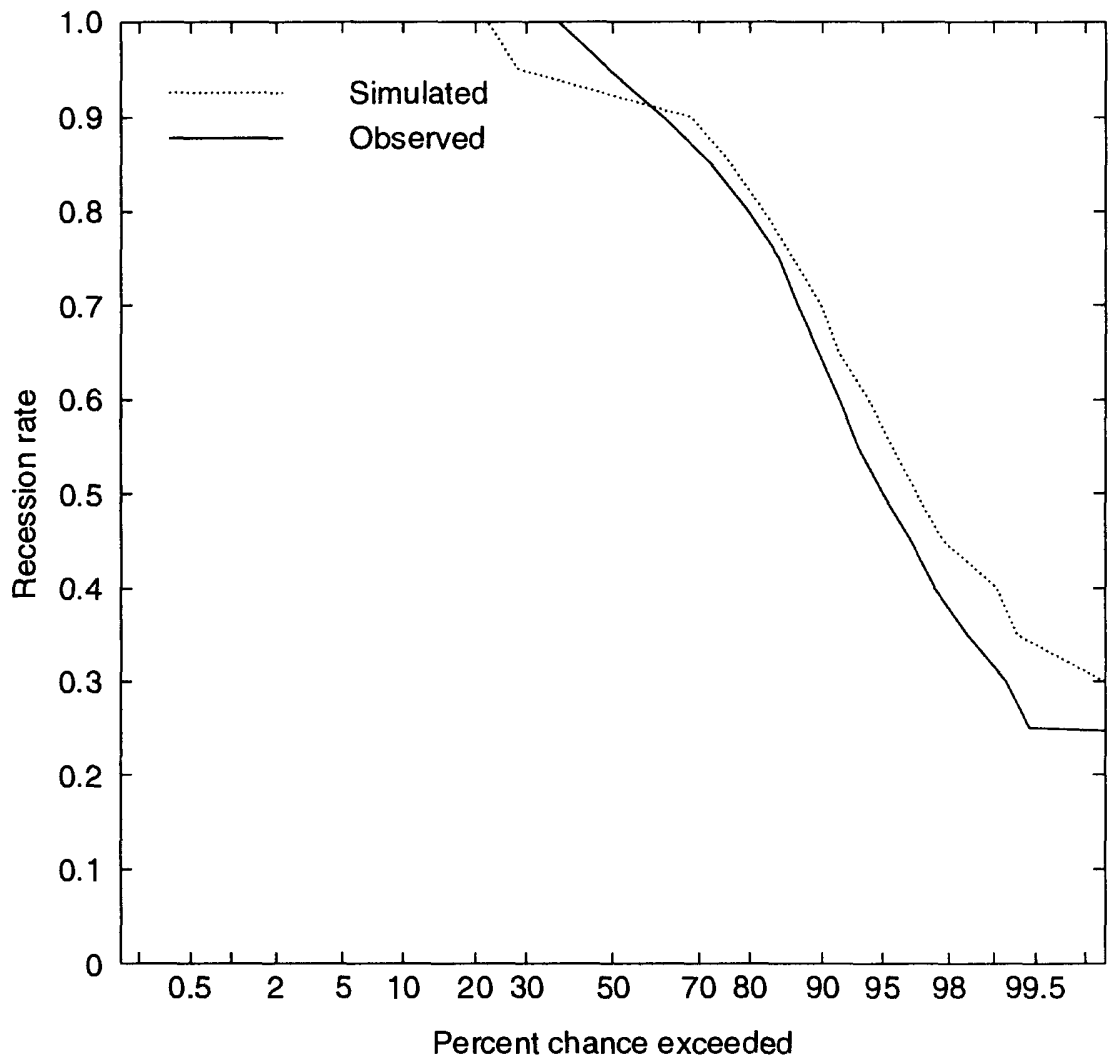

Recession rate duration plot for Hunting Creek

From hunting.wdm

Figure 19. Frequency curves of daily computed flow recession rates for observed and simulated flows. 


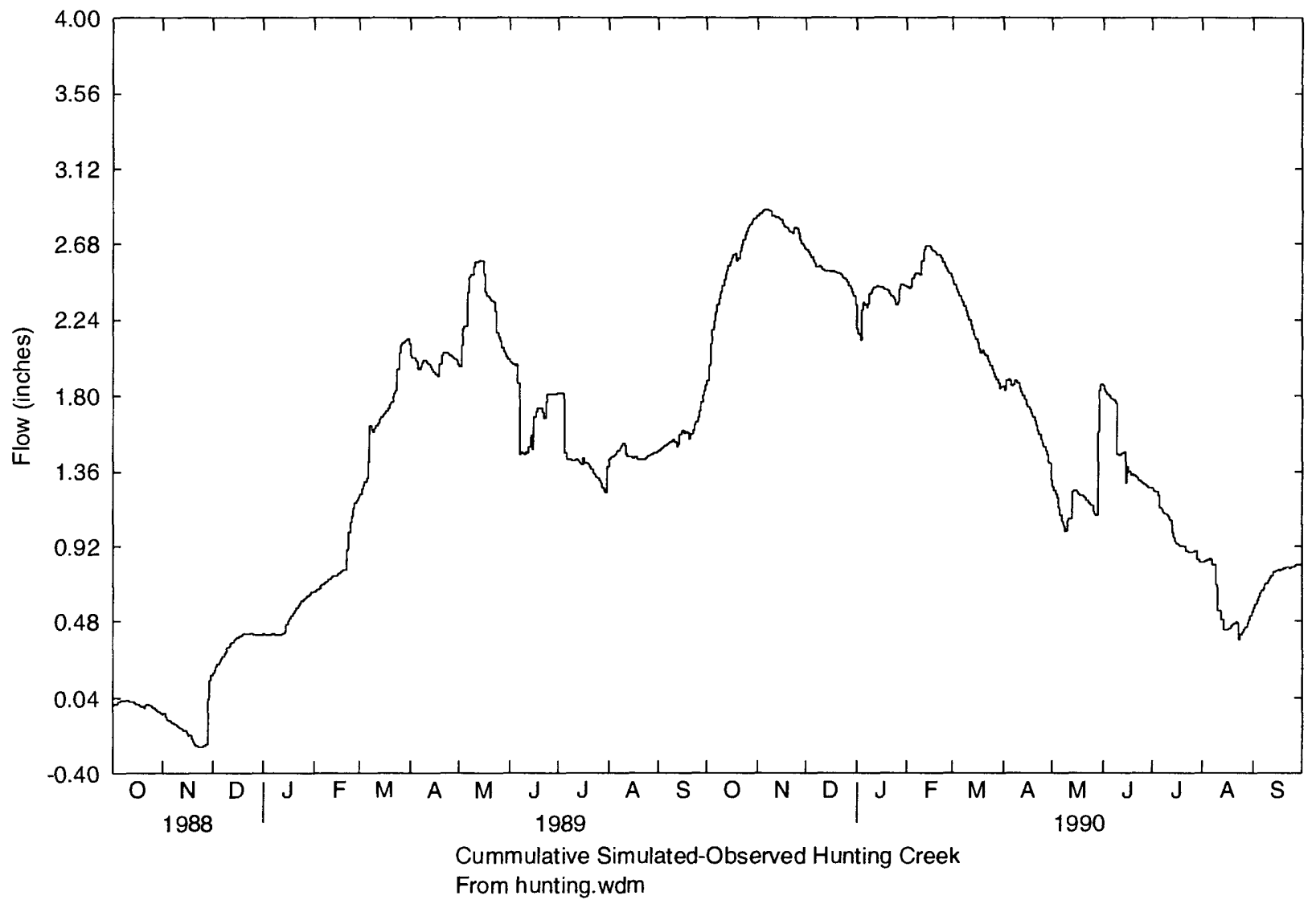

Figure 20. Time-series plot of cumulative differences between simulated and observed daily flow. 
Figure 21. Listing of graphics-specifications file for test data, hunting plt.

$\begin{array}{rrrrrrlr}1 & 1 & 2 & 2 & 3 & 1 & 2 & 100 . \\ 3 & 1 & 1 & 1 & 1 & 3 & 3 & \\ 1 & 1 & 1 & 1 & 1 & 1 & 1 & \\ 5 & 0 & 2 & 6 & 5 & 6 & 4 & \\ 1 & 7 & & & & & & \\ 1988 & 10 & 1 & 0 & 0 & 0 & & \\ 1990 & 9 & 30 & 24 & 0 & 0 & & \\ 1 & & & & & & \\ 0.000 & 0.000 & 0.580 & 0.550 & 1 \\ 0.600 & 0.000 & 1.000 & 0.310 & 7 \\ 0.600 & 0.330 & 1.000 & 0.650 & 8 \\ 0.600 & 0.670 & 1.000 & 1.000 & 11\end{array}$

Table 4. Graphics-specifications file (.plt) content and format

\begin{tabular}{|c|c|c|c|}
\hline Record & Format & Columns & Description \\
\hline \multirow[t]{8}{*}{1} & I5 & $1-5$ & DEVTYP - devce type (1-screen, 2-laser, 3-plotter, 4-metafile) \\
\hline & 15 & $6-10$ & XAXTYP - type of y-axis (1-arith or 2-log) \\
\hline & 15 & $11-15$ & PRECON - flag indicating whether precipitation will be included as an auxiliary axis (1-no, 2-yrs) \\
\hline & I5 & $16-20$ & $\begin{array}{l}\text { COMPON - flag indicating whether the base-flow and interflow components will be shown (1-no, } \\
2 \text {-yes) }\end{array}$ \\
\hline & 15 & $21-25$ & STRMTU - time units for storm plots (2-minutes, 3-hours, 4-days) \\
\hline & 15 & $26-30$ & STRMTS - time step for the storm plots \\
\hline & I5 & $31-35$ & STRMDF - default storm number \\
\hline & F10.0 & $36-45$ & ARPCSC - percent of arithmetic scale to use \\
\hline 2 & 715 & $1-35$ & LNTYP - array of codes for line types for each curve \\
\hline 3 & 715 & $1-35$ & COLOR - array of codes for color for each curve \\
\hline 4 & 715 & $1-35$ & PATTRN - array of codes for fill patterns for each curve \\
\hline \multirow[t]{2}{*}{5} & 15 & $1-5$ & MCOLOR - color of marker on $x-y$ plots \\
\hline & 15 & $6-10$ & MTYPE - type of marker on $x-y$ plots \\
\hline 6 & $6 \mathrm{I} 5$ & $1-30$ & LSTART - starting date and time for plots \\
\hline 7 & 615 & $1-30$ & LEND - ending date and time for plots \\
\hline 8 & I5 & $1-5$ & WINDOW - active window \\
\hline \multirow[t]{2}{*}{9} & 4F10.3 & $1-40$ & WINDIM - array of plot window dimensions \\
\hline & I5 & $41-45$ & DEFPLT - indicator of the type of default plot desired \\
\hline
\end{tabular}




\section{OUTPUT STATISTICS (Step 6)}

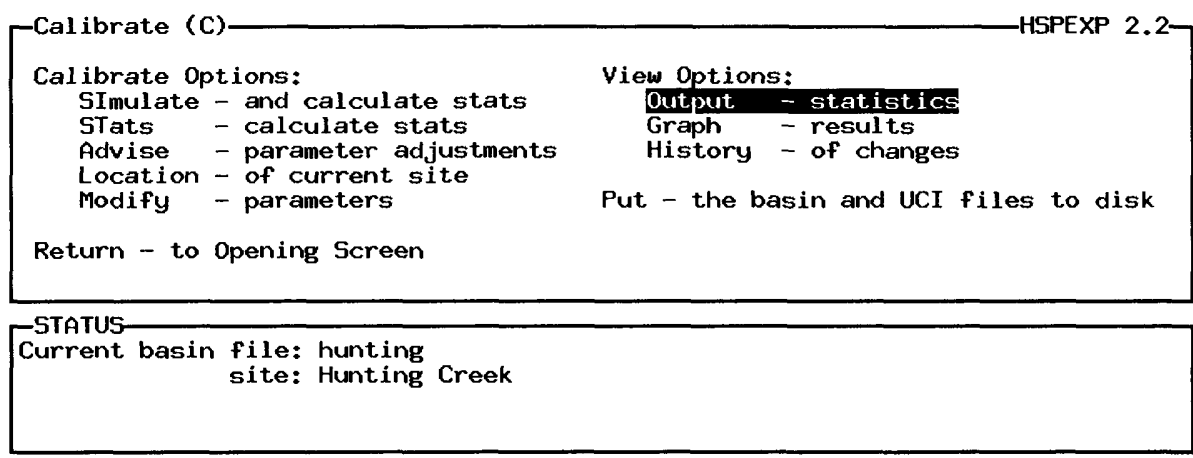

厂INSTRUCT-
Help:F1 Accept:F2 Status:F7 Quiet:FE Xpad:FG Cmhlp
$\begin{gathered}\text { Select an option using arrow keys } \\ \text { Type the first letter of an option. }\end{gathered}$

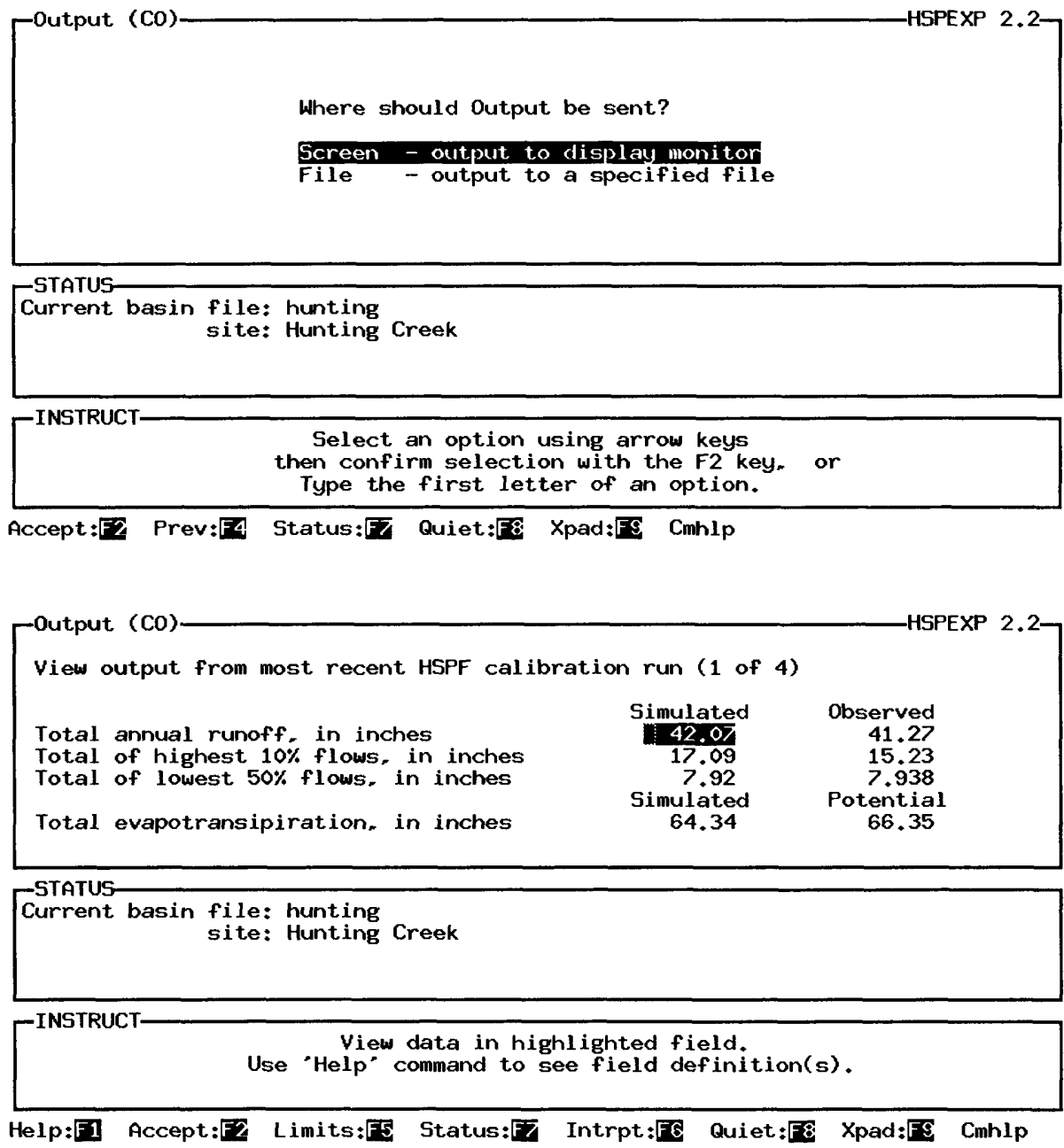




\section{OUTPUT STATISTICS (Step 6)}
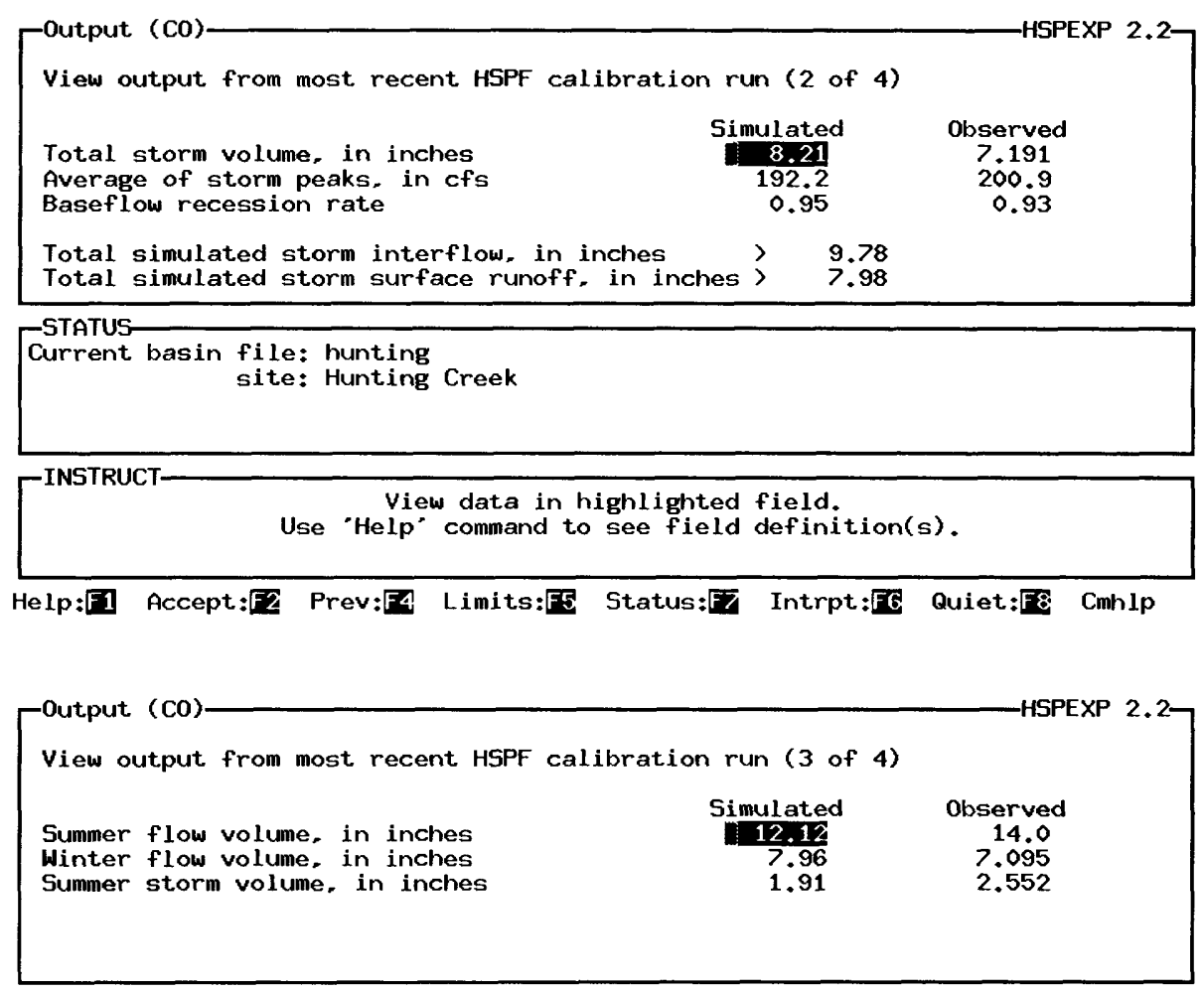

Current basin file: hunting
site: Hunting creek

Use 'Help' command to see field definition(s).
Help:F1 Accept:F2 Prev:F4 Limits:FG Status:FT Intrpt:FE Quiet:FE Cmhlp

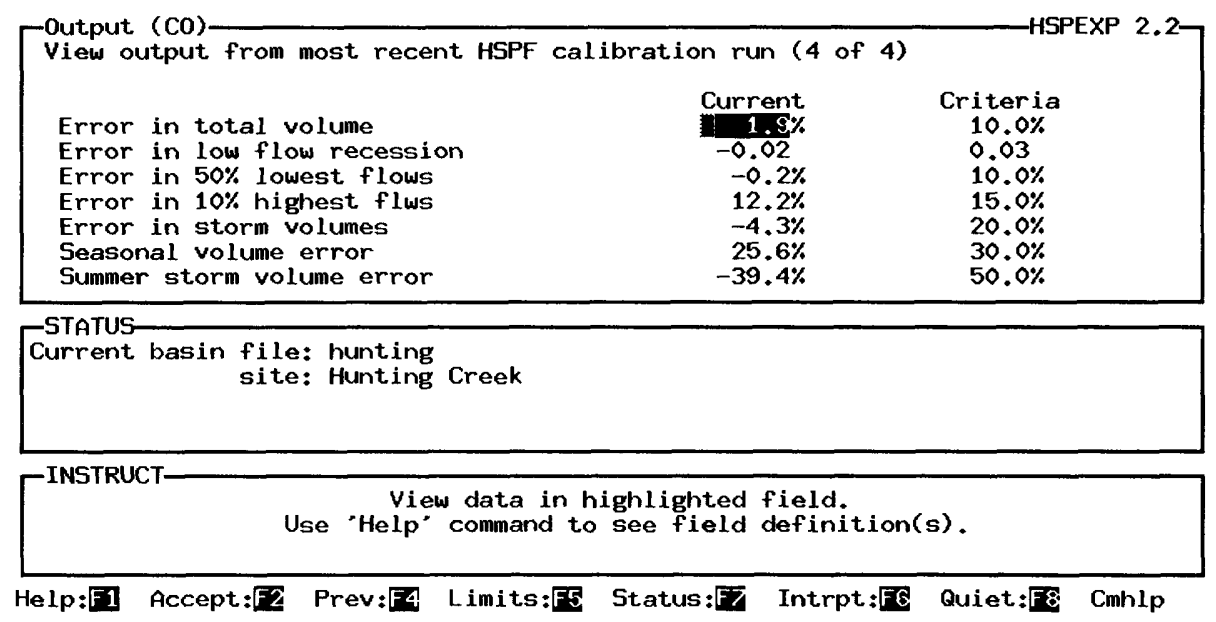




\section{CHECK CALIBRATION ADVICE (Step 7)}

ADVISE
Calibration advice from the expert system is provided by selecting the ADVISE option. The advice can be sent to a file or to the screen. The advice has three parts: (1) the conditions that cause the advice to be given, (2) the advice that suggests an increase or decrease in a parameter value, and (3) why the advice is given for the stated conditions. The amount to change a parameter is not provided. If the change is too small, you will likely get the advice again. If the change is too large, the next advice may be to change the parameter in the other direction.

Usually one screen is provided but in some cases two or three screens may contain changes. The following is a sample of the advice provided for the test data. A complete listing of the advice is presented in Appendix A. 


\section{CHECK CALIBRATION ADVICE (Step 7)}

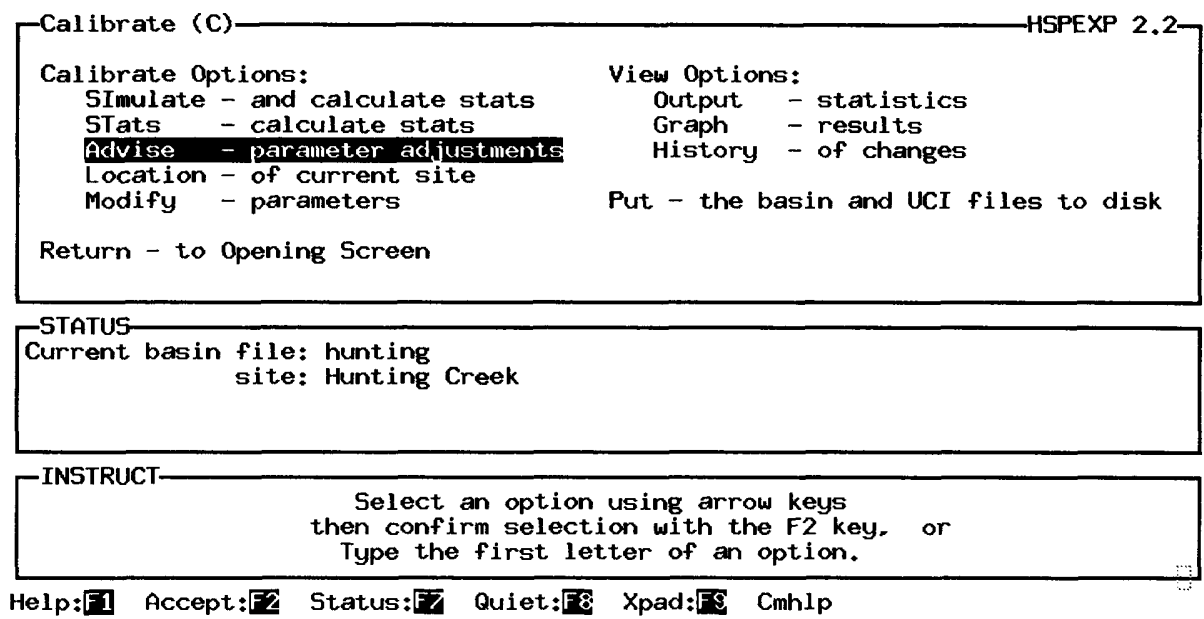

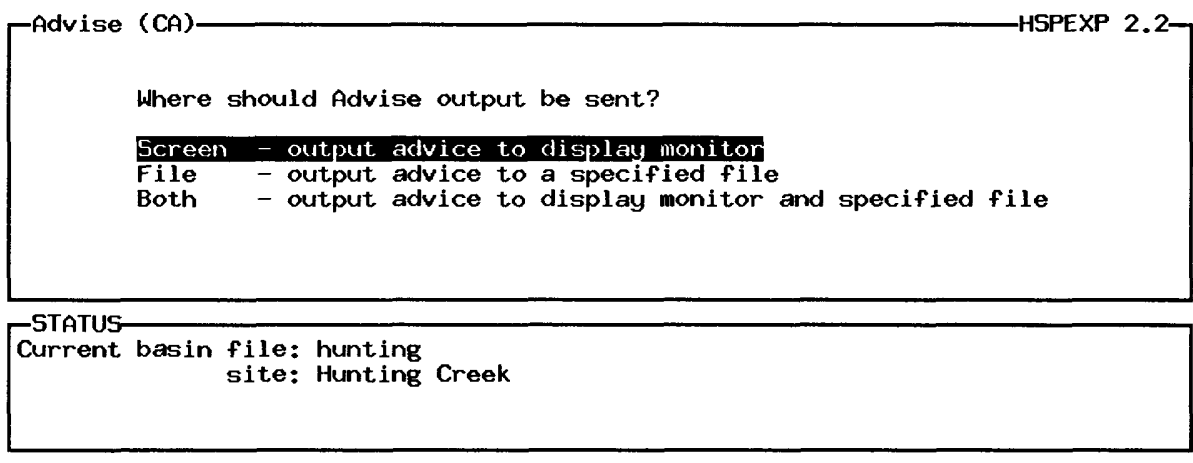

IINSTRUCT-
$\begin{gathered}\text { Select an option using arrow keys } \\ \text { then confirm selection with the F2 key. or } \\ \text { Type the first letter of an option. }\end{gathered}$
Help:F1 Accept:F2 Prev:F4 Status:FZ Quiet:FE Xpad:FG Cmhlp

\footnotetext{
CAdvise (CA), Rule 1 of 2 HSPEXP 2.2

Rule: INFLT1.1 Group: High-flow - low-flow distribution

The highest $10 \%$ of simulated daily mean flows (17.09) is more than $10.00 \%$ (E4) greater than observed $(15,23)$, and the lowest $50 \%$ of simulated daily flows (7.92) is less than observed $(7.94)$.

To correct this problem: increase INFILT

Explanation: The major effect of increased infiltration (INFILT) is to shift drainage from rapid response (surface runoff and interflow) to delayed response (base flow).

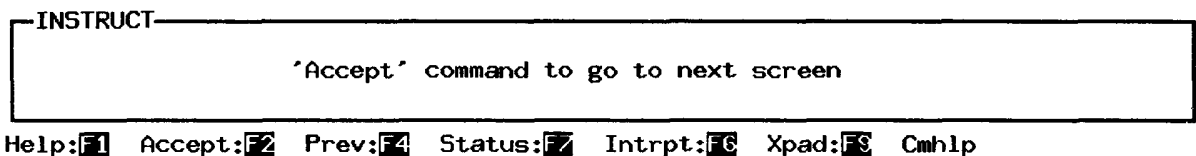




\section{CHECK CALIBRATION ADVICE (Step 7)}

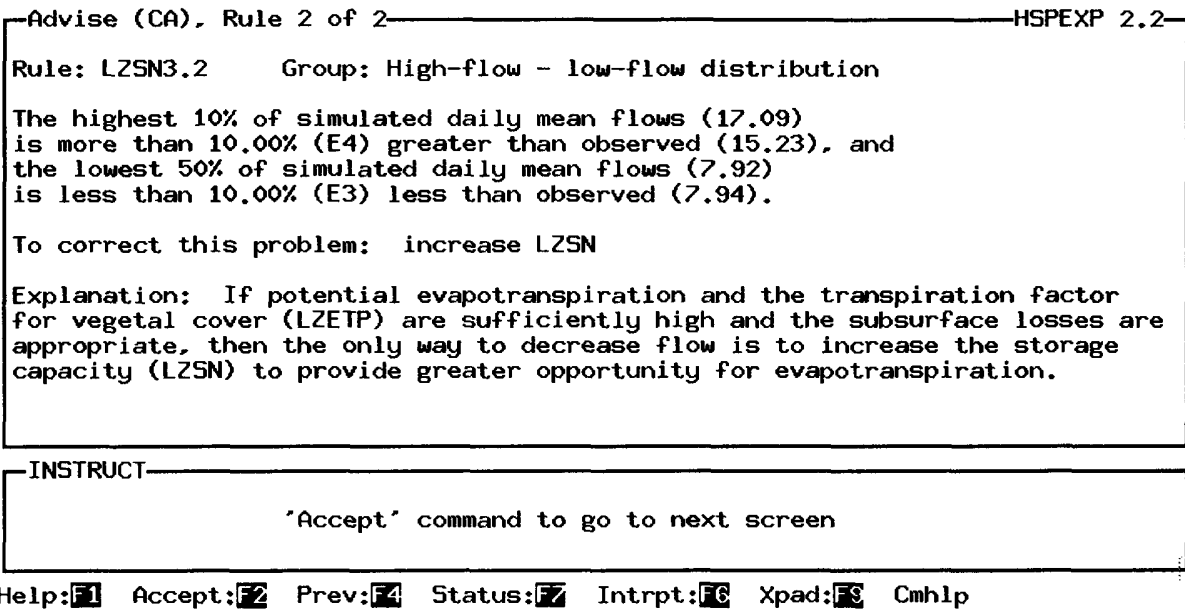




\section{ADJUST PARAMETERS (Step 8)}

\section{MODIFY}

The MODIFY option is selected to adjust parameters in the UCI file. Under MODIFY there are two options, PARAMETERS and UCI, which may be used to modify HSPF parameters. PARAMETERS is a simple option for changing the basic PERLND parameters by parameter name for all PERLND's or all parameters for a specific PERLND. When several PERLND's are used and the advice has suggested changing only one parameter, the PARAMETERS option would be most useful.

Anything in the UCI file can be changed with the UCI option. This would be needed to add a monthly table for a PERLND parameter, modify an FTABLE, or change the area for an IMPLND or PERLND in the SCHEMATIC block. The menus for the UCI option are organized in the same way as the UCI file, by blocks and tables. First the block of interest is selected, then one or more specific tables within a block are selected. Each of the selected tables are then displayed for editing. The parameter description (F1) key and parameter range (F5) key are available for each item in each table. There are over 300 tables that can be selected and edited. Only changes to existing operations in the UCI file can be made. The addition of new operations in the UCI file must be done in a text editor.

Presented below are the screens that can be used to make the parameter change suggested in the advice. Both the PARAMETER and UCI options are illustrated. 


\section{ADJUST PARAMETERS (Step 8)}

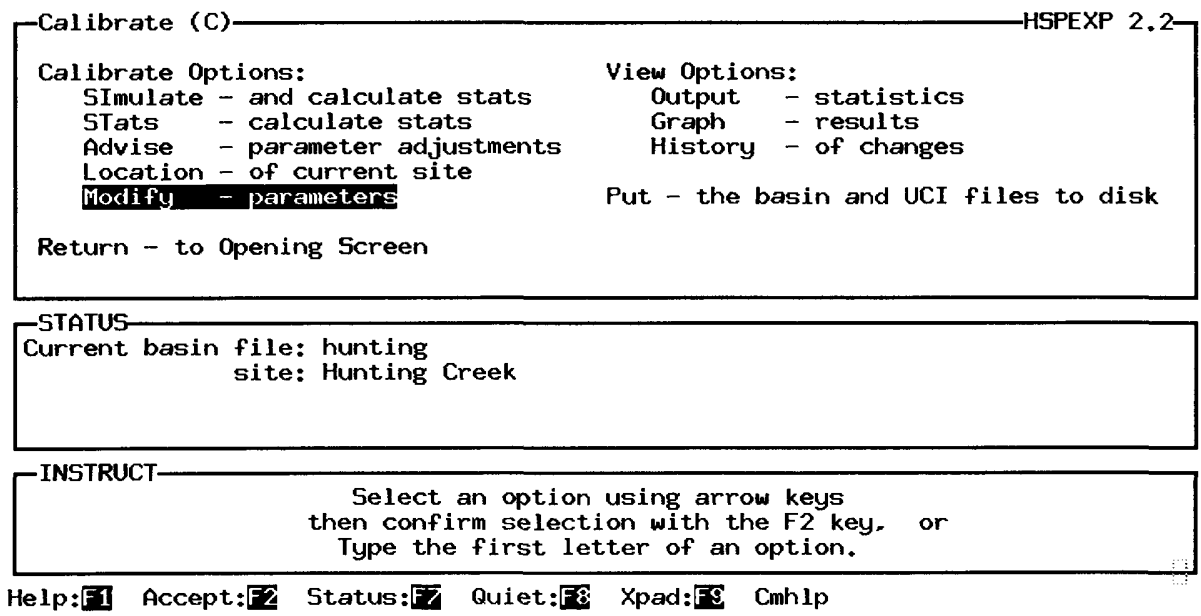
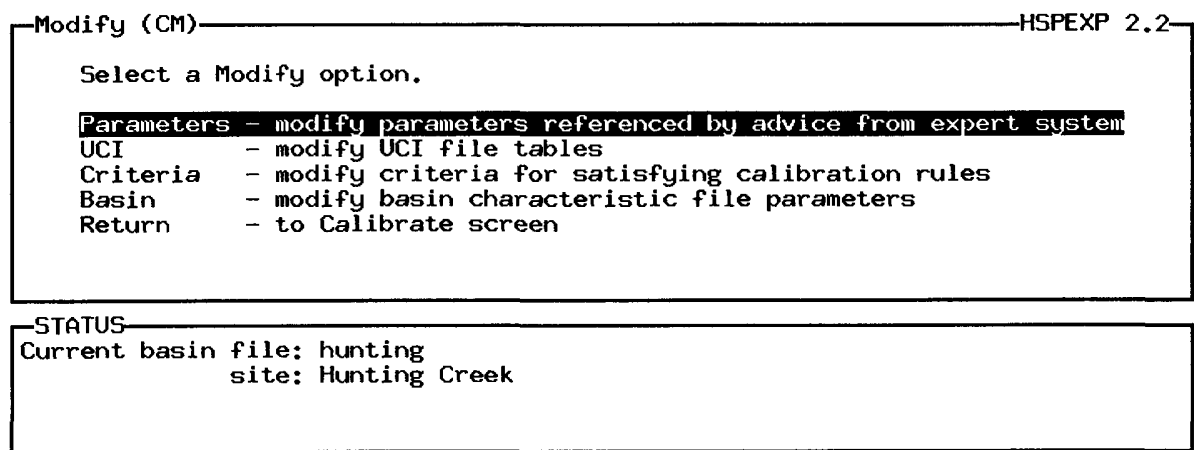

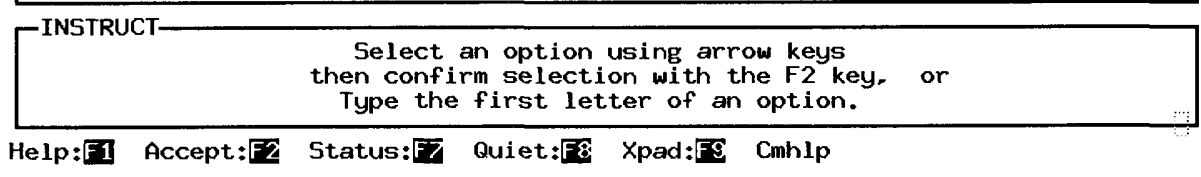

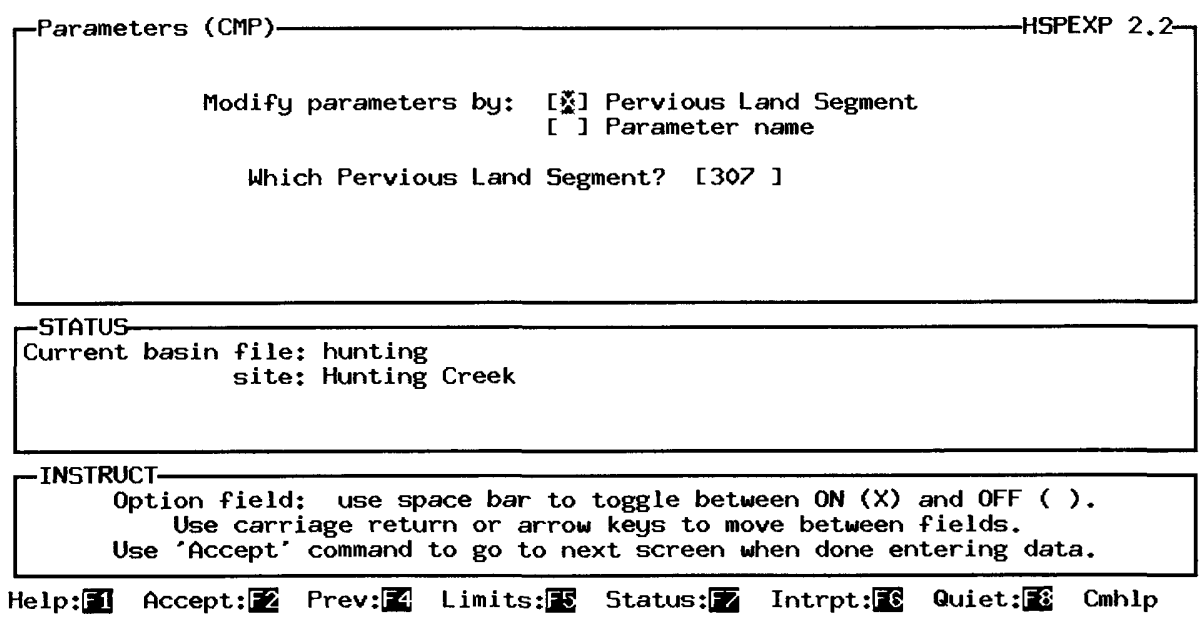




\section{ADJUST PARAMETERS (Step 8)}

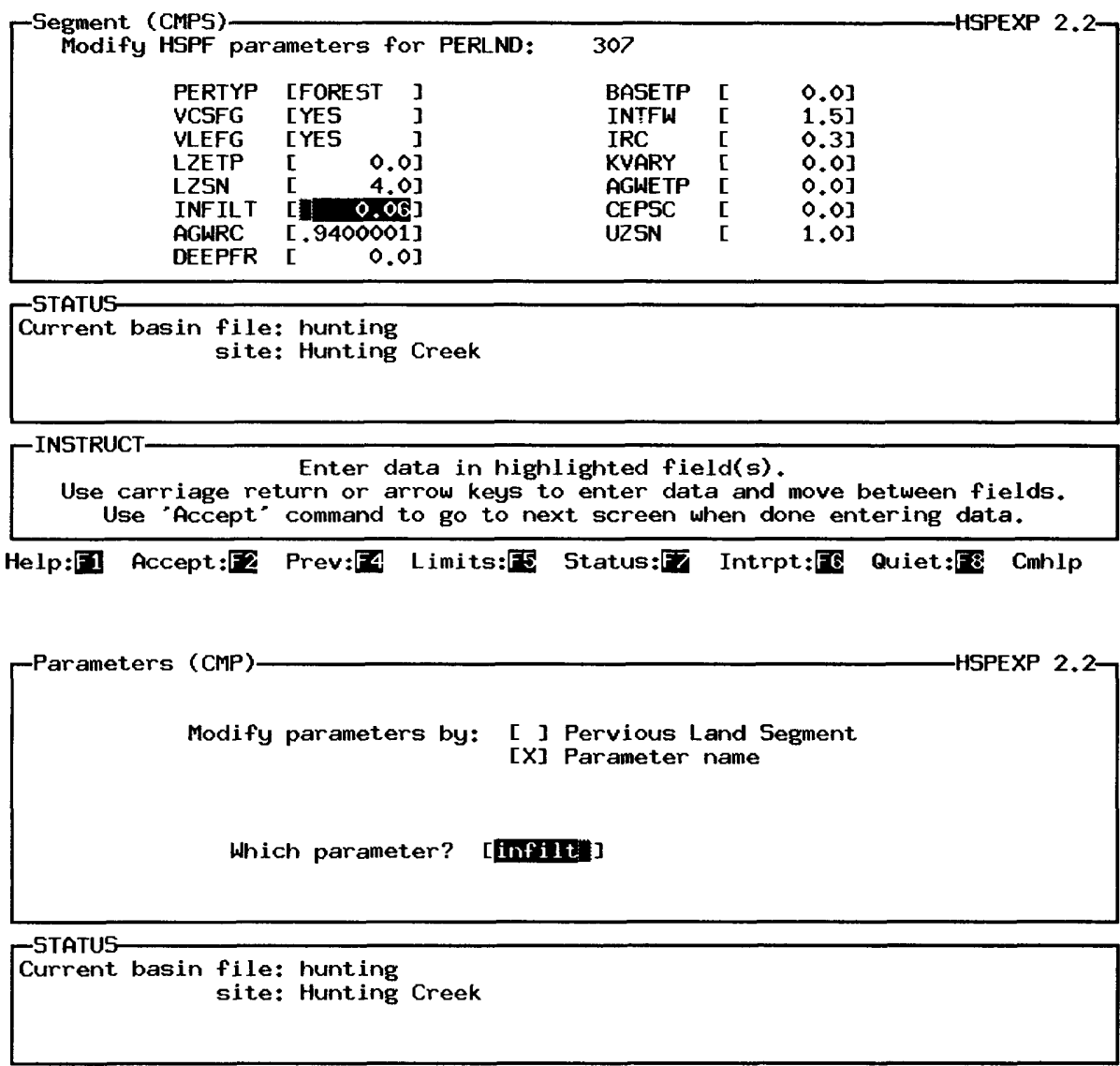

INSTRUCT- Enter data in highlighted field(s).
Use carriage return or arrow keys to enter data and move between fields.
Use "Accept' command to go to next screen when done entering data.

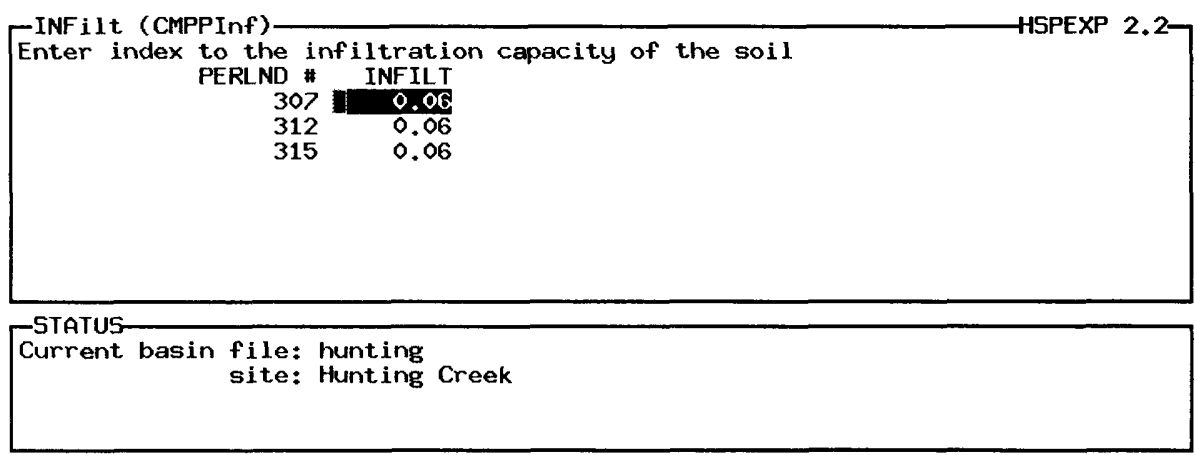

\begin{tabular}{|l} 
Enter data in highlighted field(s). \\
Use carriage return or arrow keys to enter data and move between fields. \\
Use 'Accept' command to go to next screen when done entering data.
\end{tabular}

Help:F1 Accept:F2 Prev:F4 Limits:F5 Status:F7 Intrpt:FG Quiet:FE Cmhlp 


\section{ADJUST PARAMETERS (Step 8)}

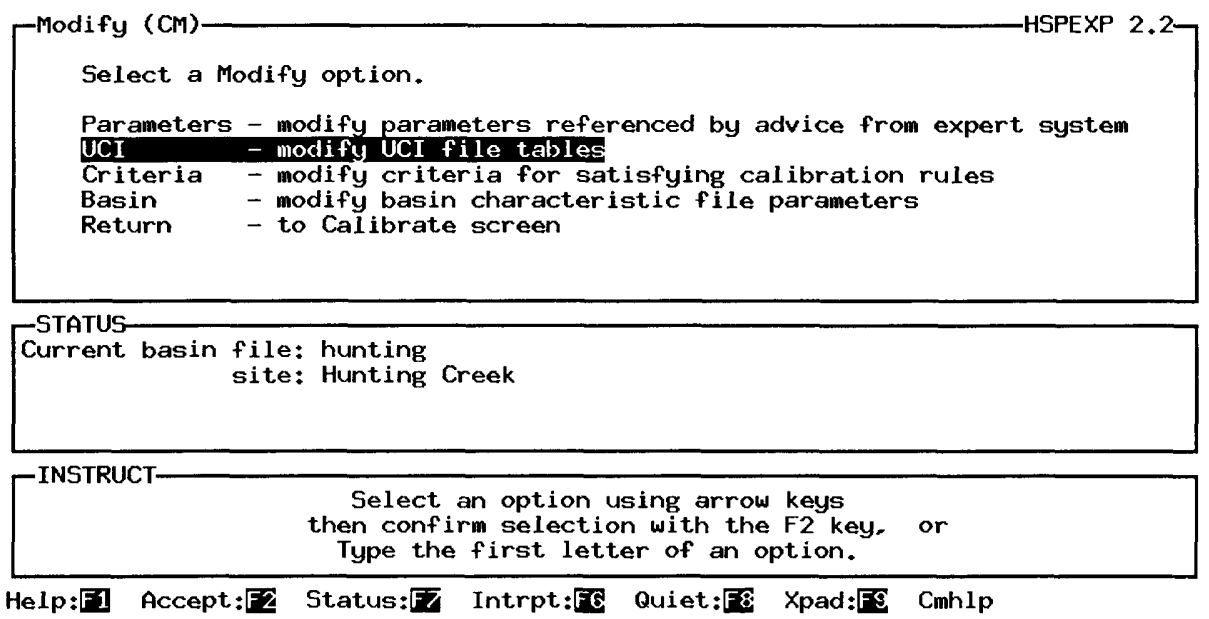

\begin{tabular}{|cccc} 
UCI (CMU) & & & \\
Select a UCI modify option. & & \\
GENERAL & SIMULATION & UTILITY & TIMESERIES \\
GLobal & PErlnd & COpy & EXT-Sources \\
Opn_Sequence & Implnd & PLtgen & FOrmats \\
FTables & RChres & DIsply & Network \\
SPec-actions & & DUranl & EXT-Targets \\
FIles & & GEner & SChematic \\
CAtegories & & MUtsin & MAss-link \\
REturn & & \\
\hline
\end{tabular}

Current basin file: hunting
site: Hunting creek

INSTRUCT- $1 \begin{gathered}\text { Select an option using arrow keys } \\ \text { then confirm selection with the F2 key, or } \\ \text { Type the first letter of an option. }\end{gathered}$
Accept:F2 Status:F7 Intrpt:FG Quiet:FE Xpad:FG Cmhlp

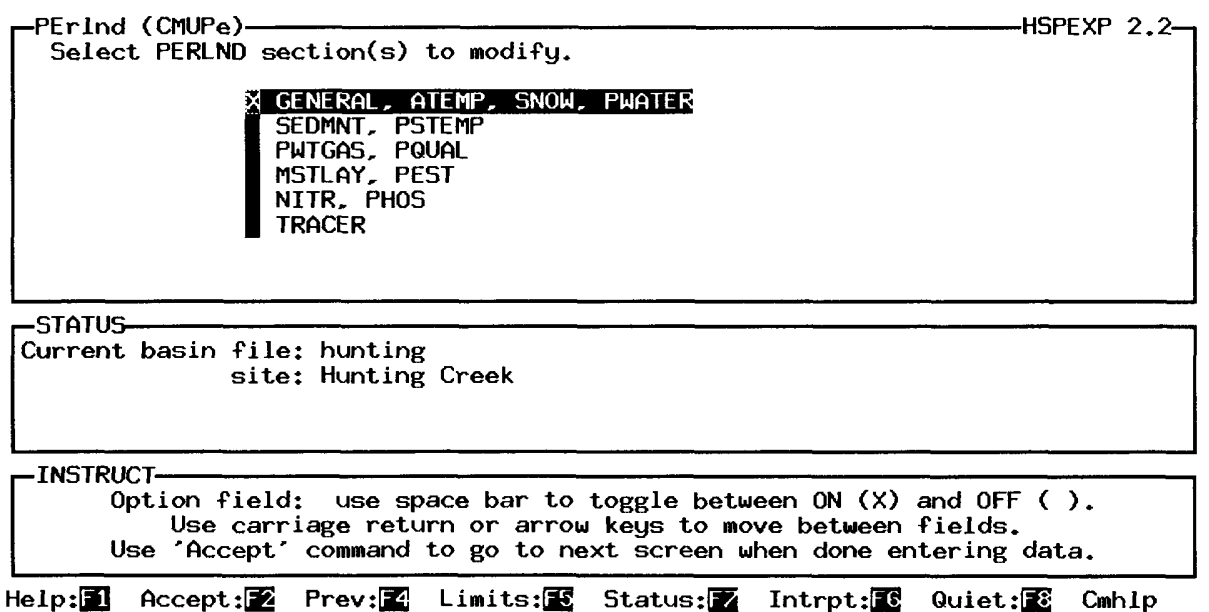




\section{ADJUST PARAMETERS (Step 8)}

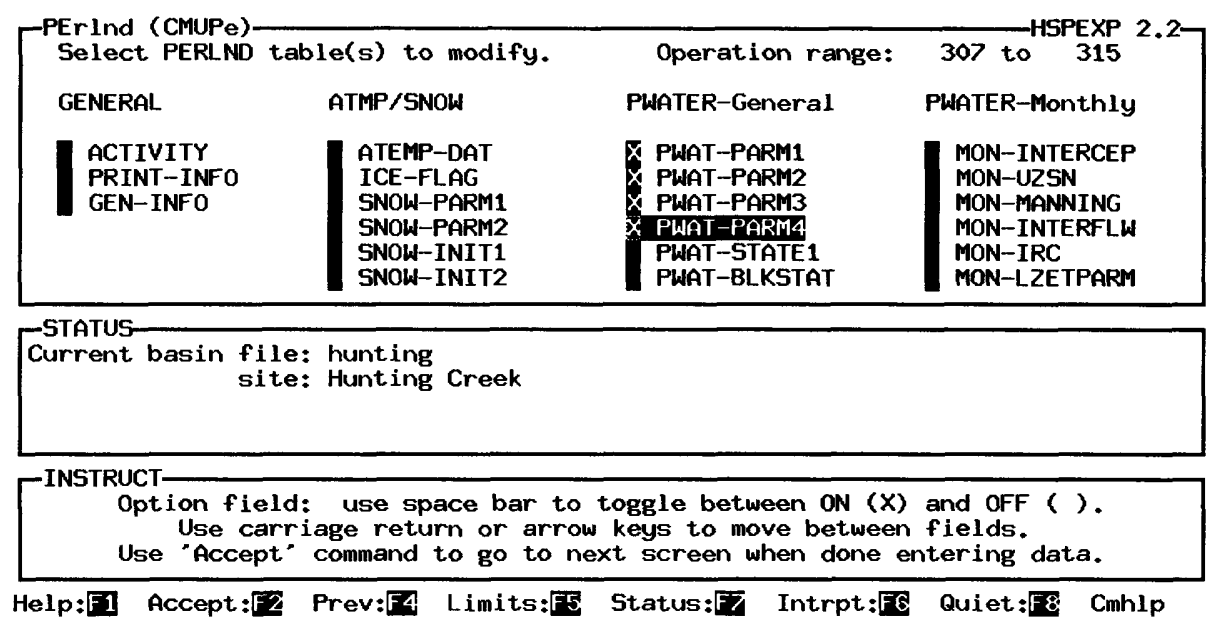

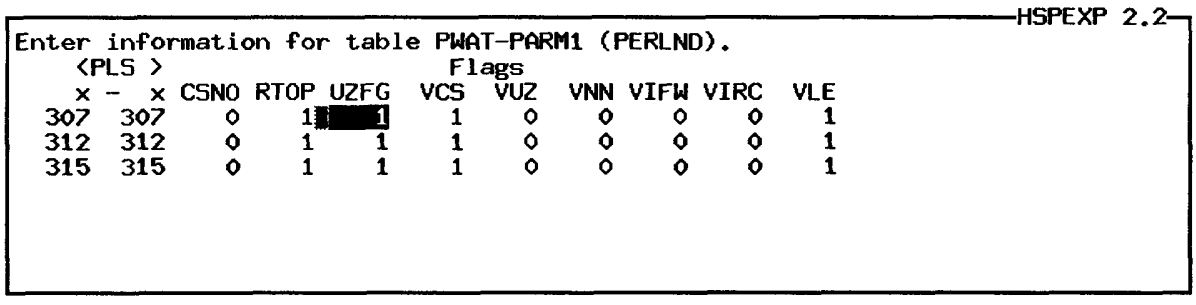

Current basin file: hunting
site: Hunting Creek
$\begin{aligned} & \text { STASTRUCT- } \\ & \text { Use carriage return or arrow keys to enter data and move between fields. } \\ & \text { Use 'Accept command to go to next screen when done entering data. }\end{aligned}$
Help:F1 Accept:F2 Prev:F4 Limits:F5 Status:F Intrpt:FG Quiet:FE Cmhlp

\begin{tabular}{|c|c|c|c|c|c|}
\hline 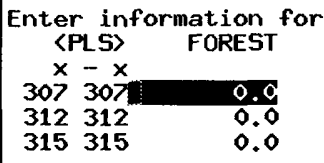 & $\begin{array}{cr}\text { table PWAT-PARM2 } \\
\text { LZSN } & \text { INFILT } \\
\text { (in) } & \text { (in/hr) } \\
4.0 & 0.06 \\
4.0 & 0.06 \\
4.0 & 0.06\end{array}$ & $\begin{array}{r}\text { (PERLND) } \\
\text { LSUR } \\
(f t) \\
800.0 \\
600.0 \\
700.0\end{array}$ & $\begin{array}{l}\text { SLSUR } \\
0.06 \\
0.04 \\
0.05\end{array}$ & $\begin{array}{r}\text { KVARY } \\
(1 / \text { in) } \\
0.0 \\
0.0 \\
0.0\end{array}$ & $\begin{array}{r}\text { AGHRC } \\
\text { (1/day) } \\
0.94 \\
0.94 \\
0.94\end{array}$ \\
\hline
\end{tabular}

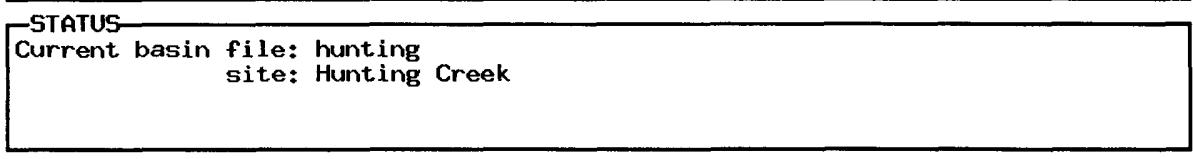

\begin{tabular}{|c} 
Enter data in highlighted field(s). \\
$\begin{array}{c}\text { Use carriage return or arrow keys to enter data and move between fields. } \\
\text { Use 'Accept" command to go to next screen when done entering data. }\end{array}$ \\
\hline
\end{tabular}




\section{MODIFY ERROR CRITERIA (Step 9)}

CRITERIA
To modify the error criteria, select the CRITERIA option of the MODIFY menu. The 10 terms (E1-E10) and their values will be displayed. Seven terms are acceptable levels of error (E1-E5, E7, and E8), two terms (E6 and E9) adjust some of the values used in the rules, and one term (E10) impacts the computation of the error in base-flow recession. E6 impacts rules for the interflow parameters IRC and INTFW and should not be changed. E9 is used to compute the error term for the volume rule for the infiltration parameter INFILT and is a multiplier on the error term that is used in the low-flow rule for INFILT. The value for E10 can be determined by viewing the base-flow recession plot. From the plot determine the percent of time the observed recession was between a lower limit and 1.0. The lower limit would usually be between 0.85 and 0.95 . The default criteria is 30 percent, which would usually be too high for arid and semi-arid regions where the stream is dry most of the time.

If no advice is given because the computed error terms are within the acceptable levels of error, the acceptable levels criteria can be reduced to attempt to refine the calibration. There is a point where no parameter sets can meet all criteria resulting in an infinite loop adjusting and readjusting with no real gains. At this point, calibration should end.

There may be an error criterion that cannot be met such as the acceptable level of error for summer storm volumes and the calibration cannot get past that step. This may be caused by large errors in the observed data or storms not well represented by a single rain gage. In this case, the error criteria for summer storm volumes could be increased so that the additional types of errors can be addressed. 

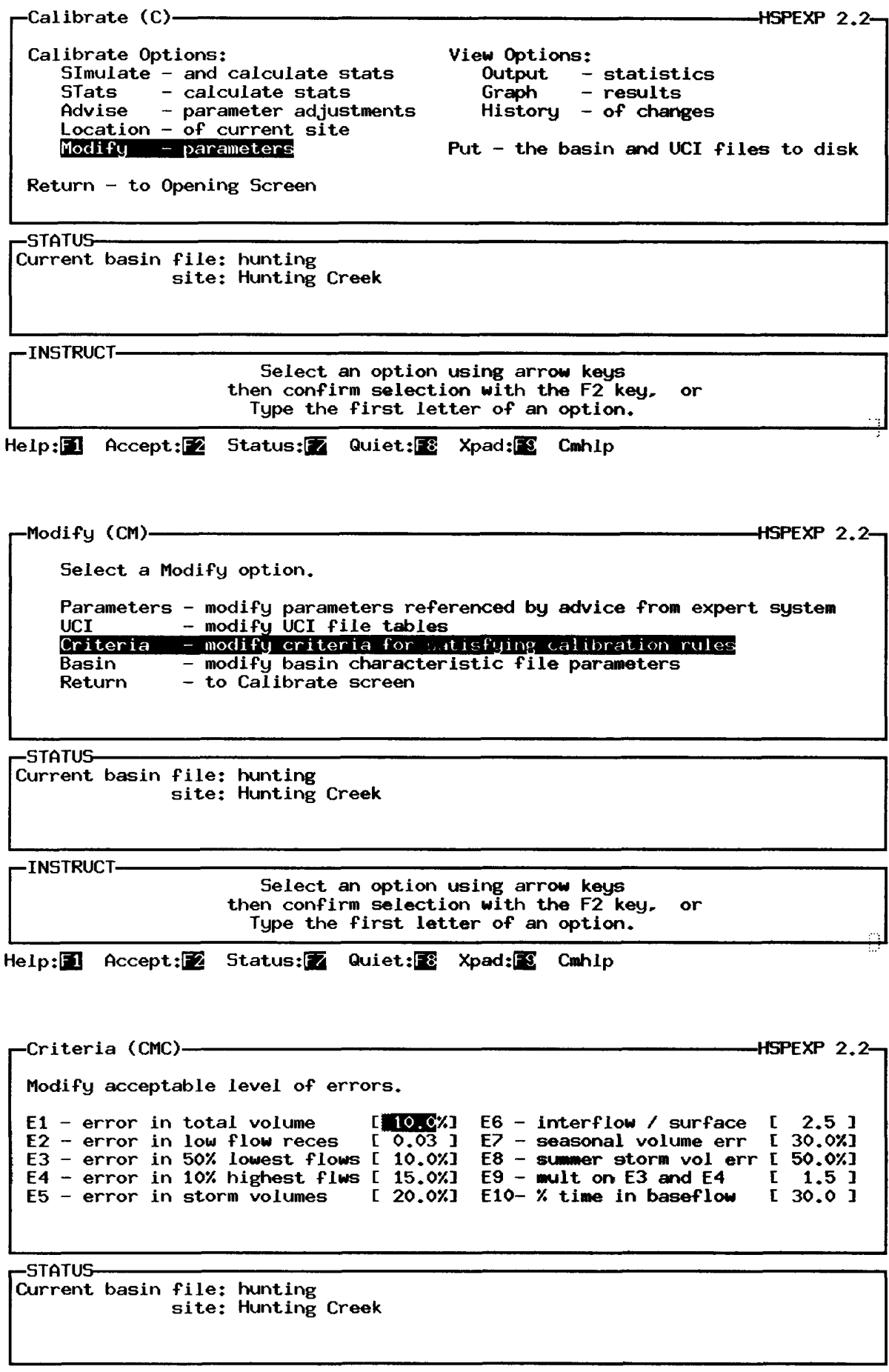

\footnotetext{
INSTRUCT- $\begin{gathered}\text { Enter data in highlighted field(s). } \\ \text { Use carriage return or arrow keys to enter data and move between fields. } \\ \text { Use Accept command to go to next screen when done entering data. }\end{gathered}$
Help:F1 Accept:F2 Prev:F4 Limits:FG Status:F7 Intrpt:FG Quiet:F8 Cmhlp
} 


\section{SELECTED REFERENCES}

Donigian, A.S., Jr., Imhoff, J.C., Bicknell, Brian, Kittle, J.L., Jr., 1984, Application guide for Hydrological Simulation Program-Fortran (HSPF): U.S. Environmental Protection Agency, Environmental Research Laboratory, Athens, Ga., EPA-600/3-84-065, 177 p.

Gaschnig, John, Reboh, Rene, and Reiter, John, 1981, Development of a knowledge-based expert system for water resources problems: Final Report, SRI Project 1619, SRI International, Menlo Park, Calif., 133 p.

Bicknell, B.R., Imhoff, J.C., Kittle, J.L., Jr., Donigian, A.S., and Johanson, R.C., 1993, Hydrological Simulation Program-Fortran, Users Manual for Release 10: EPA-600/R-93/174, Environmental Research Laboratory, Athens, Ga., 660 p.

James, L.D., 1972, Hydrologic modeling, parameter estimation, and watershed characteristics: Journal of Hydrology, v. 17 , p. $283-307$.

Kittle, J.L., Jr., Hummel, P.R., and Imhoff, J.C., 1989, ANNIE-IDE, A system for developing interactive user interfaces for environmental models (Programmers Guide): EPA/600/3-89/034, Environmental Research Laboratory, Athens, Ga., 166 p.

Kohler, M.A., Nordenson, T.J., and Fox, W.E., 1955, Evaporation from pans and lakes: U.S. Department of Commerce, Weather Bureau, Research Paper No. 38, Washington, D.C., 21 p.

Lumb, A.M., Kittle, J.L., Jr., and Flynn, K.M., 1990, Users manual for ANNIE, A computer program for interactive hydrologic analysis and data management: U.S. Geological Survey Water-Resources Investigations Report $89-4080,236 \mathrm{p}$.

Lumb, A.M., and McCammon, R.B., 1991, HYDRO-II, An expert system for watershed model calibration:

Proceedings of the Seventh International Conference on Interactive Information and Processing Systems for Meteorology, Oceanography and Hydrology, American Meteorological Society, New Orleans, La., January 1418,1991, p. 324-327.

Stefik, Mark, Bobrow, D.G., Mittal, Sanjay, and Conway, Lynn, 1983, Knowledge programming in LOOPS—Report on an experimental course: AI Magazine, v. 4, no. 3, p. 3-13. 


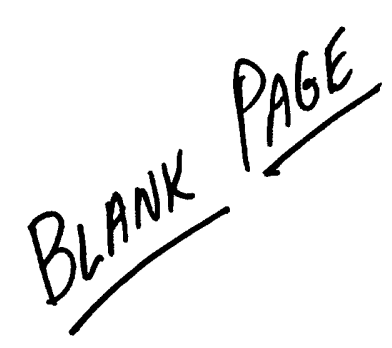

70 
APPENDIXES 


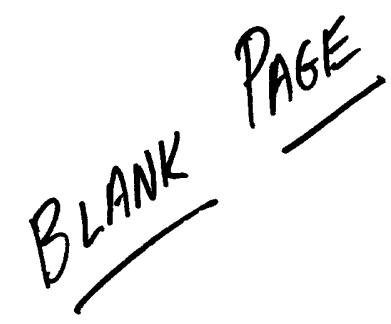

72 


\title{
APPENDIX A. RULES AND ADVICE FOR CALIBRA- TION OF HSPF
}

\author{
Rule: TRNOF1.1 Group: Water balance \\ Total runoff volume error (_z) is greater than _o (E1) \\ (simulated total runoff is _, observed total runoff is _). \\ To correct this problem: \\ 1 - Compare average annual potential ET to the value from the U.S. \\ National weather Service map of annual lake evaporation for the \\ study area and increase the multiplier on the EXTERNAL SOURCES \\ block of your UCI file if appropriate. \\ 2 - Compare total precipitation with surrounding rain gages and \\ decrease the multiplier on the EXTERNAL SOURCES block of your \\ UCI file if appropriate. \\ 3 - Check to see if there are flow diversions out of the watershed \\ and included in the model input if appropriate.
}

Explanation: Model parameters cannot or should not account for major errors in input and output time series.

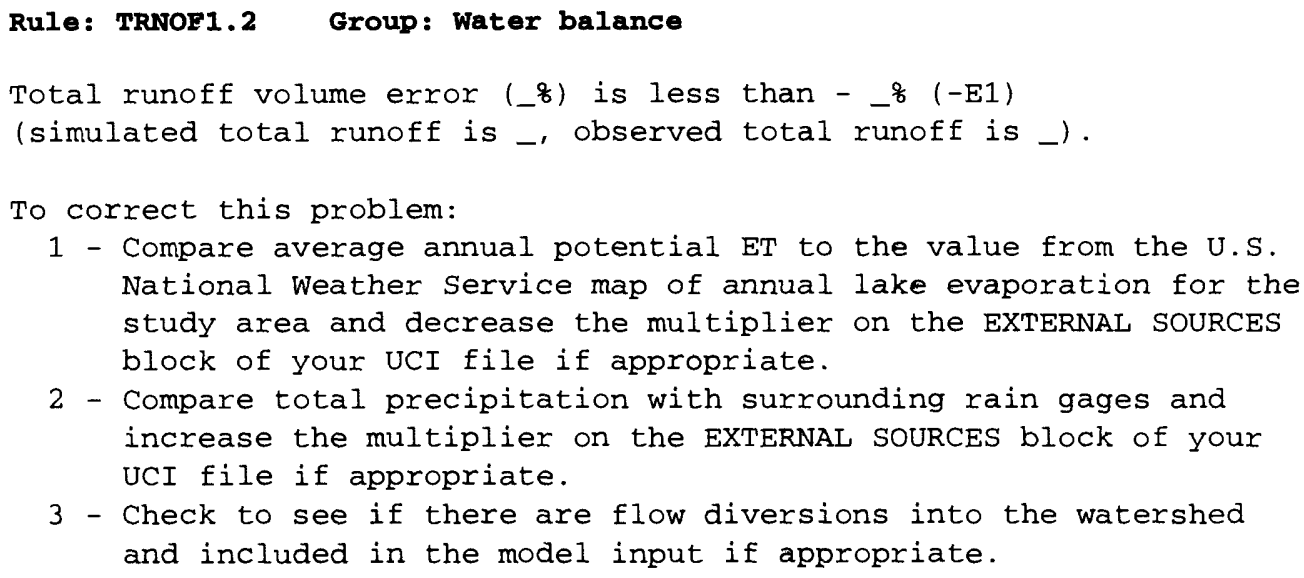

Explanation: Model parameters cannot or should not account for major errors in input and output time series.

\section{Rule: LZETP1.1 Group: Water balance}

Total runoff volume error (_o) is greater than _o (E1)

(simulated total runoff is _, observed total runoff is _), and the difference between simulated and potential ET (_) is greater than the flow difference (_).

To correct this problem: increase LzETP

Explanation: Precipitation can only leave the watershed as runoff, underflow, evapotranspiration, or diversions. If underflow and diversions are negligible, the only way to decrease simulated runoff 
is to increase simulated evapotranspiration. LZETP is the parameter that adjusts for the vigor with which vegetation transpires.

\section{Rule: LZETP1.2 Group: Water balance}

The simulated total runoff (_) is greater than the observed (_), and forested PERLND \# _ has a value for LZETP (_) below 0.6.

To correct this problem: increase LZETP

Explanation: Precipitation can only leave the watershed as runoff, underflow, evapotranspiration, or diversions. If underflow and diversions are negligible, the only way to decrease simulated runoff is to increase simulated evapotranspiration. LZETP is the parameter that adjusts for the vigor with which vegetation transpires and the current value for forested areas is low.

\section{Rule: LZETP1.3 Group: Water balance}

The simulated total runoff (_) is greater than the observed (_), and bush/grass/pasture PERLND \# _ has a value for LZETP (_) below 0.3.

To correct this problem: increase LZETP

Explanation: Precipitation can only leave the watershed as runoff, underflow, evapotranspiration, or diversions. If underflow and diversions are negligible, the only way to decrease simulated runoff is to increase simulated evapotranspiration. LZETP is the parameter that adjusts for the vigor with which vegetation transpires and the current value for bush/grass/pasture areas is low.

\section{Rule: LZETP1.4 Group: Water balance}

The simulated total runoff (_) is greater than the observed (_), row-crop PERLND \# _ has a value for LZETP (_) below 0.4.

To correct this problem: increase LZETP

Explanation: Precipitation can only leave the watershed as runoff, underflow, evapotranspiration, or diversions. If underflow and diversions are negligible, the only way to decrease simulated runoff is to increase simulated evapotranspiration. LZETP is the parameter that adjusts for the vigor with which vegetation transpires and the current value for row-crop areas is low.

\section{Rule: IZETP1.5 Group: Water balance}

The simulated total runoff (_) is greater than the observed (_), sparse PERLND \# _ has a value for LZETP (_) below 0.1 .

To correct this problem: increase LZETP

Explanation: Precipitation can only leave the watershed as runoff, underflow, evapotranspiration, or diversions. If underflow and diversions are negligible, the only way to decrease simulated runoff is to increase simulated evapotranspiration. LZETP is the parameter 
that adjusts for the vigor with which vegetation transpires and the current value for areas with sparse vegetation is low.

\section{Rule: LZETP1.6 Group: Water balance}

The simulated total runoff (_) is greater than the observed (_), bare PERLND \# _ has a value for LZETP (_) equal to 0.0 .

To correct this problem: increase LZETP

Explanation: Precipitation can only leave the watershed as runoff, underflow, evapotranspiration, or diversions. If underflow and diversions are negligible, the only way to decrease simulated runoff is to increase simulated evapotranspiration. LZETP is the parameter that adjusts for the amount of soil moisture evaporation from bare soil and the current value is zero.

\section{Rule: LZETP2.1 Group: Water balance}

Total runoff volume error $\left(-\frac{q}{8}\right)$ is less than - _o (-E1)

(simulated total runoff is _, observed total runoff is _.), and the average annual potential ET is lower than the average annual lake evaporation for the region.

To correct this problem: decrease LZETP

Explanation: Precipitation can only leave the watershed as runoff, underflow, evapotranspiration, or diversions. If underflow and diversions are negligible, the only way to increase simulated runoff is to decrease simulated evapotranspiration by lowering the potential ET or the LZETP parameter. Because the potential ET is already lower than the lake evaporation for the area, LZETP should be decreased.

\section{Rule: LZETP2.2 Group: Water balance}

The simulated total runoff (_) is below the observed (_), and forested PERLND \# _ has a value for LZETP (_) above 0.6.

To correct this problem: decrease LzETP

Explanation: Precipitation can only leave the watershed as runoff, underflow, evapotranspiration, or diversions. If underflow and diversions are negligible, the only way to increase simulated runoff is to decrease simulated evapotranspiration. LZETP is the parameter that adjusts for the vigor with which vegetation transpires and the current value for forested areas is high.

\section{Rule: LZETP2.3 Group: Water balance}

The simulated total runoff (_) is below the observed (_), and bush/grass/pasture PERLND \# _ has a value for LZETP (_) above 0.3.

To correct this problem: decrease LzETP

Explanation: Precipitation can only leave the watershed as runoff, underflow, evapotranspiration, or diversions. If underflow and 
diversions are negligible, the only way to increase simulated runoff is to decrease simulated evapotranspiration. LZETP is the parameter that adjusts for the vigor with which vegetation transpires and the current value for bush/grass/pasture areas is high.

\section{Rule: LZETP2.4 Group: Water balance}

The simulated total runoff (_) is below the observed (_), and row-crop PERLND \# _ has a value for LZETP (_) above 0.4.

To correct this problem: decrease LZETP

Explanation: Precipitation can only leave the watershed as runoff, underflow, evapotranspiration, or diversions. If underflow and diversions are negligible, the only way to increase simulated runoff is to decrease simulated evapotranspiration. LZETP is the parameter that adjusts for the vigor with which vegetation transpires and the current value for row-crop areas is high.

\section{Rule: LZETP2.5 Group: water balance}

The simulated total runoff (_) is below the observed (_), and sparse PERLND \# _ has a value for LZETP (_) above 0.1.

To correct this problem: decrease LZETP

Explanation: Precipitation can only leave the watershed as runoff, underflow, evapotranspiration, or diversions. If underflow and diversions are negligible, the only way to increase simulated runoff is to decrease simulated evapotranspiration. LzETP is the parameter that adjusts for the vigor with which vegetation transpires and the current value for sparsely vegetated areas is high.

\section{Rule: LzETP2.6 Group: Water balance}

The simulated total runoff (_) is below the observed (_), and bare PERLND \# _ has a value for LzETP (_) above 0.0.

To correct this problem: decrease LZETP

Explanation: Precipitation can only leave the watershed as runoff, underflow, evapotranspiration, or diversions. If underflow and diversions are negligible, the only way to increase simulated runoff is to decrease simulated evapotranspiration. LZETP is the parameter that adjusts for the amount of soil moisture evaporation from bare soil and the current value is above zero.

\section{Rule: DEPFR1.1 Group: Water balance}

Total runoff volume error (_f) is greater than _o (E1)

(simulated total runoff is _, observed total runoff is _), and the difference between simulated and potential ET (_) is less than the difference between simulated and observed flow(_).

To correct this problem: increase DEEPFR 
Explanation: Water budgets for watersheds must consider subsurface losses in addition to surface-water losses at the outlet and evapotranspiration losses. Assuming the estimate for potential ET is good, simulated ET cannot be increased very much. Therefore subsurface losses must be increased and DEEPFR is the only parameter used to roughly estimate those losses.

\section{Rule: DEPFR1.2 Group: Water balance}

Total runoff volume error $(\ldots)$ is greater than _o (E1)

(simulated total runoff is _, observed total runoff is _), and there could be recharge to deeper aquifers.

To correct this problem: increase DEEPFR

Explanation: Water budgets for watersheds must consider subsurface losses in addition to surface-water losses at the outlet and evapotranspiration losses. DEEPFR is the only parameter used to roughly estimate those losses and should be based on a ground-water study of the area.

\section{Rule: DEPFR2.1 Group: Water balance}

Total runoff volume error $(-z)$ is less than - $z$ (

(simulated total runoff is ,, observed total runoff is _), and the simulated recharge to deeper aquifers could be too high, and PERLND \# - has a value for DEEPFR (_) greater than 0.0 .

To correct this problem: decrease DEEPFR

Explanation: Water budgets for watersheds must consider subsurface losses in addition to surface-water losses at the outlet and evapotranspiration losses. DEEPFR is the only parameter used to roughly estimate those losses and should be based on a ground-water study of the area.

\section{Rule: LZSN1.1 Group: Water balance}

Total runoff volume error (_o) is greater than _o (E1)

(simulated total runoff is _, observed total runoff is _), and the difference between simulated and potential ET (_) is greater than the difference between simulated and observed flow (_).

To correct this problem: increase LZSN

Explanation: If potential evapotranspiration and the transpiration factor for vegetal cover (LZETP) are sufficiently high and the subsurface losses are appropriate, then the only way to decrease flow is to increase the storage capacity (LZSN) to provide greater opportunity for evapotranspiration.

\section{Rule: IzSN1.2 Group: Water balance}

The simulated total runoff (_) is greater than the observed (_), and LZSN times 1.5 is below the available water capacity of the soil for the estimated rooting depth. 
To correct this problem: increase LZSN

Explanation: If potential evapotranspiration and the transpiration factor for vegetal cover (LZETP) are sufficiently high and the subsurface losses are appropriate, then the only way to decrease flow is to increase the storage capacity (LZSN) to provide greater opportunity for evapotranspiration.

\section{Rule: LzSN2.1 Group: Water balance}

Total runoff volume error (_o ) is less than - _o (-E1)

(simulated total runoff is _, observed total runoff is _).

To correct this problem: decrease LZSN

Explanation: If potential evapotranspiration and the transpiration factor for vegetal cover (LZETP) are sufficiently low and the subsurface losses are appropriate, then the only way to increase flow is to decrease the storage capacity (LZSN) to provide less opportunity for evapotranspiration.

\section{Rule: LZSN2.2 Group: Water balance}

The simulated total runoff (_) is below the observed (_), and LZSN times 1.5 is above the available water capacity of the soil for the estimated rooting depth.

To correct this problem: decrease LZSN

Explanation: If potential evapotranspiration and the transpiration factor for vegetal cover (LZETP) are sufficiently low and the subsurface losses are appropriate, then the only way to increase flow is to decrease the storage capacity (LZSN) to provide less opportunity for evapotranspiration.

\section{Rule: INFLT3.1 Group: Water balance}

Total runoff volume error (__o) is greater than _o (E1), and the highest $10 \%$ of simulated daily mean flows (_) exceeds observed by more than - times _ $\%(E 9 \times E 4)$, and the lowest $50 \%$ of simulated daily flows (_) is lower than observed (_).

To correct this problem: increase INFILT

Explanation: The major effect of increased infiltration (INFILT) is to shift drainage from rapid response (surface runoff and interflow) to delayed response (base flow). Although INFILT does not have a strong direct influence on water balance, it may be too far off for the other parameters to correct for water-balance errors.

\section{Rule: INFLT3.2 Group: Water balance}

Total runoff volume error (_o 8 ) is greater than _o (E1), and the highest $10 \%$ of simulated daily mean flows (_) exceeds observed (_), and the lowest $50 \%$ of simulated daily mean flows (_) 
is less than observed by more than _ times _o (E9xE3).

To correct this problem: increase INFILT

Explanation: The major effect of increased infiltration (INFILT) is to shift drainage from rapid response (surface runoff and interflow) to delayed response (base flow). Although INFILT does not have a strong direct influence on water balance, it may be too far off for the other parameters to correct for water-balance errors.

\section{Rule: INFLT3.3 Group: Water balance}

The simulated storm runoff volumes tend to be high, and the subsequent simulated base flows are low.

To correct this problem: increase INFILT

Explanation: The major effect of increased infiltration (INFILT) is to shift drainage from rapid response (surface runoff and interflow) to delayed response (base flow). Although INFILT does not have a strong direct influence on water balance, it may be too far off for the other parameters to correct for water-balance errors.

\section{Rule: INFLT4.1 Group: Water balance}

Total runoff volume error (_ 8 ) is greater than _o (E1), and the highest $10 \%$ of simulated daily mean flows (_) is below observed by more than _ times _ $8(\mathrm{E} 9 \times \mathrm{xE})$, and the lowest $50 \%$ simulated flows (_) is greater than observed (_).

To correct this problem: decrease INFILT

Explanation: The major effect of decreased infiltration (INFILT) is to shift drainage from delayed response (base flow) to rapid response (surface runoff and interflow). Although INFILT does not have a strong direct influence on water balance, it may be too far off for the other parameters to correct for water-balance errors.

\section{Rule: INFLT4.2 Group: Water balance}

Total runoff volume error (_f) is greater than _f (E1), and the highest $10 \%$ of simulated daily mean flows (_) is lower than observed (_), and the lowest $50 \%$ of simulated daily mean flows (_) exceeds the observed by more than _ times _f (E9xE3).

To correct this problem: decrease INFILT

Explanation: The major effect of decreased infiltration (INFILT) is to shift drainage from delayed response (base flow) to rapid response (surface runoff and interflow). Although INFILT does not have a strong direct influence on water balance, it may be too far off for the other parameters to correct for water-balance errors.

\section{Rule: INFLT4.3 Group: Water balance}

The simulated storm runoff volumes tend to be low, and 
the subsequent simulated base flows are high.

To correct this problem: decrease INFILT

Explanation: The major effect of decreased infiltration (INFILT) is to shift drainage from delayed response (base flow) to rapid response (surface runoff and interflow). Although INFILT does not have a strong direct influence on water balance, it may be too far off for the other parameters to correct for water-balance errors.

Rule: AGWRC1.1 Group: High-flow - low-flow distribution

The difference (_) between the average value of the daily recession rate " $Q(t) / Q(t-1)$ " during the base-flow period for the simulated flow and that for the observed flow is lower than - $-(-E 2)$.

To correct this problem: increase AGWRC

Explanation: AGWRC is the fraction of yesterday's base flow that runs off today. An increase will "flatten" the base-flow recession.

\section{Rule: AGWRC1.2 Group: High-flow - low-flow distribution}

The simulated winter base flow recedes faster than the observed winter base flow, and the simulated summer base flow recedes faster than the observed summer base flow.

To correct this problem: increase AGWRC

Explanation: AGWRC is the fraction of yesterday's base flow that runs off today. An increase will "flatten" the base-flow recession.

\section{Rule: AGWRC2.1 Group: High-flow - low-flow distribution}

The difference (_) between the average value of the daily recession rate " $Q(t) / Q(t-1)$ " during the base-flow period for the simulated flow and that for the observed flow is greater than _ (E2), and PERLND \# - has a value for AGWRC (_) greater than or equal to 0.88 .

To correct this problem: decrease AGWRC

Explanation: AGWRC is the fraction of yesterday's base flow that runs off today. A decrease will "steepen" the base-flow recession. The value for $A G W R C$ is not too low.

\section{Rule: AGWRC2.2 Group: High-flow - low-flow distribution}

The simulated winter base flow recedes slower than the observed winter base flow, and the simulated summer base flow recedes slower than the observed summer base flow.

To correct this problem: decrease AGWRC

Explanation: AGWRC is the fraction of yesterday's base flow that runs off today. A decrease will "steepen" the base-flow recession. 
The difference (_) between the average value of the daily recession rate " $Q(t) / Q(t-1)$ " during the base-flow period for the simulated flow and that for the observed flow is greater than $-(E 2)$, and PERLND \# - has a value for AGWRC (_) less than 0.88 .

To correct this problem: increase BASETP

Explanation: The base-flow recession constant is so low that decreasing it more would make the flow like interflow. You should consider increasing the effect of transpiration along the channels.

Rule: DEPFR3.1 Group: High-flow - low-flow distribution

The difference (_) between the average value of the daily recession rate "Q(t)/Q(t-1)" during the base-flow period for the simulated flow and that for the observed flow is greater than _ (E2), and PERLND \# - has a value for AGWRC (_) less than 0.88 .

To correct this problem: increase DEEPFR

Explanation: The base-flow recession constant is so low that decreasing it more would make the flow like interflow. You should consider sending drainage from the soil profile to deeper aquifers instead of base flow.

\section{Rule: INFLT1.1 Group: High-flow - low-flow distribution}

The highest $10 \%$ of simulated daily mean flows (_) is more than _o (E4) greater than observed (_), and the lowest $50 \%$ of simulated daily flows (_) is less than observed (_).

To correct this problem: increase INFILT

Explanation: The major effect of increased infiltration (INFILT) is to shift drainage from rapid response (surface runoff and interflow) to delayed response (base flow).

\section{Rule: INFLT1.2 Group: High-flow - low-flow distribution}

The highest $10 \%$ of simulated daily mean flows (_) is greater than observed (_), and the lowest $50 \%$ of simulated daily mean flows (_) is more than _o (E3) less than observed (_).

To correct this problem: increase INFILT

Explanation: The major effect of increased infiltration (INFILT) is to shift drainage from rapid response (surface runoff and interflow) to delayed response (base flow).

\section{Rule: INFLT1.3 Group: High-flow - low-flow distribution}

The simulated storm runoff volumes tend to be high, and the subsequent simulated base flows are low.

To correct this problem: increase INFILT 
Explanation: The major effect of increased infiltration (INFILT) is to shift drainage from rapid response (surface runoff and interflow)

to delayed response (base flow).

Rule: INFLT2.1 Group: High-flow - low-flow distribution

The highest $10 \%$ of simulated daily mean flows (_) is

more than _\% (E4) less than observed (_), and the lowest $50 \%$

of simulated mean daily flows (_) is greater than observed (_).

To correct this problem: decrease INFILT

Explanation: The major effect of decreased infiltration (INFILT) is to shift drainage from delayed response (base flow) to rapid response (surface runoff and interflow).

Rule: INFLT2.2 Group: High-flow - low-flow distribution

The highest $10 \%$ of simulated daily mean flows (_) is less than observed (_), and the lowest $50 \%$ of simulated daily mean flows (_) is more than _o (E3) greater than observed (_).

To correct this problem: decrease INFILT

Explanation: The major effect of decreased infiltration (INFILT) is to shift drainage from delayed response (base flow) to rapid response (surface runoff and interflow).

\section{Rule: INFIT2.3 Group: High-flow - low-flow distribution}

The simulated storm runoff volumes tend to be low, and

the subsequent simulated base flows are high.

To correct this problem: decrease INFILT

Explanation: The major effect of decreased infiltration (INFILT) is to shift drainage from delayed response (base flow) to rapid response (surface runoff and interflow).

\section{Rule: LzSN3.1 Group: High-flow - low-flow distribution}

The highest $10 \%$ of simulated daily mean flows (_) is less than _o (E4) less than observed (_), and the lowest $50 \%$ of simulated daily mean flows (_) is more than _o (E3) greater than observed (_).

To correct this problem: increase LZSN

Explanation: If potential evapotranspiration and the transpiration factor for vegetal cover (LZETP) are sufficiently high and the subsurface losses are appropriate, then the only way to decrease flow is to increase the storage capacity (LZSN) to provide greater opportunity for evapotranspiration. 
Rule: LzSN3.2

The highest $10 \%$ of simulated daily mean flows (_) is more than _ $\%$ (E4) greater than observed (_), and the lowest $50 \%$ of simulated daily mean flows (_) is less than _o (E3) less than observed (_).

To correct this problem: increase LZSN

Explanation: If potential evapotranspiration and the transpiration factor for vegetal cover (LZETP) are sufficiently high and the subsurface losses are appropriate, then the only way to decrease flow is to increase the storage capacity (LZSN) to provide greater opportunity for evapotranspiration.

\section{Rule: LZSN3.3 Group: High-flow - low-flow distribution}

The simulated total winter flow is the same or greater than observed, and the simulated total summer flow is lower than observed.

To correct this problem: increase LZSN

Explanation: If potential evapotranspiration and the transpiration factor for vegetal cover (LZETP) are sufficiently high and the subsurface losses are appropriate, then the only way to decrease flow is to increase the storage capacity (LZSN) to provide greater opportunity for evapotranspiration.

\section{Rule: LzSN4.1 Group: High-flow - low-flow distribution}

The highest $10 \%$ of simulated daily mean flows (_)

is less than _ $\%$ (E4) greater than observed (_), and the lowest $50 \overline{\%}$ of simulated daily mean flows (_) is more than _o (E3) less than observed (_).

To correct this problem: decrease LZSN

Explanation: If potential evapotranspiration and the transpiration factor for vegetal cover (LZETP) are sufficiently low and the subsurface losses are appropriate, then the only way to increase flow is to decrease the storage capacity (LZSN) to provide less opportunity for evapotranspiration.

\section{Rule: LZSN4.2 Group: High-flow - low-flow distribution}

The highest $10 \%$ of simulated daily mean flows (_) is more than $z$ (E4) less than observed (_), and the lowest $50 \%$ of simulated daily mean flows (_) is less than _o (E3) greater than observed (_).

To correct this problem: decrease LZSN

Explanation: If potential evapotranspiration and the transpiration factor for vegetal cover (LZETP) are sufficiently low and the subsurface losses are appropriate, then the only way to increase flow is to decrease the storage capacity (LZSN) to provide less opportunity for evapotranspiration. 


\section{Rule: LZSN4.3 Group: High-flow - low-flow distribution}

The simulated total winter flow

is the same or lower than observed, and

the simulated total summer flow is greater than observed.

To correct this problem: decrease LZSN

Explanation: If potential evapotranspiration and the transpiration factor for vegetal cover (LZETP) are sufficiently low and the subsurface losses are appropriate, then the only way to increase flow is to decrease the storage capacity (LZSN) to provide less opportunity for evapotranspiration.

\section{Rule: INFLT5.1 Group: Stormflow}

Peak stormflow error (_- 8 ) is greater than _o (E5)

(simulated peak stormflow is _, observed peak stormflow is _), and absolute value of the storm volume error (_- 8 )

is greater than -8 (E5), and

the simulated storm volume (_) is greater than the observed (_).

To correct this problem: increase INFILT

Explanation: The major effect of increased infiltration (INFILT) is to shift drainage from rapid response (surface runoff and interflow) to delayed response (base flow), thus decreasing both simulated storm volumes and simulated storm peaks.

\section{Rule: INFLT6.1 Group: Stormflows}

Peak stormflow error (_- 8 ) is less than - _o (-E5)

(simulated peak stormflow is _, observed peak stormflow is _), and absolute value of the storm volume error (_o )

is greater than -8 (E5), and

the simulated storm volume (_) is less than the observed (_).

To correct this problem: decrease INFILT

Explanation: The major effect of decreased infiltration (INFILT) is to shift drainage from delayed response (base flow) to rapid response (surface runoff and interflow), thus increasing both simulated storm volumes and simulated storm peaks.

\section{Rule: INTFW1.1 Group: Stormflows}

Peak stormflow error (_o is greater than_o (E5)

(simulated peak stormflow is _, observed peak stormflow is _), and interflow (_) is less than _ (E6) times the surface runoff (_), and absolute value of the storm volume error (_o ) is less than _o (E5) (simulated storm volume is _, observed storm volume is _).

To correct this problem: increase INTFW

Explanation: Runoff needs to be shifted from surface runoff to interflow to put the water in a slower drainage category. If IRC is too low, however, interflow will respond like surface runoff and the increase in INTFW will have little effect. 


\section{Rule: INTFW1.2 Group: Stormflows}

Peak stormflow error (_z) is greater than _o (E5)

(simulated peak stormflow is ,, observed peak stormflow is _), and interflow (_) is less than _ (E6) times the surface runoff (_), and absolute value of the storm volume error (_o)

is greater than $-\%$ (E5), and

the simulated storm volume (_) is less than observed (_).

To correct this problem: increase INTFW

Explanation: Runoff needs to be shifted from surface runoff to interflow to put the water in a slower drainage category. If IRC is too low, however, interflow will respond like surface runoff and the increase in INTFW will have little effect.

\section{Rule: INTFW1.3 Group: Stormflows}

Peak stormflow error (_o $\%$ ) is greater than _o (E5)

(simulated peak stormflow is _, observed peak stormflow is _), and interflow (_) is more than _ (E6) times the surface runoff (_), and absolute value of the storm volume error (__o) is less than _o (E5) (simulated storm volume is _, observed storm volume is _), and PERLND \# - has values for IRC (_) $>0.6$ and INTFW (_) $<7.5$.

To correct this problem: increase INTFW

Explanation: Runoff needs to be shifted from surface runoff to interflow to put the water in a slower drainage category. If IRC is too low, however, interflow will respond like surface runoff and the increase in INTFW will have little effect.

\section{Rule: INTFW1.4 Group: Stormflows}

Peak stormflow error (__\%) is greater than _o (E5)

(simulated peak stormflow is _., observed peak stormflow is _), and interflow (_) is more than _ (E6) times the surface runoff (_), and absolute value of the storm volume error (__o) is greater than _o (E5) (simulated storm volume is _, observed storm volume is _), and PERLND \# - has values for IRC (_) $>0.6$ and INTFW (_) $<7.5$.

To correct this problem: increase INTFW

Explanation: Runoff needs to be shifted from surface runoff to interflow to put the water in a slower drainage category. If IRC is too low, however, interflow will respond like surface runoff and the increase in INTFW will have little effect.

\section{Rule: INTFW1.5 Group: Stormflows}

The simulated volume of runoff for major storms is about right and the peaks are greater than observed, and

PERLND \# - has a value for IRC (_) greater than 0.6 .

To correct this problem: increase INTFW

Explanation: Runoff needs to be shifted from surface runoff to 
interflow to put the water in a slower drainage category. If IRC is too low, however, interflow will respond like surface runoff and the increase in INTFW will have little effect.

\section{Rule: INTFW2.1 Group: Stormflows}

Peak stormflow error $(-q)$ is less than - $-q(-$ E5)

(simulated peak stormflow is _, observed peak stormflow is _), and interflow (_) is less than _ (E6) times the surface runoff (_), and absolute value of the storm volume error (_z) is less than _o (E5) (simulated storm volume is _, observed storm volume is _).

To correct this problem: decrease INTFW

Explanation: Runoff needs to be shifted from interflow to surface runoff to put the water in a faster drainage category. If IRC is too low, however, interflow will respond like surface runoff and the decrease in INTFW will have little effect on the peak.

\section{Rule: INTFW2.2 Group: Stormflows}

Peak stormflow error $(-\%)$ is less than - _ $\%$ (-E5)

(simulated peak stormflow is _, observed peak stormflow is _), and interflow (_) is less than _ (E6) times the surface runoff (_), and absolute value of the storm volume error (_o )

is greater than $-\%$ (E5), and

the simulated storm volume (_) is greater than observed (_).

To correct this problem: decrease INTFW

Explanation: Runoff needs to be shifted from interflow to surface runoff to put the water in a faster drainage category. If IRC is too low, however, interflow will respond like surface runoff and the decrease in INTFW will have little effect on the peak.

\section{Rule: INTFW2.3 Group: Stormflows}

Peak stormflow error $(-\%)$ is less than - $\%$ (-E5)

(simulated peak stormflow is _, observed peak stormflow is _), and interflow (_) is more than _ (E6) times the surface runoff (_), and absolute value of the storm volume error (_o) is less than _\% (E5) (simulated storm volume is _, observed storm volume is _), and PERLND \# - has values for IRC (_) $<0.4$ and INTFW (_) $>1.0$.

To correct this problem: decrease INTFW

Explanation: Runoff needs to be shifted from interflow to surface runoff to put the water in a faster drainage category. If IRC is too low, however, interflow will respond like surface runoff and the decrease in INTFW will have little effect on the peak.

\section{Rule: INTFW2.4 Group: Stormflows}

Peak stormflow error (_o) is less than - $\%(-E 5)$

(simulated peak stormflow is _, observed peak stormflow is _), and interflow (_) is more than _ (E6) times the surface runoff (_), and 
absolute value of the storm volume error (_ 8 ) is greater than _ 8

(simulated storm volume is -, observed storm volume is _), and

PERLND \# - has values for IRC $\left(_{-}\right)<0.4$ and INTFW (_) $>1.0$.

To correct this problem: decrease INTFW

Explanation: Runoff needs to be shifted from interflow to surface runoff to put the water in a faster drainage category. If IRC is too low, however, interflow will respond like surface runoff and the decrease in INTFW will have little effect on the peak.

\section{Rule: INTFW2.5 Group: Stormflows}

The simulated volume of runoff for major storms is about right and the peaks are lower than observed, and PERLND \# - has a value for IRC (_) less than 0.4.

To correct this problem: decrease INTFW

Explanation: Runoff needs to be shifted from interflow to surface runoff to put the water in a faster drainage category. If IRC is too low, however, interflow will respond like surface runoff and the decrease in INTFW will have little effect on the peak.

\section{Rule: IRC1.1 Group: Stormflows}

Peak stormflow error (_o ) is less than - 8 (-E5)

(simulated peak stormflow is _, observed peak stormflow is _), and interflow (_) is more than _ (E6) times the surface runoff (_), and absolute value of the storm volume error $(-8)$ is less than -8 (E5) (simulated storm volume is , observed storm volume is _), and PERLND \# - has a value for IRC (_) > 0.4, or PERLND \# - has values for IRC (_) $>0.3$ and INTFW (_) $<=$ to 1.0 .

To correct this problem: decrease IRC

Explanation: Simulated peak flows for the storms are too low and most of the storm runoff is interflow. Because IRC values are not too low and the time required for interflow to drain following a storm is regulated with the parameter IRC, a decrease in IRC should increase peak flows.

\section{Rule: IRC1.2 Group: Stormflows}

Peak stormflow error (_o ) is less than - -8 (-E5)

(simulated peak stormflow is _, observed peak stormflow is _), and interflow (_) is more than - (E6) times the surface runoff (_), and absolute value of the storm volume error (_8) is greater than _o (E5) (simulated storm volume is _, observed storm volume is _), and PERLND \# - has a value for IRC (_) > 0.4 , or PERLND \# has values for IRC $\left({ }_{-}\right)>0.3$ and INTFW $($ ) $<=$ to 1.0 .

To correct this problem: decrease IRC

Explanation: Simulated peak flows for the storms are too low and most of the storm runoff is interflow. Because IRC values are not too low and the time required for interflow to drain following a storm is 
regulated with the parameter IRC, a decrease in IRC should increase peak flows.

\section{Rule: IRC1.3 Group: Stormflows}

The recession tails of simulated storm hydrographs recede slower than the recession tails of observed storm hydrographs, and the simulated peak flow is lower than observed.

To correct this problem: decrease IRC

Explanation: Simulated peak flows for the storms are too low and a decrease in IRC should steepen the recession and increase peak flows.

\section{Rule: IRC1.4 Group: stormflows}

The simulated volume of runoff for major storms is about right and the peaks are lower than observed, and PERLND \# - has a value for IRC (_) greater than 0.4.

To correct this problem: decrease IRC

Explanation: Simulated peak flows for the storms are too low and a decrease in IRC should steepen the recession and increase peak flows without a change in volume.

\section{Rule: IRC2.1 Group: Stormflows}

Peak stormflow error (_o ) is greater than _o (E5)

(simulated peak stormflow is _, observed peak stormflow is _), and interflow (_) is more than - (E6) times the surface runoff (_), and absolute value of the storm volume error (_z) is less than _o (E5) (simulated storm volume is _, observed storm volume is _), and PERLND \# - has a value for IRC (_) $<0.6$, or

PERLND \# - has values for IRC (_) $<0.7$ and INTFW (_) $>=7.5$.

To correct this problem: increase IRC

Explanation: Simulated peak flows for the storms are too high and most of the storm runoff is interflow. Because IRC values are not too high and the time required for interflow to drain following a storm is regulated with the parameter IRC, an increase in IRC should decrease peak flows.

\section{Rule: IRC2.2 Group: Stormflows}

Peak stormflow error $\left(-\frac{q}{8}\right)$ is greater than _o (E5)

(simulated peak stormflow is _, observed peak stormflow is _), and interflow (_) is more than - (E6) times the surface runoff (_), and absolute value of the storm volume error (_o) is greater than _o (E5) (simulated storm volume is _, observed storm volume is _), and PERLND \# - has a value for IRC (_) $<0.6$, or PERLND \# - has values for IRC (_) $<0.7$ and INTFW (_) $>=$ to 7.5 . To correct this problem: increase IRC 
Explanation: Simulated peak flows for the storms are too high and most of the storm runoff is interflow. Because IRC values are not too high and the time required for interflow to drain following a storm is regulated with the parameter IRC, an increase in IRC should decrease peak flows.

\section{Rule: IRC2.3 Group: Stormflows}

The recession tails of the simulated storm hydrographs recede faster than the recession tails of the observed storm hydrographs, and the simulated peak flow is greater than observed.

To correct this problem: increase IRC

Explanation: Simulated peak flows for the storms are too high and an increase in IRC should flatten the recession and decrease peak flows.

\section{Rule: IRC2.4 Group: Stormflows}

The simulated volume of runoff for major storms is about right and the peaks are greater than observed, and PERLND \# - has a value for IRC (_) less than 0.6 .

To correct this problem: increase IRC

Explanation: Simulated peak flows for the storms are too high and an increase in IRC should flatten the recession and decrease peak flows without a change in volume.

\section{Rule: KVARY1.1 Group: Seasonal}

Simulated base flow during wet periods recedes more slowly than the observed base flow, or simulated winter base flow recedes more slowly than the observed winter base flow; and simulated summer base flow recedes faster than the observed summer base flow, or simulated base flow during dry periods recedes faster than the observed base flow during dry periods.

To correct this problem: increase KVARY, decrease BASETP if there is channel or flood-plain vegetation, or decrease AGWETP if vegetation roots reach the ground-water table.

Explanation: KVARY has the effect of shifting base-flow drainage from drier periods (no recharge) to shortly after wet periods (recent recharge). It accounts for greater contributing area immediately following a storm period. Evapotranspiration from the ground-water storage (AGWETP) or from the base flow at the channel (BASETP) has a greater impact during the summer than the winter, which gives the effect of a steeper recession in the summer.

\section{Rule: KVARY2.1 Group: Seasonal}

Simulated base flow during wet periods recedes faster than the observed base flow, or winter base flow recedes faster than the observed winter base flow; and simulated summer base flow recedes more slowly than the observed summer base flow, or simulated base flow during dry periods recedes more slowly than the observed base flow during dry periods. 
To correct this problem: decrease KVARY, or increase BASETP if there is channel or flood-plain vegetation, or increase AGWETP if vegetation roots reach the ground-water table.

Explanation: KVARY has the effect of shifting base-flow drainage from drier periods (no recharge) to shortly after wet periods (recent recharge). It accounts for greater contributing area immediately following a storm period. Evapotranspiration from the ground-water storage (AGWETP) or from the base flow at the channel (BASETP) has a greater impact during the summer than the winter, which gives the effect of a steeper recession in the summer.

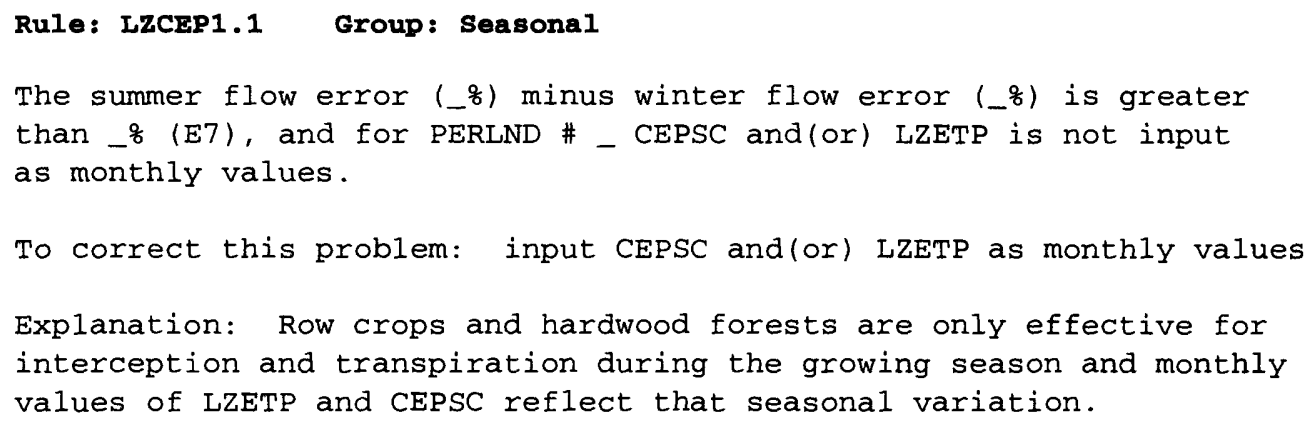

Rule: LZCEP1.2 Group: Seasonal

For PERLND \#, the vegetation type is forest, mixed, or crop, and CEPSC and(or) LZETP is not input as monthly values.

To correct this problem: input CEPSC and(or) LZETP as monthly values

Explanation: Row crops and hardwood forests are only effective for interception and transpiration during the growing season and monthly values of LZETP and CEPSC reflect that seasonal variation.

\section{Rule: UzSN1.1 Group: Seasonal}

The average summer flow error (_o) minus the average winter flow error (_z) is less than - _o $(-E 7)$.

To correct this problem: decrease UZSN

Explanation: Surface storage in depressions and the upper few inches of soil or forest litter remain near capacity in winter so that the value of this storage (UZSN) has minimal effect in winter but a much larger influence in summer where losses for UzS are at or near the potential evapotranspiration.

\section{Rule: UZSN1.2 Group: Seasonal}

Storms with little antecedent rain (dry periods) are simulated low, and storms with more antecedent rain (wet periods) are simulated high.

To correct this problem: decrease UZSN

Explanation: Surface storage in depressions and the upper few 
inches of soil or forest litter remain near capacity in winter so that the value of this storage (UZSN) has minimal effect in winter but a much larger influence in summer where losses for UzS are at or near the potential evapotranspiration.

\section{Rule: UZSN2.1 Group: Seasonal}

The average summer flow error (_ ( $\left.\frac{\circ}{\circ}\right)$ minus

the average winter flow error ( $\left(-\frac{\%}{0}\right)$ is more than _o (E7).

To correct this problem: increase UZSN

Explanation: Surface storage in depressions and the upper few inches of soil or forest litter remain near capacity in winter so that the value of this storage (UZSN) has minimal effect in winter but a much larger influence in summer where losses for UzS are at or near the potential evapotranspiration.

\section{Rule: UZSN2.2 Group: Seasonal}

Storms with little antecedent rain (dry periods) are simulated high, and storms with more antecedent rain (wet periods) are simulated low.

To correct this problem: increase UZSN

Explanation: Surface storage in depressions and the upper few inches of soil or forest litter remain near capacity in winter so that the value of this storage (UZSN) has minimal effect in winter but a much larger influence in summer where losses for UzS are at or near the potential evapotranspiration.

\section{Rule: BSETP1.1 Group: Seasonal}

Observed base flow increases in the fall and the simulated base flow does not, and there was no substantial rainfall.

To correct this problem: increase BASETP

Explanation: Although subsurface drainage to the channels takes place during the summer, the vegetation around the channels is transpiring much of the water; as transpiration drops off in the fall, the flows will increase with no additional rainfall.

\section{Rule: BSETP2.2 Group: Seasonal}

Observed base flow decreases in the fall and the simulated base flow does not, and there was no substantial rainfall, and PERLND \# - has a value for BASETP (_) greater than 0.0.

To correct this problem: decrease BASETP

Explanation: Although subsurface drainage to the channels takes place during the summer, the vegetation around the channels is transpiring much of the water; as transpiration drops off in the fall, the flows will increase with no additional rainfall. 


\section{Rule: PRIMP1.1 Group: Seasonal}

The difference (_o ) between simulated and observed

high flow during the summer months is greater than _o (E8)

(simulated summer high flow is _, observed summer high flow is _).

To correct this problem: increase PERLND area and

decrease IMPLND area by a corresponding amount.

Explanation: The most detectable effect from urban area

(impervious area) on streamflow is an increase in stormflows

during hot, dry periods usually in the summer.

\section{Rule: PRIMP1.2 Group: Seasonal}

The simulated high flow during summer months is greater than observed, and there are urban areas in the watershed, and

the amount of IMPLND area might have been estimated high.

To correct this problem: increase PERLND area and

decrease IMPLND area by a corresponding amount.

Explanation: The most detectable effect from urban area

(impervious area) on streamflow is an increase in stormflows

during hot, dry periods usually in the summer.

\section{Rule: PRIMP2.1 Group: Seasonal}

The difference (_o ) between simulated and observed

high flow during the summer months is less than -

(simulated summer high flow is _, observed summer high flow is _).

To correct this problem: decrease PERLND area and

increase IMPLND area by a corresponding amount.

Explanation: The most detectable effect from urban area

(impervious area) on streamflow is an increase in stormflows

during hot, dry periods usually in the summer.

\section{Ru1e: PRIMP2.2 Group: Seasonal}

The simulated high flow during summer months is lower than observed, and there are urban areas in the watershed, and

the amount of IMPLND area might have been estimated low.

To correct this problem: decrease PERLND area and

increase IMPLND area by a corresponding amount.

Explanation: The most detectable effect from urban area (impervious area) on streamflow is an increase in stormflows

during hot, dry periods usually in the summer. 


\section{APPENDIX B. USER SYSTEM SPECIFICATIONS FILE}

\section{TERM.DAT}

The TERM.DAT file contains a number of parameters that define the configuration of the user's computer system and the user's preferences. All of these parameters default to a value that is considered most appropriate for the user's computer system. Any number of these defaults can be overridden by adding a TERM.DAT file to the directory where the program is being run. The first time the program needs any one of these parameters, they are read from the main message file. Then the user's TERM.DAT file is read, if it exists, and the parameters found replace the defaults from the message file. All of the parameters are saved for the duration of the run. Table B.1 lists the keyword, default value, allowable values, and the definition for each parameter. Table B.2 is the TERM.DAT parameters specifically for MS-DOS PC with color display only. Table B.3 is the TERM.DAT parameters for graphics options. Table B.4 shows a TERM.DAT file that modifies the background color of the graphics window from the default of black to a shade of purple. The keyword starts in column 1 and the value starts in column 8 .

Many of the parameters depend on the implementation of GKS and give the user the opportunity to change or correct colors, line types, symbol types, symbol sizes, background color, text fonts, and graphics devices. With most implementations of GKS, text may be modified with the parameters GKPREC, GKSCFT, GKPRFT, GKPLFT, TXTEXF, and TXTCHS. Background color on color monitors can be changed using parameters BCOLOR or BGRED, BGREEN, and BGBLUE. Symbol size can be modified with the parameter SYSSIZ. Eight parameters are available to reset the default code numbers for each of the curve specification, line type, symbol, color, and pattern. All code numbers should be available in the GKS documentation for workstations or device drivers.

Table B.1. TERM.DAT parameters for general use

\begin{tabular}{|c|c|c|c|}
\hline $\begin{array}{l}\text { Parameter } \\
\text { keyword }\end{array}$ & $\begin{array}{c}\text { Default } \\
\text { value }\end{array}$ & $\begin{array}{c}\text { Allowable } \\
\text { values }\end{array}$ & Definition \\
\hline TRMTYP & $\mathrm{PC}$ & $\begin{array}{l}\text { PC } \\
\text { VT100 }\end{array}$ & Terminal type. \\
\hline GRAPHS & YES & $\begin{array}{l}\text { NO } \\
\text { YES }\end{array}$ & Are GKS library and drivers available? \\
\hline USRLEV & 0 & 0 to 2 & User experience level 0 -lots, $2=$ none. \\
\hline
\end{tabular}

Table B.2. TERM.DAT parameters for color display (MS-DOS PC)

\begin{tabular}{llll}
\hline $\begin{array}{c}\text { Parameter } \\
\text { keyword }\end{array}$ & $\begin{array}{c}\text { Default } \\
\text { value }\end{array}$ & $\begin{array}{c}\text { Allowable } \\
\text { values }\end{array}$ & \multicolumn{1}{c}{ Definition } \\
\hline CLRFRM & 15 & 0 to 15 & Color of text for messages related to parameter input. \\
CLRFRT & 11 & 0 to 15 & Color of titles and headers for full screen. \\
CLRFRL & 13 & 0 to 15 & Color of limits for parameters. \\
CLRFRE & 4 & 0 to 15 & Color for error messages. \\
CLRFRC & 14 & 0 to 15 & Color for user input on command line. \\
CLRFRP & 7 & 0 to 15 & Color for protected data values. \\
CLRFRD & 15 & 0 to 15 & Color for data to be modified. \\
CLRFRN & 14 & 0 to 15 & Color of data to be modified when currently none. \\
CLRFRS & 7 & 0 to 15 & Standard color except for full screen. \\
CLRBKO & 2 & 0 to 15 & Color of border. \\
CLRBKB & 1 & 0 to 15 & Color of background for full screen. \\
CLRBKS & 0 & 0 to 15 & Standard background color. \\
CLRBKD & 0 & 0 to 15 & Color of background block for data to be modified. \\
\hline
\end{tabular}


Table B.3. TERM.DAT parameters for graphics options

\begin{tabular}{|c|c|c|c|c|c|}
\hline \multirow[b]{2}{*}{$\begin{array}{l}\text { Parameter } \\
\text { keyword }\end{array}$} & \multicolumn{3}{|c|}{ Default values } & \multirow[b]{2}{*}{$\begin{array}{l}\text { Allowable } \\
\text { values }\end{array}$} & \multirow[b]{2}{*}{ Definition } \\
\hline & DG & PC & UNIX & & \\
\hline \multicolumn{6}{|c|}{ See the GKS implementation manual for your system or ask your GKS administrator for a list of supported codes. } \\
\hline GKSDIS & 4107 & & & any & GKS code number for workstation type for display terminal. \\
\hline GKSPRT & 102 & & & any & GKS code number for workstation type for printer device. \\
\hline GKSPLT & 9012 & & & any & GKS code number for workstation type for pen plotter. \\
\hline GKSMET & 9005 & & & any & GKS code number for metafile. \\
\hline GKSDSP & 102 & & & any & DISSPLA metafile code number. \\
\hline GKPREC & CHAR & & & $\begin{array}{l}\text { STRING } \\
\text { CHAR } \\
\text { STROKE }\end{array}$ & $\begin{array}{l}\text { Text precision, see GKS manual for computer system and device } \\
\text { type. }\end{array}$ \\
\hline GKSCFT & l & & & -9999 to 9999 & Text font for screen. \\
\hline GKPRFT & 1 & & & -9999 to 9999 & Text font for printer. \\
\hline GKPLFT & 1 & & & -9999 to 9999 & Text font for plotter. \\
\hline LSOLID & 1 & & & -9999 to 9999 & Code for solid line. \\
\hline LDASH & 2 & & & -9999 to 9999 & Code for dashed line. \\
\hline LDOT & 3 & & & -9999 to 9999 & Code for dotted line. \\
\hline LMIXED & 4 & & & -9999 to 9999 & Code for dot dashed line. \\
\hline 1LUSER & 1 & & & -9999 to 9999 & Extra line type code. \\
\hline 2LUSER & 1 & & & -9999 to 9999 & Extra line type code. \\
\hline 3LUSER & 1 & & & -9999 to 9999 & Extra line type code. \\
\hline 4LUSER & 1 & & & -9999 to 9999 & Extra line type code. \\
\hline CBLACK & 1 & & & -9999 to 9999 & Code for black. \\
\hline CWHITE & 2 & & & -9999 to 9999 & Code for white. \\
\hline CRED & 3 & & & -9999 to 9999 & Code for red. \\
\hline CGREEN & 4 & & & -9999 to 9999 & Code for green. \\
\hline CBLUE & 5 & & & -9999 to 9999 & Code for blue. \\
\hline CCYAN & 6 & & & -9999 to 9999 & Code for cyan. \\
\hline CMAGNT & 7 & & & -9999 to 9999 & Code for magenta. \\
\hline CYELLOW & 8 & & & -9999 to 9999 & Code for yellow. \\
\hline CDOT & 1 & & & -9999 to 9999 & Symbol code for dot. \\
\hline CPLUS & 2 & & & -9999 to 9999 & Symbol code for plus. \\
\hline CSTAR & 3 & & & -9999 to 9999 & Symbol code for star. \\
\hline CZERO & 4 & & & -9999 to 9999 & Symbol code for circle. \\
\hline $\mathrm{CX}$ & 5 & & & -9999 to 9999 & Symbol code for $\mathrm{X}$. \\
\hline ISUSER & 1 & & & -9999 to 9999 & Extra symbol code. \\
\hline 2SUSER & 1 & & & -9999 to 9999 & Extra symbol code. \\
\hline PSOLID & 2 & & & -9999 to 9999 & Code for solid fill area. \\
\hline PHORIZ & 3 & & & -9999 to 9999 & Code for horizontal fill area. \\
\hline PVERT & 4 & & & -9999 to 9999 & Code for vertical fill area. \\
\hline PDIAG & 5 & & & -9999 to 9999 & Code for diagonal fill area. \\
\hline 1PUSER & 1 & & & -9999 to 9999 & Extra fill code. \\
\hline 2PUSER & 1 & & & -9999 to 9999 & Extra fill code. \\
\hline 3PUSER & 1 & & & -9999 to 9999 & Extra fill code. \\
\hline 4PUSER & 1 & & & -9999 to 9999 & Extra fill code. \\
\hline SYMSIZ & 100 & & & 1 to 10000 & Symbol size ratio in hundredths. \\
\hline TXTEXF & 0 & & & 0 to 200 & Text expansion factor in hundredths. \\
\hline TXTCHS & 0 & & & 0 to 200 & Text character spacing in hundredths. \\
\hline
\end{tabular}


Table B.3. TERM.DAT parameters for graphics options--Continued

\begin{tabular}{|c|c|c|c|c|c|}
\hline \multirow[b]{2}{*}{$\begin{array}{c}\text { Parameter } \\
\text { keyword }\end{array}$} & \multicolumn{3}{|c|}{ Default values } & \multirow[b]{2}{*}{$\begin{array}{l}\text { Allowable } \\
\text { values }\end{array}$} & \multirow[b]{2}{*}{ Definition } \\
\hline & DG & PC & UNIX & & \\
\hline$\overline{B C O L O R}$ & BLACK & & & $\begin{array}{l}\text { BLACK } \\
\text { WHITE } \\
\text { OTHER }\end{array}$ & Background color. \\
\hline BGRED & 0 & & & 0 to 100 & Percent red for background if BCOLOR=OTHER. \\
\hline BGREEN & 0 & & & 0 to 100 & Percent green for background if $B C O L O R=O T H E R$. \\
\hline BGBLUE & 0 & & & 0 to 100 & Percent blue for background if $\mathrm{BCOLOR=OTHER.}$ \\
\hline
\end{tabular}

Table B.4. Example TERM.DAT

\begin{tabular}{ll}
\hline \multicolumn{1}{c}{ File contents } & \multicolumn{1}{c}{$\begin{array}{c}\text { Description } \\
\text { (Note: description is not part of file) }\end{array}$} \\
\hline BCOLOR OTHER & Background color is other \\
BGBLUE 60 & Percent blue is 60 \\
BGRED 40 & Percent red is 40 \\
BGREEN 0 & Percent green is 0 \\
\hline
\end{tabular}




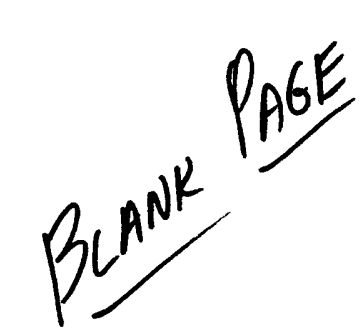




\section{APPENDIX C. LOG FILE INTERPRETATIONS}

A file named HSPEXP.LOG is created each time the HSPEXP program is run. This file contains a record of all of the user's keystrokes. To make the log file easier to interpret, it is suggested that menu selections be made by entering the first character of an option, instead of the arrow keys, followed by F2. Keystrokes are chained together on a line until a nonprinting, special character, such as a function key (or arrow key or return), is pressed. Table C.1 contains a list of the codes used in a log file for the nonprinting characters.

Table C.1. Codes used for nonprinting characters in a log file

\begin{tabular}{cc}
\hline Code & Users \\
keystrokes
\end{tabular}




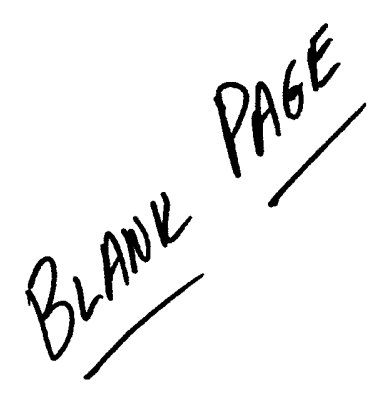

98 


\section{APPENDIX D. HSPEXP ATTRIBUTES}

\begin{tabular}{|c|c|c|c|c|c|c|}
\hline \multirow[b]{2}{*}{ Name } & \multirow[b]{2}{*}{ Type } & \multirow[b]{2}{*}{ Length } & \multirow[b]{2}{*}{ Update } & \multicolumn{2}{|c|}{ Data-set type } & \multirow[b]{2}{*}{ Description } \\
\hline & & & & Time & Table & \\
\hline ACODE & Int & 1 & Yes & Opt & $\mathrm{Opt}$ & Area units code, user defined. \\
\hline AGENCY & Char & 8 & Yes & Opt & Opt & Agency code. See WATSTORE users manual, volume 1, chapter 3. \\
\hline BASEQ & Real & 1 & Yes & Opt & Opt & $\begin{array}{l}\text { Base discharge, in cubic feet per second. See WATSTORE users } \\
\text { manual, volume } 1 \text {, chapter } 3 \text {. }\end{array}$ \\
\hline BLNGTH & Real & 1 & Yes & Opt & Opt & $\begin{array}{l}\text { Stream length, in miles, from gage to end of defined channel, blue line } \\
\text { on topographic map. }\end{array}$ \\
\hline BRANCH & Real & 1 & Yes & Opt & Opt & lnteger id number of a channel segment. \\
\hline BSLOPE & Real & 1 & Yes & Opt & Opt & Average basin slope, in feet per mile. \\
\hline CHEAT & Int & 1 & Yes & Opt & Opt & Pointer to an associated data set. \\
\hline COCODE & Int & 1 & Yes & Opt & Opt & County or parish code. See WATSTORE users manual, Appendix C. \\
\hline COMPFG & Int & 1 & No & Opt & No & $\begin{array}{l}\text { Compression flag } \\
\text { I - yes, data are compressed (default) } \\
2 \text { - no, data are not compressed } \\
\text { Compressed data will take up less space in the WDM file but may } \\
\text { require a COPY operation to update data values. }\end{array}$ \\
\hline CONTDA & Real & 1 & Yes & Opt & Opt & Drainage area, in square miles, that contributes to surface runoff. \\
\hline DAREA & Real & 1 & Yes & Opt & Opt & Total drainage area, in square miles, including noncontributing areas. \\
\hline DATUM & Real & 1 & Yes & Opt & Opt & Reference elevation, to mean sea level. \\
\hline DCODE & Int & 1 & Yes & Opt & Opt & Attribute DCODE. \\
\hline DEPH25 & Real & 1 & Yes & Opt & Opt & $\begin{array}{l}\text { Flow depth, in feet. Corresponding to the difference between the } 25 \text { - } \\
\text { percent flow duration gage height and point of zero flow. }\end{array}$ \\
\hline DEPTH & Real & 1 & Yes & Opt & Opt & Sampling depth, in feet, at which observation was made. \\
\hline DESCRP & Char & 80 & Yes & Opt & Opt & $\begin{array}{l}\text { Data-set description. Might include name and/or location, or some } \\
\text { anedotal information. }\end{array}$ \\
\hline DSCODE & Int & 1 & Yes & Opt & Opt & $\begin{array}{l}\text { State code of the Geological Survey office that operates the station. } \\
\text { Usually the same as the state code (STPIPS). See WATSTORE users } \\
\text { manual, Appendix B. }\end{array}$ \\
\hline EL1085 & Real & 1 & Yes & Opt & Opt & $\begin{array}{l}\text { Average of channel elevations, in feet above mean sea level, at points } 10 \\
\text { and } 85 \text { percent of stream length upstream from gage. }\end{array}$ \\
\hline ELEV & Real & 1 & Yes & $\mathrm{Opt}$ & Opt & Elevation (mean sea level) \\
\hline FOREST & Real & 1 & Yes & Opt & Opt & $\begin{array}{l}\text { Forested area, in percent of contributing drainage area, measured by the } \\
\text { grid sampling methods. }\end{array}$ \\
\hline FROST & Real & 1 & Yes & Opt & Opt & Mean frost depth on February 28, in inches. \\
\hline GCODE & Int & 1 & Yes & Opt & Opt & Angle (slope) code, user defined. \\
\hline GLACER & Real & 1 & Yes & Opt & Opt & Area of glaciers, in percent of contributing drainage area. \\
\hline HUCODE & Int & 1 & Yes & Opt & Opt & $\begin{array}{l}\text { Hydrologic unit code ( } 8 \text { digits). These codes are given in the U.S. } \\
\text { Geological Survey map series "State Hydrologic Unit Maps," Open-File } \\
\text { Report 84-708. }\end{array}$ \\
\hline ISTAID & Int & 1 & Yes & Opt & Opt & Station identification number, as an integer. \\
\hline JANAVE & Real & 1 & Yes & $\mathrm{Opt}$ & Opt & Mean monthly temperature for January, in degrees Fahrenheit. \\
\hline JANMIN & Real & 1 & Yes & Opt & Opt & Mean minimum January temperature, in degrees Fahrenheit. \\
\hline JULAVE & Real & 1 & Yes & Opt & Opt & Mean monthly temperature for July, in degrees Fahrenheit. \\
\hline JULMAX & Real & 1 & Yes & Opt & Opt & Mean maximum July temperature, in degrees Fahrenheit. \\
\hline LAKE & Real & 1 & Yes & Opt & Opt & Area of lakes and ponds in percent of contributing drainage area. \\
\hline LATCTR & Real & 1 & Yes & Opt & Opt & Latitude of center of basin, decimal degrees. \\
\hline LATDEG & Real & 1 & Yes & Opt & Opt & Latitude in decimal degrees. \\
\hline LATDMS & Int & 1 & Yes & Opt & Opt & Latitude in degrees, minutes, seconds (dddmmss). \\
\hline LCODE & Int & 1 & Yes & Opt & Opt & Length units code, user defined. \\
\hline LENGTH & Real & 1 & Yes & Opt & Opt & Channel length, units user defined. \\
\hline LKEVAP & Real & 1 & Yes & Opt & Opt & Mean annual lake evaporation, in inches. \\
\hline
\end{tabular}




\begin{tabular}{|c|c|c|c|c|c|c|}
\hline \multirow[b]{2}{*}{ Name } & \multirow[b]{2}{*}{ Type } & \multirow[b]{2}{*}{ Length } & \multirow[b]{2}{*}{ Update } & \multicolumn{2}{|c|}{ Data-set type } & \multirow[b]{2}{*}{ Description } \\
\hline & & & & Time & Table & \\
\hline LNGCTR & Real & 1 & Yes & Opt & Opt & Longitude of center of basin, decimal degrees. \\
\hline LNGDEG & Real & 1 & Yes & Opt & Opt & Longitude in decimal degrees. \\
\hline LNGDMS & Int & 1 & Yes & Opt & Opt & Longitude in degrees, minutes, seconds (dddmmss). \\
\hline LOESS & Real & 1 & Yes & Opt & Opt & Depth of surficial loess, in feet. \\
\hline MARMAX & Real & 1 & Yes & Opt & Opt & Mean maximum March temperature, in degrees Fahrenheit. \\
\hline MAXVAL & Real & 1 & Yes & Opt & No & Maximum value in data set, general use. \\
\hline MEANVL & Real & 1 & Yes & Opt & No & Mean of values in data set, general use. \\
\hline MINVAL & Real & 1 & Yes & Opt & No & Minimum value in data set, general use. \\
\hline NONZRO & Int & 1 & Yes & Opt & No & Number of nonzero values in the time series. \\
\hline NUMZRO & Int & 1 & Yes & Opt & No & Number of zero values in the time series. \\
\hline PARMCD & Int & 1 & Yes & Opt & Opt & Parameter code, see WATSTORE users manual, Appendix D. \\
\hline PNEVAP & Real & 1 & Yes & Opt & Opt & Mean annual Class A pan evaporation, in inches. \\
\hline PRCAPR & Real & 1 & Yes & Opt & Opt & April mean monthly precipitation, in inches. \\
\hline PRCAUG & Real & 1 & Yes & Opt & Opt & August mean monthly precipitation, in inches. \\
\hline PRCDEC & Real & 1 & Yes & Opt & Opt & December mean monthly precipitation, in inches. \\
\hline PRCFEB & Real & 1 & Yes & Opt & Opt & February mean monthly precipitation, in inches. \\
\hline PRCJAN & Real & 1 & Yes & Opt & Opt & January mean monthly precipitation, in inches. \\
\hline PRCJUL & Real & 1 & Yes & Opt & Opt & July mean monthly precipitation, in inches. \\
\hline PRCJUN & Real & 1 & Yes & Opt & Opt & June mean monthly precipitation, in inches. \\
\hline PRCMAR & Real & 1 & Yes & Opt & Opt & March mean monthly precipitation, in inches. \\
\hline PRCMAY & Real & 1 & Yes & Opt & Opt & May mean monthly precipitation, in inches. \\
\hline PRCNOV & Real & 1 & Yes & Opt & Opt & November mean monthly precipitation, in inches. \\
\hline PRCOCT & Real & 1 & Yes & Opt & Opt & October mean monthly precipitation, in inches. \\
\hline PRCSEP & Real & 1 & Yes & Opt & Opt & September mean monthly precipitation, in inches. \\
\hline PRECIP & Real & 1 & Yes & Opt & Opt & $\begin{array}{l}\text { Mean annual precipitation, in inches, from U.S. Weather Bureau Series } \\
\text { "Climates of States;" grid sampling methods used if isohyetal map is } \\
\text { available, otherwise anomaly map constructed (Water-Supply Paper } \\
\text { 1580-D). }\end{array}$ \\
\hline RFOOT & Real & 1 & Yes & Opt & Opt & Distance from mouth of river, in feet. \\
\hline RMILE & Real & 1 & Yes & Opt & Opt & Distance from basin outlet, in miles. \\
\hline RWFLAG & Int & 1 & Yes & Opt & Opt & $\begin{array}{l}\text { Read/Write flag: } \\
0 \text { - read and write } \\
1 \text { - read only }\end{array}$ \\
\hline SEASBG & Int & 1 & Yes & Opt & Opt & $\begin{array}{l}\text { Beginning month of a user-defined season. Will start on first day of the } \\
\text { month. Used with attribute SEASND to define a specific time period, } \\
\text { usually a year. January is month } 1 \text { and December is month } 12 \text {. }\end{array}$ \\
\hline SEASND & Int & 1 & Yes & Opt & Opt & $\begin{array}{l}\text { Ending month of a user-defined season. Will end on the last day of the } \\
\text { month. Used with attribute SEASBG to define a specific time period, } \\
\text { usually a year. January is month } 1 \text { and December is month } 12 \text {. }\end{array}$ \\
\hline SITECO & Char & 4 & Yes & Opt & Opt & $\begin{array}{l}\text { Site code, see WATSTORE users manual, volume } 1 \text {, chapter } 3 . \\
\text { SW - stream } \\
\text { SP - spring } \\
\text { ES - estuary } \\
\text { GW - well } \\
\text { LK - lake or reservoir } \\
\text { ME - meteorological }\end{array}$ \\
\hline SKEWCF & Real & 1 & Yes & Opt & No & Skew coefficient of values in data set, general use. \\
\hline SLOPE & Real & 1 & Yes & Opt & Opt & Slope, units are user defined. \\
\hline SN002 & Real & 1 & Yes & Opt & Opt & $\begin{array}{l}\text { Maximum water equivalent, in inches, of snow cover as of March 15, } 2 \text { - } \\
\text { year recurrence interval. }\end{array}$ \\
\hline SN010 & Real & 1 & Yes & Opt & Opt & $\begin{array}{l}\text { Maximum water equivalent, in inches, of snow cover as of March } 15 \text {, } \\
10 \text {-year recurrence interval. }\end{array}$ \\
\hline SN025 & Real & 1 & Yes & Opt & Opt & $\begin{array}{l}\text { Maximum water equivalent, in inches, of snow cover as of March } 15 \text {, } \\
25 \text {-year recurrence interval. }\end{array}$ \\
\hline
\end{tabular}




\begin{tabular}{|c|c|c|c|c|c|c|}
\hline \multirow[b]{2}{*}{ Name } & \multirow[b]{2}{*}{ Type } & \multirow[b]{2}{*}{ Length } & \multirow[b]{2}{*}{ Update } & \multicolumn{2}{|c|}{ Data-set type } & \multirow[b]{2}{*}{ Description } \\
\hline & & & & Time & Table & \\
\hline SN100 & Real & 1 & Yes & Opt & Opt & $\begin{array}{l}\text { Maximum water equivalent, in inches, of snow cover as of March 15, } \\
\text { 100-year recurrence interval. }\end{array}$ \\
\hline SNOAPR & Real & 1 & Yes & Opt & Opt & Mean water equivalent, in inches, of snow cover as of April 30. \\
\hline SNOFAL & Real & 1 & Yes & Opt & Opt & Mean annual snowfall, in inches. \\
\hline SNOMAR & Real & 1 & Yes & Opt & Opt & Mean water equivalent, in inches, of snow cover as of March 1. \\
\hline SOILIN & Real & 1 & Yes & Opt & Opt & $\begin{array}{l}\text { Soils index, in inches, a relative measure of potential infiltration (soil } \\
\text { water storage), from Soil Conservation Service. }\end{array}$ \\
\hline STAID & Char & 16 & Yes & Opt & Opt & Station identification, up to 16 alpha-numeric characters. \\
\hline STANAM & Char & 48 & Yes & Opt & Opt & Station name or description of the data set. \\
\hline STATCD & Int & 1 & Yes & Opt & Opt & Statistics code, see WATSTORE users manual, Appendix E. \\
\hline STCODE & Char & 4 & Yes & Opt & Opt & $\begin{array}{l}\text { Standard 2-character post office state abbreviation, includes } \\
\text { DC - District of Columbia } \\
\text { PR - Puerto Rico } \\
\text { VI - Virgin Islands } \\
\text { GU - Guam } \\
\text { PI - Pacific Trust Territories } \\
\text { Use NON for no state abbreviation. }\end{array}$ \\
\hline STDDEV & Real & 1 & Yes & Opt & No & Standard deviation of values in data set, general use. \\
\hline STFIPS & Int & 1 & Yes & $\mathrm{Opt}$ & Opt & State FIPS code, see WATSTORE users manual, Appendix B. \\
\hline STORAG & Real & 1 & Yes & Opt & Opt & $\begin{array}{l}\text { Area of lakes, ponds, and swamps in percent of contributing drainage } \\
\text { area, measured by the grid sampling methods. }\end{array}$ \\
\hline SUBHUC & Int & 1 & Yes & Opt & Opt & $\begin{array}{l}\text { Extension to hydrologic unit code (HUCODE). See the U.S. Geological } \\
\text { Survey map series "State Hydrologic Unit Maps," Open-File Report } \\
84-708 \text {. }\end{array}$ \\
\hline TCODE & Int & 1 & No & Reqd & Opt & $\begin{array}{ll}\text { Time units code. } & \\
1 \text { - seconds } & 4 \text { - days } \\
2 \text { - minutes } & 5 \text { - months } \\
3 \text { - hours } & 6 \text { - years } \\
\text { Used in combination with TSSTEP. }\end{array}$ \\
\hline TGROUP & Int & 1 & No & Reqd & No & $\begin{array}{l}\text { Unit for group pointers, depending on the time step of the data, may } \\
\text { effect the speed of data retrievals. The default group pointer is } 6 \text { (years). } \\
\text { See table } 1 \text { in users manual for recommended values. } \\
\begin{array}{ll}3 \text { - hours } & 6 \text { - years } \\
4 \text { - days } & 7 \text { - centuries } \\
5 \text { - months } & \end{array}\end{array}$ \\
\hline TMTOPK & Real & 1 & Yes & Opt & Opt & $\begin{array}{l}\text { Time, in hours, measured as time difference between center of mass of } \\
\text { total rainfall and peak discharge. }\end{array}$ \\
\hline TMZONE & Int & I & Yes & Opt & Opt & $\begin{array}{l}\text { Time zone. Each time zone is represented as the number of hours to be } \\
\text { added to, or subtracted from, Greenwich time: } \\
-4 \text { - Atlantic Standard } \\
-5 \text { - Eastern Standard } \\
-6 \text { - Central Standard } \\
-7 \text { - Mountain Standard }\end{array}$ \\
\hline TOLR & Real & 1 & No & Opt & No & $\begin{array}{l}\text { Data compression tolerance. Data values within } \pm \text { of TOLR will be } \\
\text { considered the same value and compressed in the data set. Once data } \\
\text { have been compressed, the original values cannot be retrieved. }\end{array}$ \\
\hline TSBDY & Int & 1 & No & Opt & No & Starting day for time-series data in a data set. Defaults to day 1 . \\
\hline TSBHR & Int & 1 & No & Opt & No & Starting hour for time-series data in a data set. Defaults to hour 1. \\
\hline TSBMO & Int & 1 & No & Opt & No & $\begin{array}{l}\text { Starting month for time-series data in a data set. Defaults to month } 1 \\
\text { (January). }\end{array}$ \\
\hline TSBYR & Int & 1 & No & Reqd & No & Starting year for time-series data in a data set. Defaults to year 1900. \\
\hline TSFILL & Real & 1 & No & Opt & Opt & $\begin{array}{l}\text { Time-series filler value. This value will be used for missing values. The } \\
\text { default is } 0.0 \text {. }\end{array}$ \\
\hline
\end{tabular}




\begin{tabular}{|c|c|c|c|c|c|c|}
\hline \multirow[b]{2}{*}{ Name } & \multirow[b]{2}{*}{ Type } & \multirow[b]{2}{*}{ Length } & \multirow[b]{2}{*}{ Update } & \multicolumn{2}{|c|}{ Data-set type } & \multirow[b]{2}{*}{ Description } \\
\hline & & & & Time & Table & \\
\hline TSFORM & Int & 1 & No & Reqd & No & $\begin{array}{l}\text { Form of data: } \\
1 \text { - mean over the time step (default) } \\
2 \text { - total over the time step } \\
3 \text { - instantaneous @ time (end of time step) } \\
4 \text { - minimum over the time step } \\
5 \text { - maximum over the time step }\end{array}$ \\
\hline TSPREC & Int & 1 & No & Opt & No & $\begin{array}{l}\text { New group, new record flag: } \\
0 \text { - start new group at the end of the last group (default) } \\
1 \text { - start new group at the beginning of a record }\end{array}$ \\
\hline TSPTAD & Int & 1 & Yes & Opt & No & Time series put aggregation/disaggregation code. \\
\hline TSSTEP & Int & 1 & No & Reqd & Opt & Time step, in TCODE units (used in combination with TCODE). \\
\hline TSTYPE & Char & 4 & Yes & Opt & Opt & $\begin{array}{l}\text { User-defined four-character descriptor. Used to describe the contents of } \\
\text { the data set, for example: } \\
\text { PRCP, RAIN, SNOW - precipitation } \\
\text { FLOW, DISC, PEAK - discharge } \\
\text { TEMP, TMIN, TMAX - temperature } \\
\text { EVAP, PET - evapotranspiration } \\
\text { Some models and application programs may require a specific TSTYPE } \\
\text { for data sets they use. }\end{array}$ \\
\hline VALLGH & Real & 1 & Yes & Opt & Opt & $\begin{array}{l}\text { Valley length, in miles, measured along general path of flood plain from } \\
\text { gage to basin divide. }\end{array}$ \\
\hline VBTIME & Int & 1 & No & Reqd & No & $\begin{array}{l}\text { Variable time-step option for the data set } \\
1 \text { - all data are at the same time step } \\
2 \text { - time step may vary (default) }\end{array}$ \\
\hline VCODE & Int & 1 & Yes & Opt & Opt & Volume units code, user defined. \\
\hline VLCODE & Int & 1 & Yes & Opt & Opt & Velocity units code, user defined. \\
\hline WEMAR2 & Real & 1 & Yes & Opt & Opt & $\begin{array}{l}\text { Water equivalent, in inches, of snow cover as of the first week in March, } \\
\text { 2-year recurrence interval. }\end{array}$ \\
\hline XSECLC & Real & 1 & Yes & Opt & Opt & $\begin{array}{l}\text { Cross-section locater, distance in feet from left bank (as determined by } \\
\text { facing downstream). }\end{array}$ \\
\hline YRSDAY & Int & 1 & Yes & Opt & Opt & $\begin{array}{l}\text { Number of years of daily-flow record, from WATSTORE flow } \\
\text { variability program W } 4422 \text {. }\end{array}$ \\
\hline YRSLOW & Int & 1 & Yes & Opt & Opt & Number of years of low-flow record. \\
\hline
\end{tabular}

